DOE/SF/11592-1

(DE85004580)

\title{
Energy
}

NASA-CR-174182

19850005971

\section{SITE-SPECIFIC RESEARCH CONDUCTED IN SUPPORT OF THE SALTON SEA SOLAR POND PROJECT-FY 1982 REPORT}
By
R. L. French
H. E. Marsh
E. J. Roschke
Y. C. Wu

September 1, 1984

Work Performed Under Contract No. Al03-82SF11592

Jet Propulsion Laboratory

Pasadena, California

\section{LIBRARY COPY \\ JUL 31985 \\ LANGLEY RESEARCH CENTER \\ LIERARY, NASA \\ HAMPTON, VIRGINIA}

Technical Information Center

Office of Scientific and Technical Information

United States Department of Energy 


\section{DISCLAIMER}

This report was prepared as an account of work sponsored by an agency of the United States Government. Neither the United States Government nor any agency thereof, nor any of their employees, makes any warranty, express or implied, or assumes any legal liability or responsibility for the accuracy, completeness, or usefulness of any information, apparatus, product, or process disclosed, or represents that its use would not infringe privately owned rights. Reference herein to any specific commercial product, process, or service by trade name, trademark, manufacturer, or otherwise does not necessarily constitute or imply its endorsement, recommendation, or favoring by the United States Government or any agency thereof. The views and opinions of authors expressed herein do not necessarily state or reflect those of the United States Government or any agency thereof.

This report has been reproduced directly from the best available copy.

Available from the National Technical Information Service, U. S. Department of Commerce, Springfield, Virginia 22161.

Price: Printed Copy A06

Microfiche A01

Codes are used for pricing all publications. The code is determined by the number of pages in the publication. Information pertaining to the pricing codes can be found in the current issucs of the following publications, which are generally available in most libraries: Energy Research Abstracts (ERA); Government Reports Announcements and Index $(G R A$ and I); Scientific and Technical Abstract Reports (STAR); and publication NTIS-PR-360 available from NTIS at the above address. 


\title{
Site-Specific Research Conducted in Support of the Salton Sea Solar Pond Project - FY 1982 Report
}

\author{
R.L. French \\ H.E. Marsh \\ E.J. Roschke \\ Y.C. Wu
}

September 1, 1984

Prepared for

U.S. Department of Energy

Through an Agreement with

National Aeronautics and Space Administration

by

Jet Propulsion Laboratory

California Institute of Technology

Pasadena, California

JPL Publication 84-68 

The design and operation of a salt-gradient solar pond power plant at the Salton Sea presents problems not encountered at small research ponds that have been built in the United States. The specific characteristics of the Salton Sea site and the desire to construct the pond using the local clay as a sealant represent major deviations from previous solar pond experience.

This document reports on the site-specific research conducted by the Jet Propulsion Laboratory in support of the plant design. The research activity included validation of the spectrophotometric light transmission measurement technique, a search for options for clarifying the turbid and colored water of the Salton Sea, development of water clarification specifications in terms common to industry practice, quantification of gas production from microbiological reactions in the ground, a determination of the combined effects of temperature and salinity on the permeation of the local clays, and a preliminary evaluation of material corrosion. 


\section{CONTENTS}

1. INTRODUCTION ..................... 1-1

2. SUMMARY OF RESULTS . . . . . . . . . . . . . 2-1

3. LABORATORY INVESTIGATIONS . . . . . . . . . . . 3-1

3.1 LIGHT TRANSMISSION MEASUREMENTS . . . . . . . . . 3-1

3.1.1. Background ................ 3-1

3.1.2. Phase 1A Effort.............. 3-2

3.2 WATER QUALITY AND TREATMENT . . . . . . . . . . 3-9

3.2.1. Background ................ 3-9

3.2.2. Phase 1A Effort............... 3-. . . .

3.2.3. Water Specification........... 3-10

3.2.4. Conclusions and Recommendations ..... . 3-13

3.3 BRINE/SOIL INTERACTIONS . . . . . . . . 3-13

3.3.1. Background ............... 3-13

3.3.2. Phase 1A Effort ............. 3-14

3.4 SOIL PERMEABILITY ................ 3-16

3.4.1. Background .............. 3-16

3.4.2. Phase IA Effort ............. 3-16

3.5 CORROSION TESTING ...................... 3-21

3.5.1. Objective ............... 3-21

3.5.2. Approach ................. 3-21

3.5.3. Results ................. 3-23

3.5.4. Conclusions and Recommendations ...... . 3-27

3.6 GENERAL METHODOLOGY FOR SITE-SPECIFIC INVESTIGATIONS • • 3-27

3.6.1. Background ... . . . . . . . . 3-27

3.6.2. Physics, Chemistry and Biology . . . . . . . 3-28 
4. ANALYTICAL MODELS ......................... 4-

4.1 SOLAR POND THERMODYNAMICS PERFORMANCE ELEMENT . . . . 4-1

4.2 POWER GENERATION SUBSYSTEM .................. 4-4

4.2.1 Description and Status .......... 4-4

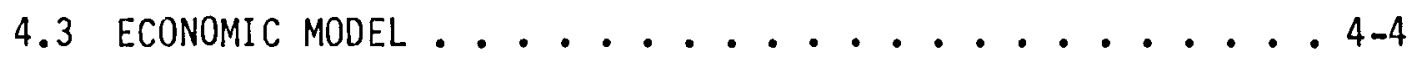

4.3 .1 objective ................. 4-4

4.3.2 Description..................4-4

5. REFERENCES ............................

APPENDIXES

A. The Spectrophotometric Method of Determining the Transmission of Solar Energy in Salt Gradient Solar Ponds. . A-1

B. Material Selection Considerations for Solar Ponds . . . B-1

C. A Summary Description of a Computer Program Concept for the Design and Simulation of Solar Pond Electric

Power Generation Systems ............. C-1

\section{Figures}

1. Test Fixture for Measuring Transmission of Sunlight Through

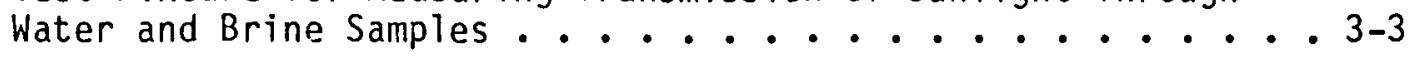

2. Outdoor Measurement of Light Trarsmission ........ 3-7

3. Percentage of Solar Radiation Transmitted Through Saline Waters ................... 3-8

4. Sample Preparation Scheme for Commercial Analysis Applicability Tests .................... 3-11

5. Evidence of Light-Attenuating Contamination from Black

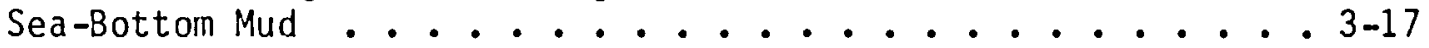

6. Effect of Filtration on Contamination Caused by Mud .... 3-18

7. Test Fixture for the Measurement of Permeation Rate of Clay at Elevated Temperatures ................ 3-19 
8. Permeation Test History of Salton Sea Clay . . . . . . 3-22

9. Corrosion of 1020 Steel in Salton Sea Brines ....... 3-24

10. Effect of Salton Sea Brine on Stainless Steel Alloy 321 . . 3-25

11. Methodology for Achieving Acceptable Optical Quality in

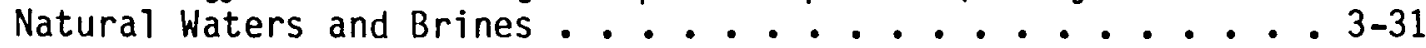

12. A General Computer Model Information Flow Diagram ...... 4-2

13. Electric Power Generation Subsystem ........... . 4-3

Tables

1. Outdoor Relative Light Transmission (Preliminary Tests) . . 3-5

2. Spectral Distributions of Outdoor Test Sample ...... 3-6

3. Optical Quality Preliminary Test of Commercial Test Applicability .................... 3-12

4. Corrosion Test Exposures ........... 3-23

5. Corrosivity of Steel 1020 in Salton Sea Solutions as Determined from Coupon Exposure Tests ......... 3-26

6. Corrosion Rates of Various Alloys as Determined from Potentiodynamic Analyses ......... 3-27

7. Methodology Outline: Water, Salt, and Soil ...... 3-29 


\section{SECTION 1}

\section{INTRODUCTION}

In FY 1981, the U.S. Department of Energy (DOE) in cooperation with the Southern California Edison Company and the State of California, sponsored.a feasibility study for a solar pond power plant at the Salton Sea. The study focused on a $5-M W_{e}$ proof-of-concept experiment and conceptualized a commercial $600-\mathrm{MW}_{\mathrm{e}}$ design. The results pointed out some technical concerns and a large uncertainty relative to the cost of dike construction in the lake. The sponsors agreed to continue joint project sponsorship with a strong emphasis on refining construction cost estimates.

The second phase of the project (Phase 1A) started with the Jet Propulsion Laboratory (JPL) functioning in the role of project manager. Major design work was subcontracted, general research was coordinated with other DOE laboratories, and site-specific research was undertaken at JPL. This document reports only the site-specific research conducted by JPL during Phase $1 A$.

As the year progressed, plans were changed and the level of effort was reduced. Research tasks reflecting JPL Proposal 70-1732, Annual Operating Plan, were initiated but reduced in scope during the year. Consequently, some of the activities reported herein are incomplete. 
SECTION 2

SUMMARY OF RESULTS

JPL conducted both laboratory experiments and analytical analyses during this reporting period. Laboratory experiments included (1) experiments to validate spectrophotometric light transmission measurements, (2) a continuation of the search for suitable Salton Sea water treatment methods, (3) an evaluation of the suitability of formulating water clarity specifications in terms of standard commercial procedures, (4) a more in-depth investigation into soil/brine interactions, and (5) a preliminary examination into material corrosion potentials. Analytical efforts were directed toward refining a solar pond thermal model and beginning the development of a system-level design and performance model.

An experimental approach was selected to validate the extrapolation of small sample spectrophotometric measurements. Two test fixtures of differing size were constructed. Preliminary results from the smaller fixture produced promising results. The test approach proved to be good, and the test results displayed the expected shape and sensitivity. The larger test fixture was assembled but not tested.

Investigations to find methods for removing color and turbidity from the Salton Sea water continued. 0zone treatment appeared to be as effective as activated carbon treatment, and carbon plus ozone in a series process produced the best results. A wide spectrum of flocculents were tested and all produced negative results.

Spectrophotometric measurements produce very useful research data but such data is difficult to incorporate into water quality process design specifications. In the search for a more suitable quality descriptor, water samples were submitted to standard commercial analyses. Standard colorimeter analys is correlated with the spectrophotometric results while standard turbidity tests produced no correlation. A Salton Sea water clarification process design specification was formulated based on industry-acceptable colorimeter measurements.

The potential for soil/brine interations that could be damaging to solar pond operation has been recognized and briefly studied in earlier work. During this reporting period, more sophisticated laboratory investigations were performed to determine the effects of temperature, evolve a more efficient test method, and examine the potential for the soil to cause light-attenuating contamination. Although hydrogen sulfide gas has been produced in some tests, no pond-damaging free gas tubbles were formed. A theory has evolved that Salton Sea soils contain an insufficient supply of organic carbon for sustained high production of hydrogen sulfide. In separate tests, Salton Sea soils were found to degrade the light transmission characteristics of clarified waters and brines.

A preliminary test to examine material corrosion potential was conducted. Coupons of stainless steel and low carbon steel were immersed in both brine and Salton Sea water. Low carbon steel corrosion is most pronouced in Salton 
Sea water but also occurs in brine. Stainless steel did not corrode in either liquid.

Several types of analytic models must be developed in order to select appropriate solar pond sites and applications, conduct systems level design trade-offs, and perform data reduction and analysis. JPL has directed effort toward two such models: a solar pond performance model and a systems design model. The solar pond performance model is similar to other one-dimensional heat conduction models described in the literature but has the feature of accepting spectrophotometric water transmissivity data. A functional plan and program structure was developed for the systems design model but effort was curtailed and the model remains in an incomplete state. 
SECTION 3

\section{LABORATORY INVESTIGATIONS}

The primary objectives of the laboratory investigations were to examine carefully the site-specific physical, chemical, and biological factors that could impact construction, durability and performance of the proposed $5-\mathrm{MW}_{\mathrm{e}}$ solar pond system at the Salton Sea. These investigations concentrated on the interactions of the water, salt, and soil of the site and on material compatibility. Potential interactions of the water/brine and soil are particularly important because the pond will utilize the naturally occurring clays as a bottom seal.

In setting up the laboratory investigations, an attempt was made to look first at the most critical items. Some of the studies proceeded to logical end points; others were terminated early because of 1 imited resources. More work should be done in certain areas to provide more accurate design data, but with respect to water, salt, and soil, the overall system appears technically feasible.

Although there is a considerable and growing solar pond literature, little written information deals with the important site-specific investigations of water, salt, and soil. Therefore, technical effort was directed toward identifying the factors that should be investigated and determining methods of investigation. As a result, a by-product of this work has been the development of an approach for site-specific investigations and some specific methodologies. This development should continue in order to establish a generic approach for evaluating the suitability of any site for the construction of large-scale solar ponds.

\subsection{Light Transmission Measurements}

3.1.1 Background (Phase 1 Final Report, Reference 1). During Phase 1, spectrophotometric measurements of light transmission were made on Salton Sea water samples, and significant light absorbing color and turbidity were observed. A variety of water clarification experiments was conducted but only activated carbon and ozone treatments proved to be effective. Solar pond performance estimates based on the laboratory data indicated that without treatment the thermal efficiency of the solar pond would be only $8 \%$, but with carbon treatment the efficiency would increase to $24 \%$. However, considerable uncertainty exists in the above efficiency values because of unavoidable errors in measurements and the extrapolation of small-scale measurements. Light transmission measurements were made with a Cary 14 spectrophotometer. The major sources of error are the exclusion of forward-scattered light and the multiplying effects of the mathematics needed to convert the laboratory data to estimates of radiant energy transmission rates in solar ponds. A limited error analysis (Appendix A) indicated that the pond performance estimates could be off by as much as 25\%. With these potential error magnitudes, little confidence can be generated in the concept that decolorization of Salton Sea water will produce a three-fold improvement in pond thermal performance. 
The above-cited accuracy problems notwithstanding, spectrophotometric measurements and data analysis have the potential of being developed into a procedure that will yield accurate estimates quickly and at low cost (Appendix A). Attenuation of radiant energy transmission due to both absorption by dissolved subtances and reflection by suspended matter can be measured in small samples and the resulting data mathematically integrated over the solar spectrum and pond real dimensions. The general procedure needs to be validated and calibrated.

3.1.2 Phase IA Effort. The effort in Phase IA was directed toward a laboratory-sized experiment that would directly measure solar radiant energy transmission through Salton Sea water and simultaneously develop information for correlation with spectophotometric data. The key requirements of the experiment were the use of actual solar radiation and a geometry that would not exclude forward-scattered light. The general plan was to develop, through experimentation, a suitable apparatus to measure relative light transmission of a variety of Salton Sea waters and brines and to correlate these results with spectrophotometric data.

Progress was made toward these goals. A preliminary apparatus was assembled and tests were inade of some Salton Sea water and brine samples. An improved, larger test fixture was assembled but not tested. Further work is needed to develop the test fixture, to test a full representative set of Salton Sea water samples, and to investigate the correlation of outdoor measurements of optical quality with spectrophotometer results. Preliminary results are promising.

The general configuration of the preliminary test apparatus is illustrated in Figure 1. The two basic elements are a sample container with a transparent bottom and a black-body pyranometer enclosed to $v i e w$ only the light passing through the container bottom. An Eppley Radiometer, Model \#8-48, was selected because of its flat response to solar radiant energy. The vertical orientation of the fixture is adjustable to allow tilting towards the sun. Absorption or attenuation of radiant energy by the contained liquid is deterinined by obtaining a reference reading with the device empty and then collecting a series of readings with incremental changes in liquid level. Thus, for a particular water sample, data reflecting energy transmission as a function of depth can be quickly obtained.

Data taken from the preliminary fixture are presented in Table 1 and Figure 2. Data analyses are incomplete, but qualitatively these data appear to have the expected pattern (Figure 3 ). A surprising result of the preliminary test data, Figure 2, is the high levels of light transmission of settled and filtered Salton Sea water as compared to tap water.

Spectrophotometric measurements of the same water samples were also made, and the data are presented in Table 2. Reduction of these data remains incomplete; therefore, it is unclear if the spectrophotometric data would also show that filtered Salton Sea water is superior to tap water. The complicating factor in the analysis is the distribution of energy in the 


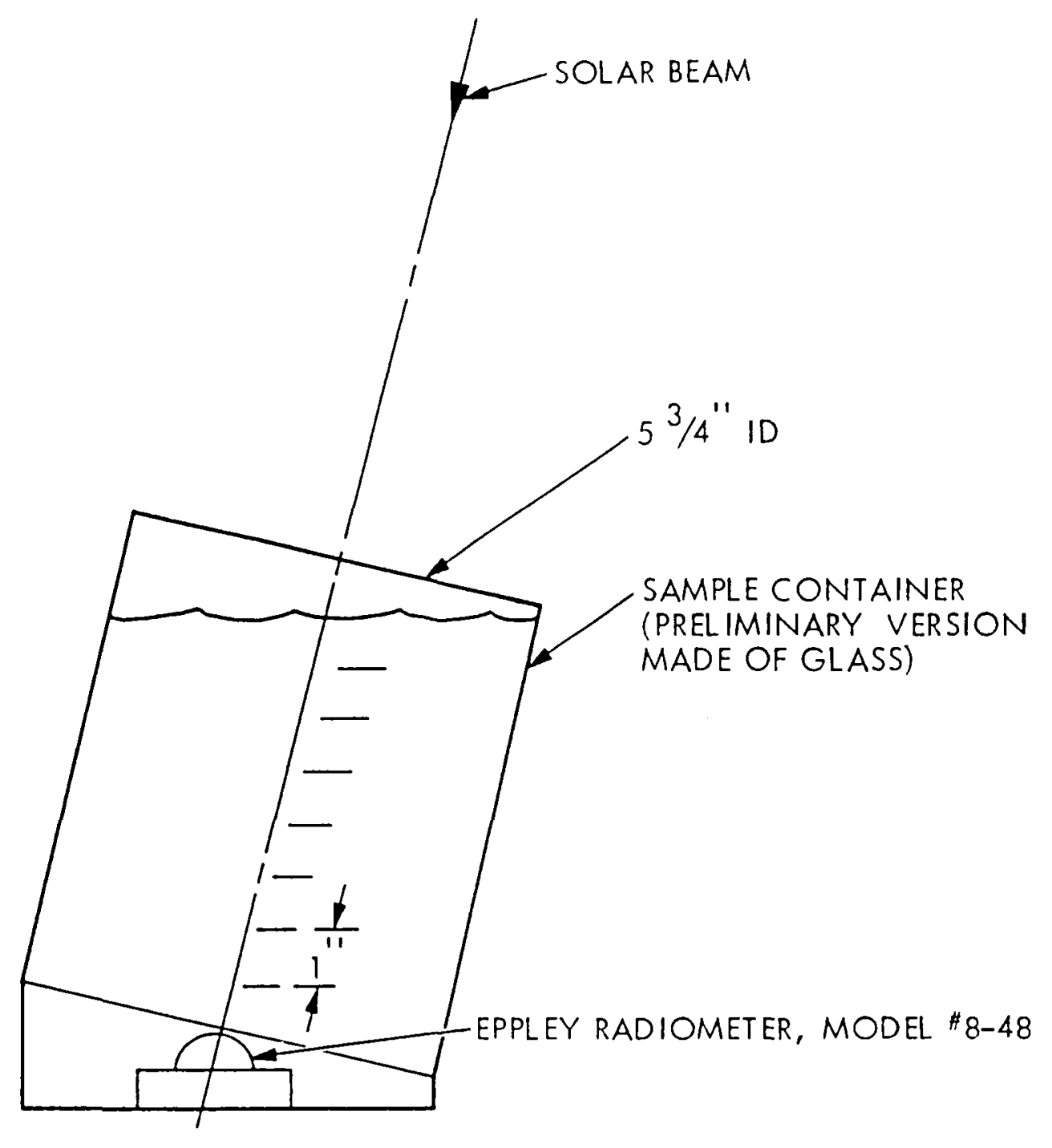

Figure 1. Test Fixture for Measurirg Transmission of Sunlight Through Water and Brine Samples 
solar spectrum. In the wavelength band below 400 nanometers $(\mathrm{nm})$, where tap water is much more transparent, energy in the solar spectrum is low. In the wavelength band from 540 to $700 \mathrm{~nm}$, solar radiation intensity increases and the Salton Sea water is measured to be slightly more transparent. Above 700 $\mathrm{nm}$ to approximately $830 \mathrm{~nm}$, solar intensity is high. From past experience, the light transmission characteristics of filtered Salton sea water and tap water have been found to be very similar in the wavelength band above $700 \mathrm{~nm}$. However, because the solar intensity is high, small differences in clarity can produce significant variations in total energy transmission. In the future, spectrophotometric measurements must be continued above the $700-n m$ wavelength range. 
Table 1. Outdoor Relative Light Transmission (Preliminary Tests)

\begin{tabular}{|c|c|c|c|c|c|c|}
\hline \multirow[t]{2}{*}{$\begin{array}{l}\text { Path } \\
\text { Length, } \\
\text { in. }\end{array}$} & \multicolumn{2}{|c|}{$\begin{array}{l}\text { Tap } \\
\text { Water }\end{array}$} & \multicolumn{2}{|c|}{$\begin{array}{l}\text { Salton Sea Water } \\
\text { Not Decolorized }\end{array}$} & \multicolumn{2}{|c|}{$\begin{array}{l}\text { Salton Sea Brine } \\
\text { Not Decolorized }\end{array}$} \\
\hline & Opena & Shieldeda & Open & Shielded & Open & Shielded \\
\hline$a^{b}$ & 1 & & 1 & & 1 & \\
\hline 1 & 0.75 & & 0.81 & & 0.70 & \\
\hline 2 & 0.71 & 0.69 & 0.81 & 0.75 & 0.61 & 0.60 \\
\hline 3 & 0.68 & 0.64 & 0.77 & 0.68 & 0.57 & 0.56 \\
\hline 4 & 0.66 & 0.59 & 0.73 & 0.62 & 0.51 & 0.48 \\
\hline 5 & 0.63 & 0.57 & 0.71 & & 0.46 & \\
\hline 6 & 0.61 & 0.56 & 0.68 & 0.60 & 0.44 & 0.41 \\
\hline 7 & 0.63 & 0.60 & 0.68 & 0.65 & 0.41 & 0.40 \\
\hline
\end{tabular}

Conditions:

Apparatus: $\quad$ See Figure 1.

Time: July 27,1982 , from 12:00 to $1: 30$ p.m. standard time.

Sky: Thin, variable haze.

a. The side wall of the sample container is glass. Duplicate runs were made with the side wall covered with black paper.

b. Zero readings were taken through the empty vessel. 
Table 2. Spectral Distributions of Outdoor Test Sample, Transmission Measured with Cary 14, 5-cm Path Length

Transmission, \%

\begin{tabular}{llll}
\hline $\begin{array}{l}\text { Wave } \\
\text { Length, } \\
\text { nm }\end{array}$ & Tap Water & $\begin{array}{l}\text { Salton Sea Water, } \\
\text { Not Decolorized }\end{array}$ & $\begin{array}{l}\text { Salton Sea Brine, } \\
\text { Not Decolorized }\end{array}$ \\
\hline & & & \\
300 & 83 & 20 & 0 \\
320 & 89 & 37 & 0 \\
340 & 91 & 53 & 1 \\
360 & 92 & 65 & 4.5 \\
380 & 93 & 74 & 39 \\
400 & 93 & 79.5 & 54 \\
420 & 93 & 83.5 & 65.5 \\
440 & 93 & 86.5 & 74 \\
460 & 93 & 88.5 & 80.5 \\
480 & 93 & 90.5 & 85.5 \\
500 & 93 & 91.5 & 89 \\
520 & 93 & 92.5 & 91.5 \\
540 & 92.5 & 93.5 & 93.5 \\
560 & 92.5 & 94 & 94 \\
580 & 92 & 94.5 & 94 \\
600 & 91.5 & 94 & 94.5 \\
620 & 91.5 & 94 & 94.5 \\
640 & 91.5 & 94.5 & 94.5 \\
660 & 90.5 & 94.5 & 94 \\
680 & 90 & 94 & \\
700 & 89 & 93 & \\
& & & \\
\hline
\end{tabular}




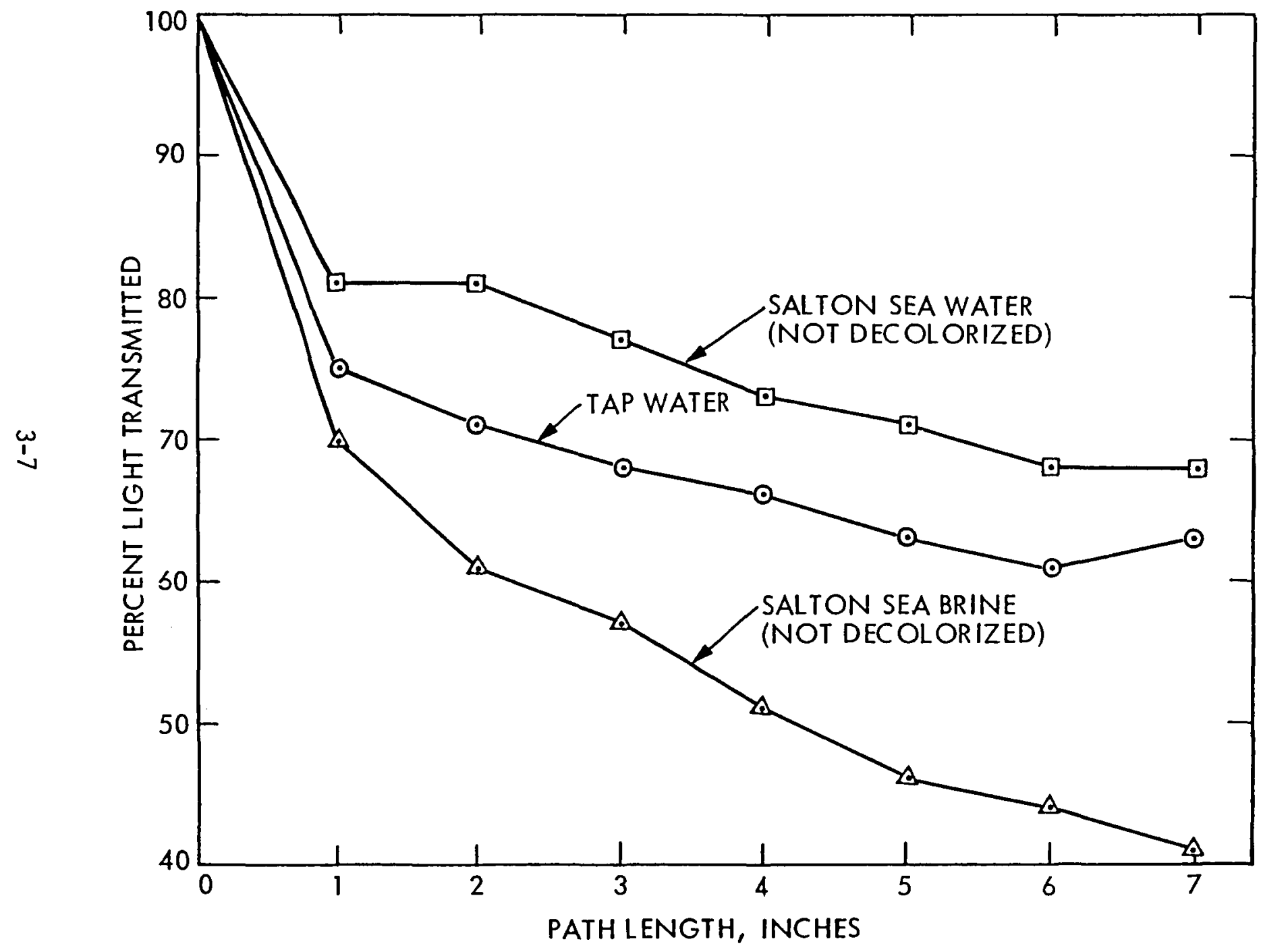

Figure 2. Outdoor Measurement of Light Transmission 


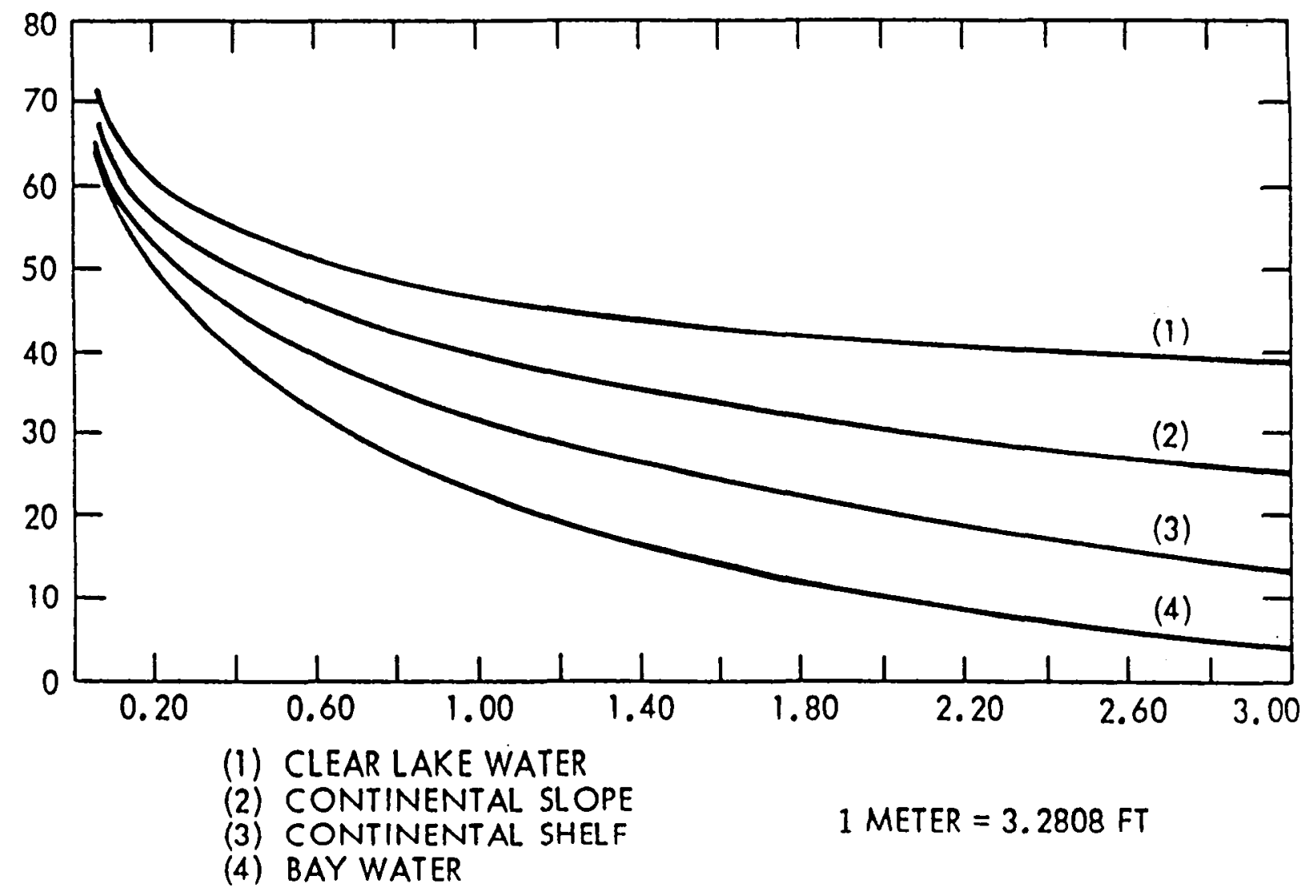

Figure 3. Percentage of Solar Radiation Transmitted Through Saline Waters 
The small container used in the preliminary tests was selected primarily to husband the small, on-hand supply of Salton Sea water. The built, yet unused larger test fixture is approximately 1 meter $(m)$ deep. Some of the questions remaining that are related to the test fixture include: (1) What ratios of vessel diameter to height are necessary to reduce wall effects to insignificant levels? (2) Can this ratio be reduced by control of wall optics? (3) How much is the ratio increased by not tilting the vessel to coincide with the solar beam? (4) In the case of tilted vessels, how important will it be to engineer provisions for parallel upper and lower water surfaces?

Following development, the original plan called for testing a variety of water and brine samples to create a data base for evaluating and calibrating the spectrophotometric method. This evaluation would be done by performing rigorous mathematical correlations between data from the two types of measurements.

\subsection{Water Quality and Treatment}

3.2.1 Background (Phase 1 Final Report, Reference 1). Salton Sea water contains both suspended particulate matter and dissolved substances. Simple settling (clarification) appears to remove the major portion of the suspended particles. Clarification is further enhanced by evaporation in the manufacture of brine. However, clarification alone is not sufficient treatment to provide acceptable energy collection performance in a solar pond. The dissolved substances absorb light in the blue end of the solar spectrum. They are thought to be biological in origin and concentrate with the salts during the evaporation process for making brine. Activated carbon treatinent (decolorization) removes the dissolved substances.

Two other potential sources of light-attenuating contamination are in-pond precipitation and subsoil/brine interaction. All laboratory observations of in-pond precipitation indicate that settling was fast enough to obviate significant optical quality changes. Contamination from the pond subsoil has been investigated in Phase $1 A$ and is discussed in Section 3.3 below.

\subsubsection{Phase 1A Effort. The objectives of. Phase 1A were to (1) investi-} gate the possibility of substituting other treatment methods for the activated carbon decolorization process, (2) investigate the adequacy of standard commercial water analysis methods as a substitute for the spectrophotometric method, and (3) generate a set of brine optical quality specifications that are consistent with industry practices.

The study of alternate methods of decolorizing Salton Sea water was reported. In summary, ozone treatment decolorized Salton Sea water to about the same degree as did activated carbon. A sequence of ozone followed by carbon produced better results than either process alone. None of a representative group of flocculents was found to be effective in decolorizing Salton Sea water.

Spectrophotometry has been found to be an excellent tool for studying the optical qualities of waters and brines and for quantifying the effects of 
various water treatment processes. When the procedures are more fully developed, the technique also will provide a fast, low-cost method of evaluating proposed water/brine sources and will provide insight into appropriate site-specific treatment requirements. Spectrophotometric data, however, do not provide specifications that are easily understood by designers of water treatment plants. A preliminary investigation was made to determine if standard water analysis procedures could be applied. Results of this investigation indicate that, while standard colorimetric measurement appears to be applicable, more work is necessary for developing an understandable measurement of turbidity. The investigation and results are described below.

Two series of samples were prepared to represent possible sequential steps in preparing Salton Sea water and concentrated brine for solar pond use. These series are represented as part of a larger, overall test scheme (shown in Figure 4), which was designed to show, in addition to the effects of treatment, the weighted effects on optical properties of blending. 0ptical properties were measured at each step of each series in two ways: spectrophotometry and commercial analysis. The commercial analyses were done by Jacobs Laboratories, Pasadena, using Standard Methods for the Examination of Water and Waste Water, 15th Edition, 1980, Method 204A for Color and Method 214A for Turbidity. The results of these tests are condensed in Table 3.

Good, qualitative correlation was found between the spectrophotometer and the standard colorimeter. The effect of color shows up in the shortest wavelengths. Trends in the 300,400 , and $500 \mathrm{~nm}$ columns of Table 3 match the trends in the colorimeter column. No similar correlation is evident with the turbidity measurements. As can be seen in the table, agitation is necessary to suspend particulate matter in the stored Salton Sea water (sample 10); the effects of this agitation are evident across the spectrum. However, the effect does not show up in the commercial turbidity test.

An interim specification for water and brine was generated on the basis of optical quality research carried out in Phases 1 and 1 . The purpose of the specification is to provide a way of assuring the optical quality of waters and brines before they are introduced into a solar pond. This interim specification applies only under the general assumption that Salton Sea water is the sole source of water and brine for the pond; brines will be prepared by evaporation. Because a meaningful standard method for turbidity has not yet been found, and because, fortunately, adequate clarification was found to be obtainable by settling, the specification includes processing as well as properties.

\subsubsection{Water Specification}

1. Source Salton Sea water will be clarified and decolorized before it is either introduced into the solar pond or evaporated to make brine. Clarification based on sedimentation should be adequate. Activated carbon is a good decolorant; ozone appears to be a suitable alternate. 


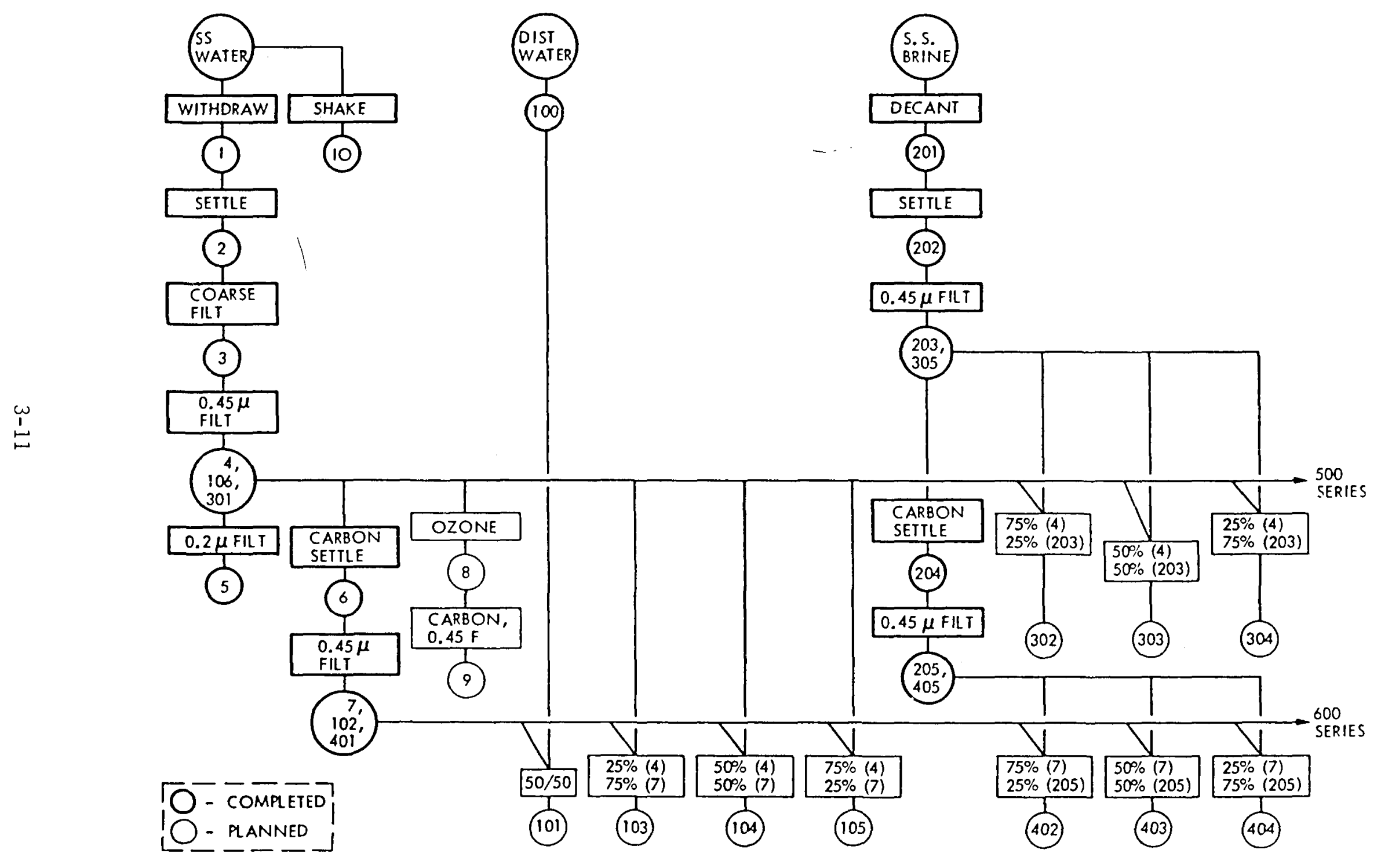

Figure 4. Sample Preparation Scheme for Commercial Analysis Applicability Tests 
Table 3. Optical Quality Preliminary Tests of Commercial Test Applicability

\begin{tabular}{|c|c|c|c|c|c|c|c|c|}
\hline \multirow{2}{*}{\multicolumn{2}{|c|}{ Sample }} & \multirow{2}{*}{\multicolumn{5}{|c|}{$\begin{array}{l}\text { Spectrophotometer } \\
\% \text { Transmitted at Wavelength }(5-\mathrm{cm} \text { Cell) }\end{array}$}} & \multicolumn{2}{|c|}{ Commercial Tests } \\
\hline & & & & & & & & \\
\hline Source/Treatment & ID No. & $300 \mathrm{~nm}$ & $400 \mathrm{~nm}$ & $500 \mathrm{~nm}$ & $600 \mathrm{~nm}$ & $700 \mathrm{~nm}$ & $\begin{array}{l}\text { Untes lolor } \\
\text { Pt-Co Scale }\end{array}$ & Turbidity, NTU ${ }^{a}$ \\
\hline SALTON SEA WATER & & & & & & & & \\
\hline Stirred Up & 10 & 19 & 69 & 81 & 85 & 85.5 & 15 & 0.43 \\
\hline Settled & 2 & 20 & 81 & 94 & 96 & 95 & 10 & 0.65 \\
\hline $\begin{array}{l}\text { Filtered } \\
\text { Coarse } \\
\text { Fine } \\
\text { Super Fine }\end{array}$ & $\begin{array}{l}3 \\
4 \\
5\end{array}$ & $\begin{array}{l}21 \\
20 \\
21\end{array}$ & $\begin{array}{c}83.5 \\
79.5 \\
81\end{array}$ & $\begin{array}{l}95.5 \\
91.5 \\
91.5\end{array}$ & $\begin{array}{c}97.5 \\
94 \\
94\end{array}$ & $\begin{array}{c}95.5 \\
93 \\
93\end{array}$ & $\begin{array}{l}10 \\
10 \\
10\end{array}$ & $\begin{array}{l}0.60 \\
0.38 \\
0.50\end{array}$ \\
\hline $\begin{array}{l}\text { Carbon Treated } \\
\text { Settled } \\
\text { Filtered }\end{array}$ & $\begin{array}{l}6 \\
7\end{array}$ & $\begin{array}{l}50 \\
51\end{array}$ & $\begin{array}{l}90 \\
93\end{array}$ & $\begin{array}{l}94.5 \\
97.5\end{array}$ & 96 & $\begin{array}{l}94 \\
96\end{array}$ & $\begin{array}{l}<5 \\
<5\end{array}$ & $\begin{array}{l}0.33 \\
0.68\end{array}$ \\
\hline $\begin{array}{l}\text { DISTILLED WATER } \\
\text { SALTON SEA BRINE }\end{array}$ & 100 & 85 & 98.5 & 100 & 99.5 & 97 & $<5$ & 0.20 \\
\hline As Is & 201 & 0 & 36 & 84.5 & 95.5 & 93.5 & 80 & 0.54 \\
\hline Settled & 202 & 0 & 36.5 & 84.5 & 94 & 94 & 90 & 2.0 \\
\hline Filtered (fine) & 203 & 0 & 39 & 85.5 & 94 & 94 & 90 & 0.45 \\
\hline $\begin{array}{l}\text { Carbon Treated } \\
\text { Too Little } \\
\text { Carbon } \\
\text { Sufficient } \\
\text { Carbon }\end{array}$ & $\begin{array}{l}205 A \\
205 B\end{array}$ & 0 & $\begin{array}{c}60.5 \\
88\end{array}$ & $\begin{array}{c}93 \\
99.5\end{array}$ & $\begin{array}{c}97 \\
99.5\end{array}$ & 97 & $\begin{array}{l}40 \\
10\end{array}$ & $\begin{array}{l}0.29 \\
0.60\end{array}$ \\
\hline
\end{tabular}

${ }^{a}$ NTU $=$ Nephelometric turbidity units 
2. Brines being withdrawn from evaporation pans may require clarification, depending upon the degree of agitation produced by withdrawal.

3. Decolorized water (not concentrated) must measure less than 5 units color on the Pt-Co ( $p l a t i n u m-c o b a l t)$ scale as determined by Method 204A of the Standard Methods for the Examination of Water and Waste Water, 15th Edition, 1980.

4. By the same method as in Item (3) above, concentrated brines must measure 10 units or lower.

3.2.4 Conclusions and Recommendations. Salton Sea water is an abundant source of water and salt for large solar pond operation. Brines of any required concentration can be made by evaporation of the water. Unconcentrated Salton Sea water has sufficiently low salt concentration to be a good gradient-maintenance flushing stream for the solar pond surface. In order to achieve good solar energy collection performance, the Salton Sea water must be treated to improve optical properties before use or evaporation. Clarification will be needed to remove inherent turbidity. After clarification, the water must be decolorized.

Before a final design of a Salton Sea solar pond system is prepared, further study of light transmission and water treatment should be done. Improvement in the prediction accuracy of contaminants and treatment effects on performance is needed. Treatment processes need data for sizing equipment (rates, residence time, etc.). Economic analysis is needed to select which decolorization process is best--activated carbon or ozone. Treatment process should be verified in a pilot-scale plant.

Standard commercial color measurement is adequate for design and operation of the decolorization process. Further work is needed to apply or adapt commercial turbidity methods.

After the objectives stated above have been accomplished, the interim specification of water and brine optical quality should be revised.

\subsection{Brine/Soil Interactions}

3.3.1 Background (Phase 1 Report, Reference 1). In Phase 1, a series of experiments were conducted to determine the likelihood of deleterious microbiological reactions in a Salton Sea solar pond. Shoreline soil samples were immersed in Salton Sea brine and water and heated to $75^{\circ} \mathrm{C}$ for periods up to four months. Because one common class of potentially damaging microbes produces hydrogen sulfide $\left(\mathrm{H}_{2} \mathrm{~S}\right)$, liquid samples were taken periodically near the soil surface and analyzed for sulfide. 0xygen was excluded from all tests. None of the tests with brine generated $\mathrm{H}_{2} \mathrm{~S}$. Small amounts of $\mathrm{H}_{2} \mathrm{~S}$ were generated in one test using Salton Sea water (non-concentrated) as the supernatant fluid. Conclusions from this test series are the following: (1) sulfide-producing organisms were present in at least one shoreline sample and (2) concentrated brine at $75^{\circ} \mathrm{C}$ appeared to suppress all $\mathrm{H}_{2} \mathrm{~S}$ generation.

The question of temperature remained opened at the conclusion of the Phase 1 effort. Even though brine prevented reaction at $75^{\circ} \mathrm{C}$, it may not 
limit reaction at lower temperatures. During initial heat-up of the pond, the bottom zone temperature will slowly heat from ambient to $75^{\circ} \mathrm{C}$ and expose the soil to a variable temperature. At steady-state, a temperature profile will be estabished below the pond providing more favorable temperature zones for microbiological reactions.

3.3.2 Phase 1A. Effort. Three objectives were defined for the brine/soil interaction investigation in Phase 1A. The first objective was a site-specific experiment to assess the effects of temperature on $\mathrm{H}_{2} \mathrm{~S}$ generation. The second objective was more general and directed toward the development of a more efficient test for determining the potential of damaging gas evolution. The third objective focused on determining if the soil could cause light-attenuating contamination of clarified and decolorized brine.

The effect of temperature was studied in a gradient column with a soil sample at the bottom composed of $50 \%$ of the active soil from the earlier test (from frozen storage) and 50\% of a new soil sample selected on the bas is of appearance and odor. The bottom of the column was heated as in the earlier experiments but much more slowly, about $1^{\circ} \mathrm{C}$ per day to $50^{\circ} \mathrm{C}\left(50^{\circ} \mathrm{C}\right.$ is believed to be a temperature that is much more benign to microbiological reactions than $75^{\circ} \mathrm{C}$ ). The bottom of the column was maintained at $50^{\circ} \mathrm{C}$ for a month. Periodically, brine samples were analyzed for sulfide; none was found. During the slow temperature rise, in the $30^{\circ} \mathrm{C}$ region, a few bubbles were observed escaping the soil. Some of these were collected and analyzed in a mass spectrograph. The results indicated that their source was probably trapped air. No hydrogen sulfide or methane was detected. On the basis of these soil samples, no damaging gassing should be expected under the conditions of starting and operating a solar pond.

The plan for developing a general and more efficient test for determining the potential for gas generation was based upon identification of the essential requirements and conditions. For the specific class of inicroorganism under consideration, the material requirements are water, organic carbon, and sulfate salts. These oryanisms obtain needed oxygen from the sulfate and excrete the unneeded by-product sulfur as hydrogen sulfide gas. The environment of the soil at the bottom of the pond is anaerobic, can be as hot as $100^{\circ} \mathrm{C}$, and is highly saline. Microorganisms that generate hydrogen sulfide are anaerobic. In general, such organisms metabolize faster with rising temperature up to about $50^{\circ} \mathrm{C}$; response to higher temperature environments is organismspecific, and the sensitivity to dissolved salt concentration must be determined by testing.

A careful review of the information generated to date on one of the soil samples will be helpful.

(1) Presence - Sulfide-producing microorganisms were found to be present in the test at $75^{\circ} \mathrm{C}$ and low salt concentration.

(2) Material availability.

(a) Water was abundant.

(b) The sulfate ion was $42 \%$ by weight of the anion content in the low salt concentrate liquid and $32 \%$ by weight in the 
brine. (Some sulfate is lost during evaporation to brine by calcium sulfate precipitation.)

(c) The total organic carbon was $0.2 \%$ on a dry weight basis.

(3) Anaerobic conditions were assured by degassing all water and brines.

(4) The hydrogen sulfide generated in the one active test was produced at $75^{\circ} \mathrm{C}$. The reaction started several days after that temperature had been quickly reached.

(5) Slowly heated tests with brine produced no sulfides.

Although it appears that high salt concentration will limit gassing activity at the Salton Sea, the question remains as to why the rate of sulfide generation was so low in the one active case. From the above analysis, it could be concluded that too little organic carbon was present. An experiment was undertaken to test this theory. The same 50/50 soil mixture described above was submerged in degassed Salton Sea water. The assembly was held at room temperature for one month with a slow nitrogen purge of the surface. At the end of the month, no sulfide was detected. A large quantity of brain heart infusion (an organic carbon nutrient for bacteriological testing) was added, and slow heating was applied. Hydrogen sulfide generation started almost immediately. The toxic gas production became so vigorous that it was necessary to remove the apparatus to an exhaust hood. $\mathrm{H}_{2} \mathrm{~S}$ generation continued at a high rate until a temperature of $60^{\circ} \mathrm{C}$ was reached. In spite of the vigorous activity, no bubbling was observed. The results of this experiment support . the theory that the Salton Sea soil sample had insufficient organic carbon.

Methane is another common gaseous product of anaerobic microorganisms. Methane may well be more critical than hydrogen sulfide because the solubilities are very different. Hydrogen sulfide is very soluble in water and can be transported at high rates by diffusion. Methane has a low solubility, and low rates of generation could produce undesirable bubbling. From time to time, tests were made for methane but no methane was detected. Therefore, either no methane-producing organisms were present or some other limiting factor existed. An experiment to test for one of the more probable limiting factors was conceived but not performed. This test would have been based on the need of methane-producing organisms for chemical precursors such as short-chain carboxylic acids.

All tests for gas-producing reactions using Salton Sea soil and water samples have thus far produced negative results. Before initiating construction of a plant, further verification tests with more representative samples would be appropriate. The development of a generalized evaluation procedure based on chemical contents of the soil and water is dependent upon a larger data base that includes other sites.

During all of the tests of Phase 1 and $1 A$ in which Salton Sea soil samples were submerged in Salton Sea water or brine, a constant watch was maintained for evidence of light-attenuating contamination of the water by the soil. Particulate deposits on column walls were observed and reported (Ref. 1), but no deposits were attributed to the soil. In all of the tests, the water 
or brine used had not been decolorized, and it seemed possible that lightattenuating contamination might not be noticed.

A special test was designed to investigate soil-induced light-attenuating contamination. Decolorized Salton Sea brine was placed in contact with a dirty appearing Salton Sea soil sample. The test combination was held at room temperature for one month; then, it was heated to $80-85^{\circ} \mathrm{C}$ and held for another month. Brine samples were taken and measured spectrophotometrically before contact, after room temperature exposure, and after high-temperature exposure. The results of this test are illustrated in Figures 5 and 6 .

Clearly, a significant amount of light-attenuating contamination occurred in this test. Most of the change occurred in the first month of exposure at room temperature. Turbidity caused by suspended particulates plays a small part in the change; chiefly, the attenuation is absorption of radiant energy by dissolved substances that cannot be removed by filtration. More testing and some mathematical treatment of the data would be necessary to obtain a quantitative estimate of this effect. However, based on past observations, a pond collection efficiency drop of about $5 \%$ can be anticipated. This result demonstrates the need to conduct further tests of this kind and to develop criterion for the selection of liner surface materials.

\subsection{Soil Permeability}

3.4.1 Background (Feasibility Study, Reference 3). Ormat Turbines Ltd. (Ref. 3) set a limit of $1.176 \times 10^{-6} \mathrm{~cm} / \mathrm{s}(0.04 \mathrm{in.} /$ day) for the rate of acceptable seepage of brine through the liner of the pond. A very good clay will be required to meet this specification. A direct translation of the seepage to a limiting permeation coefficient produces a value of $1.96 \times 10^{-7} \mathrm{~cm} / \mathrm{s}$. Clays exhibit permeation coefficients for water of $1 \times 10^{-6} \mathrm{~cm} / \mathrm{s}$ and less (Ref. 3).

Several other considerations complicate evaluation of the suitability of the Salton Sea clay. First, because of the design, the solar pond will be in approximate hydrostatic balance with the adjacent Salton Sea. Thus, the potential seepage driving force will be very $10 \mathrm{w}$. On the other side of the scale, brine--and in particular hot brine--can change the characteristics of clay soils.

3.4.2 Phase IA Effort. Clay is present at the Salton Sea site (Ref. 3). Its quantitative and economic availability for solar pond construction was not determined in the Phase 1 study. A series of experiments was undertaken during Phase IA to obtain an estimate of the clay quality. The clay sample for testing was extracted from an exposed lense of clay at the proposed site. Preliminary tests of this sample indicated good permeation quality; a permeation coefficient of $7.3 \times 10^{-8} \mathrm{~cm} / \mathrm{s}$ was measured. However, this test was a short-term exposure to brine at room temperature.

The structure of some clays are known to degenerate in the presence of high salt concentrations; this process can also be accelerated by elevated 


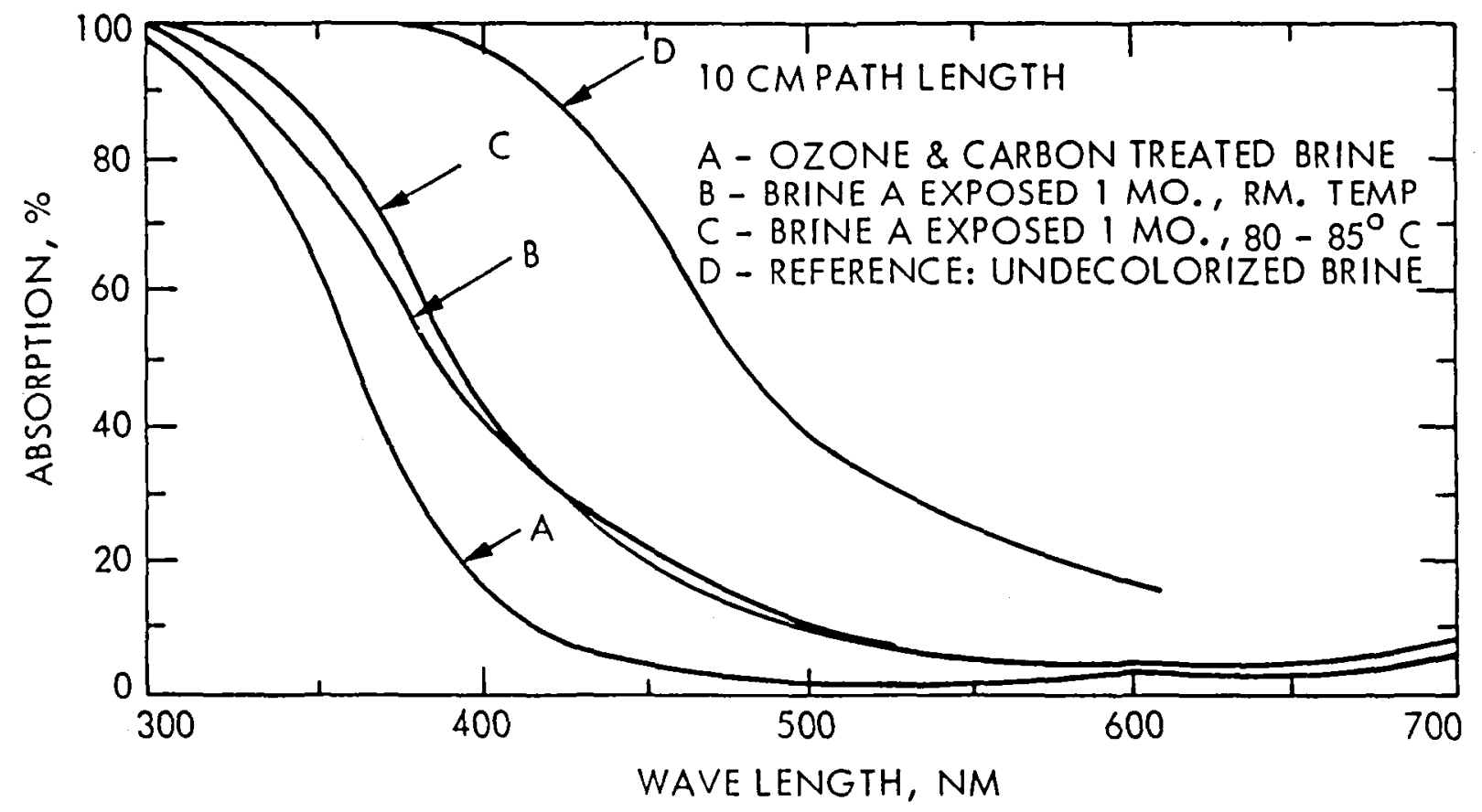

Figure 5. Evidence of Light-Attenuating Contamination from Black Sea-Bottom Mud 


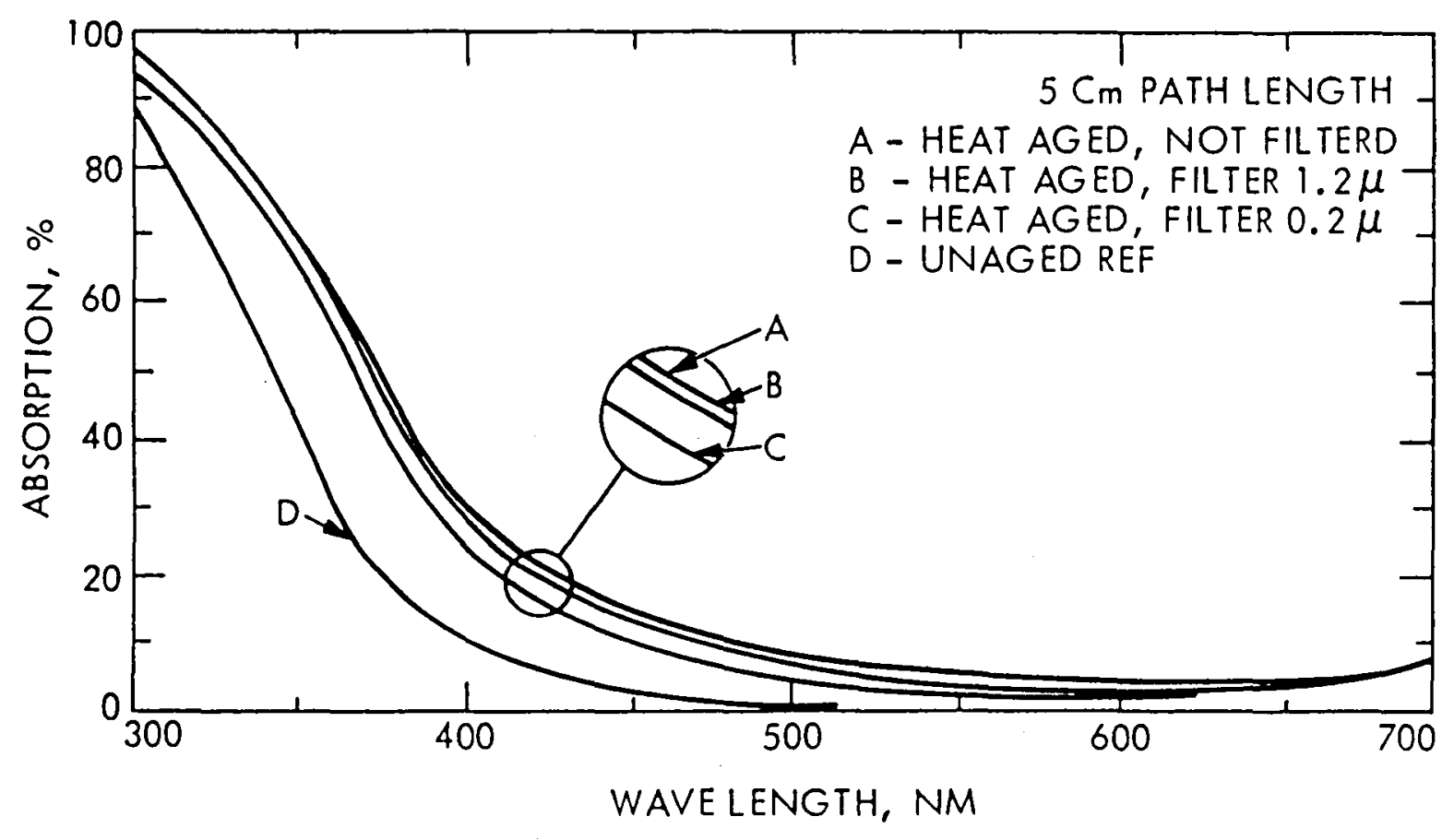

Figure 6. Effect of Filtration on Contamination Caused by Mud 


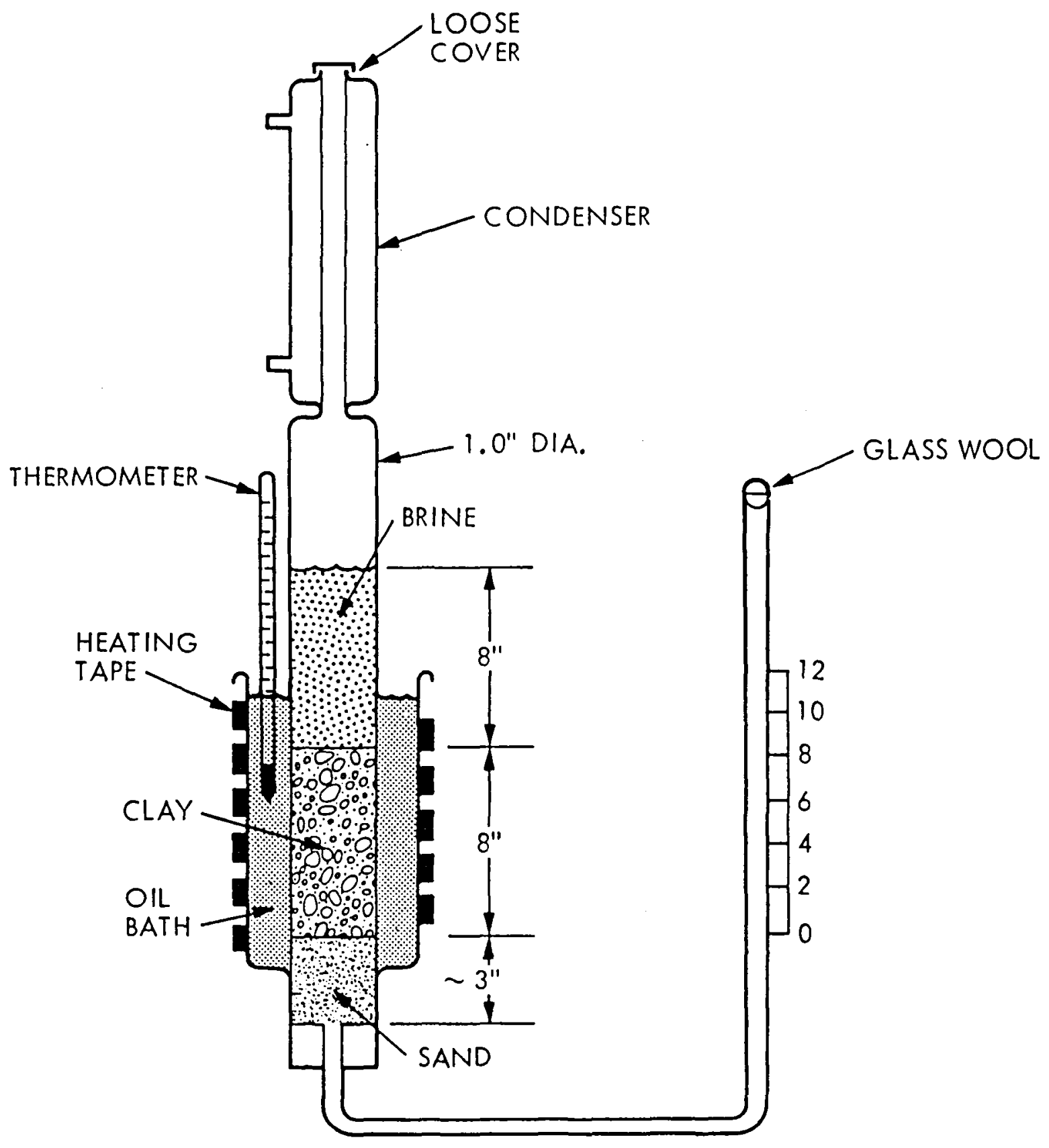

Figure 7. Test Fixture for the Measurement of Permeation Rate of Clay at Elevated Temperatures 
temperature. A special test fixture was built to test the effect of temperature on the permeation of Salton Sea brine through the Salton Sea clay. A diagram of the fixture is shown in Figure 7 .

In this setup, an 8 -in. bed of natural, wet, plastic clay was tamped into the large tube on top of a bed of sand. The voids in the sand bed and the side tube were filled with brine to a level corresponding to the clay/sand interface. Approximately $8 \mathrm{in}$. of brine was introduced on top of the clay. All of the clay and the lower portion of brine were heated to a uniform temperature by an oil bath. A reflux condenser was installed to avoid loss of water by vaporization. To gain precision, flow was measured as the rate of rise of liquid in the small-diameter side tube instead of the corresponding rate drop in the main tube.

The one sample of Salton Sea clay was subjected to a series of successively higher temperatures. The test apparatus was held at each temperature for several days during which a number of flow measurements were inade. Exposure time ranged from 58 days at room temperature to 3 days at $93^{\circ} \mathrm{C}$. The Darcy equation applies to measurements in which the heat is constant. For the falling head case experienced in these tests, the equation had to be modified:

Darcy Equation: $\quad v=k \cdot H / L$

where $v$ is the velocity of flow, $\mathrm{cm} / \mathrm{s}$
$k$ is the permeation coefficient, $\mathrm{cm} / \mathrm{s}$
$H$ is the head (pressure drop), $\mathrm{cm}$
$L$ is the thickness of the sealing soil, cm
Let $\quad V=\frac{\mathrm{dx}}{\mathrm{dt}}$, velocity of flow, $\mathrm{cm} / \mathrm{s}$
Let $\quad H=H_{0}-x-y$, head

where $\quad H_{0}=$ head at start $(t=0), \mathrm{cm}$

and $\quad x=$ drop in main tube at time $t, c m$

and $y=$ rise in side tube at time $t, c m$

Let $\quad R=A_{x} / A_{y}$, area of ratio of the two tubes

Hence $\quad R=y / x$ 
Then

$$
\frac{d y}{d t}=\frac{R \cdot K}{L} \cdot\left(H_{0}-y / R-y\right)
$$

Upon integration, this expression becomes

$$
x=\frac{y}{R}=\frac{H_{0}}{R+1}\left[1-e-\frac{(R+1) \cdot k t}{L}\right]
$$

The permeation coefficient can be calculated from this expression, rearranged,

$$
k=\frac{L}{(R+1) \cdot t} \ln \left[\frac{R H_{0}}{R H_{0}-(R+1) y}\right]
$$

The results of this experiment are shown in graphical form in Figure 8. There appears to be three regions of temperature effect on permeation of brine, all rising. Clearly, the sealing properties of this clay sample degenerate with temperature. However, this experiment was not able to distinguish between the effects of time and of brine composition. The importance of this question is demonstrated in the evidence of continued degradation of the sample as the temperature dropped from $93^{\circ} \mathrm{C}$ to $60^{\circ} \mathrm{C}$.

The sealing properties of a shoreline sample of clay deteriorated in the presence of concentrated Salton Sea brine at elevated temperature. Results of short-term testing indicate the possibility that further deterioration can be expected from longer exposure, but the limits of change cannot be predicted. A comprehensive investigation must be made with the objective of obtaining good estimates of seepage rates in the proposed solar pond.

\subsection{Corrosion Testing}

3.5.1 Objective. The objective of this effort was to obtain data that could be used in the selection of materials for the construction of process and fluid transport equipment. Of particular interest is the long-term durability of heat exchanger tubing in the vaporizer, preheater, and condenser of the power conversion subsystem.

3.5.2 Approach. Two test approaches were utilized: sample exposure and potentiodynamic polarization. Sample exposure involves relatively simple coupon immersion tests. Potentiodynamic polarization is a sophisticated technique for quantifying relative material behavior in an accelerated test (Appendix B and Ref. 4).

3.5.2.1 Sample Exposure. Five steel (alloy 1020) and two stainless steel (alloy 231) coupons were exposed for 20 weeks to a variety of conditions simulating those of a solar pond. Periodically, the coupons were removed, 


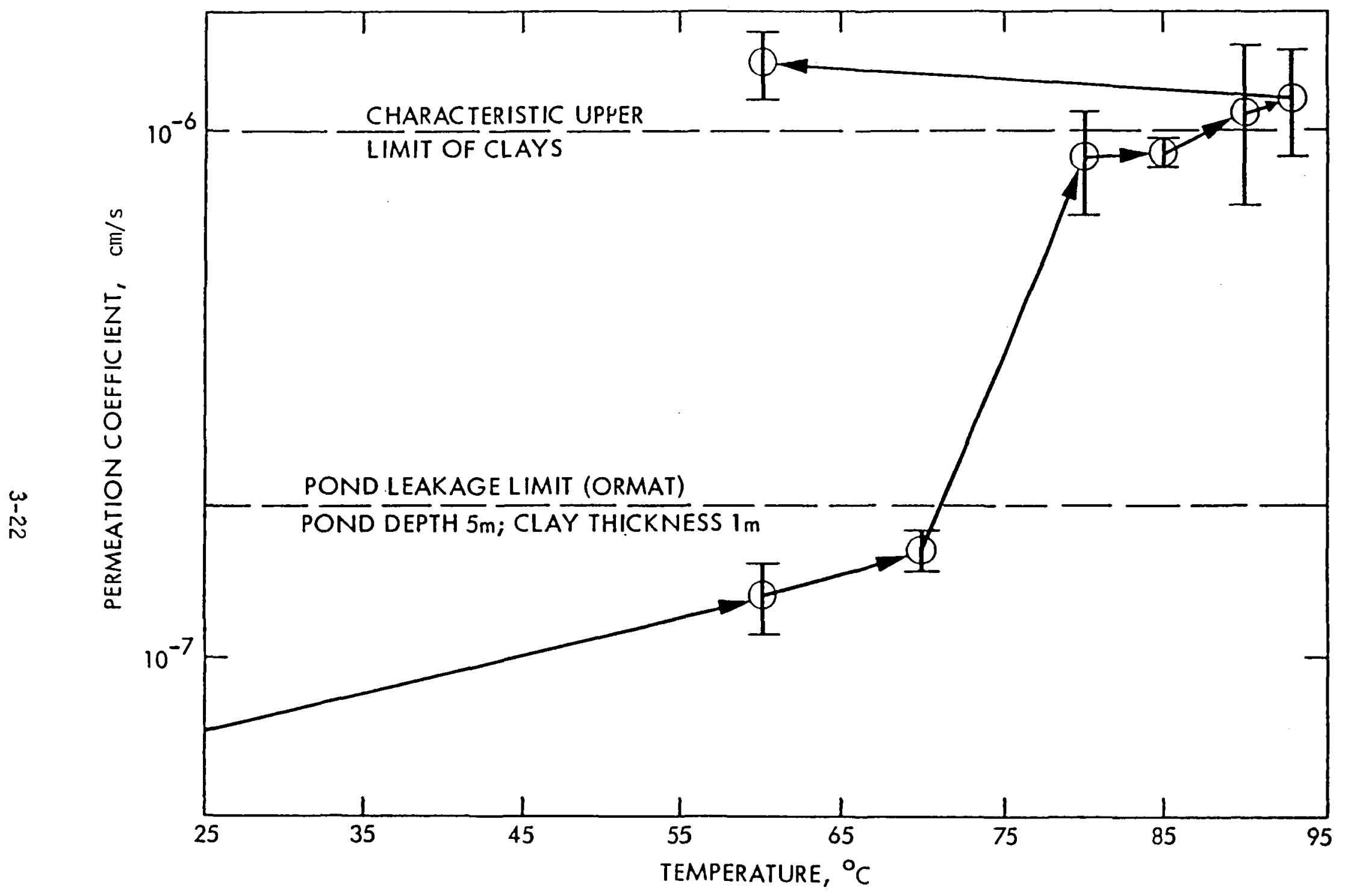

Figure 8. Permeation Test History of Salton Sea Clay 
cleaned with distilled water and a soft-bristled brush (per ASTM test G31), dried, and weighed. The metal samples were exposed in three separate test setups. In two of the setups, the samples were immersed in Salton Sea brine at $80^{\circ} \mathrm{C}$ in a closed vessel with either oxygen or nitrogen constantly bubbling through the brine. The immersion was arranged so that the samples could not touch each other and were also protected from direct influence of the bubbling agitation. The third test setup consisted of a laboratory model salt-gradient pond in a 4-ft. long, 4-in. diameter glass pipe. The bottom was heated, and the gradient was maintained. Metal samples were immersed in each of the three layers of the model pond.

3.5.2.2 Potentiodynamic Polarization. Anodic polarization analyses of several alloys were carried out in aerated Salton Sea type water ( $3.8 \%$ salt concentration) and concentrated brine (20\% salt concentration). Current density profiles produced by this technique were then used as a basis for predicting corrosion rates. (See Ref. 4 for a discussion of method.) The principle investigator in the work was Dr. S. Sastri of New York City Technical College who worked at JPL during the summer of 1982 under the DOE/ASEE (U.S. Department of Energy and American Society of Engineering Education) Summer Faculty Program. Dr. Sastri reported his findings in a report, which is included as Appendix $B$ of this document.

3.5.3 Results. Conditions of the sample exposure testing are summarized in Table 4. The results are presented in Figures 9 and 10.

Table 4. Corrosion Test Exposure

\begin{tabular}{|c|c|c|c|c|}
\hline $\begin{array}{c}\text { Test } \\
\text { Identification }\end{array}$ & Temp. & $\begin{array}{c}\text { Salt } \\
\text { Concentration }\end{array}$ & $\begin{array}{l}\text { Proximate } \\
\text { Atmosphere }\end{array}$ & Sample \\
\hline \multicolumn{5}{|l|}{ Lab Model Pond } \\
\hline Storage Zone & $70^{\circ} \mathrm{C}$ & $22-24 \%$ & None & Steel 1020 \\
\hline Mid-Gradient & Approx. $50^{\circ} \mathrm{C}$ & Approx. $15 \%$ & None & Steel 1020 \\
\hline $\begin{array}{l}\text { Upper Convecting } \\
\text { Zone }\end{array}$ & $25^{\circ} \mathrm{C}$ & $4-6 \%$ & Air & Steel 1020 \\
\hline \multicolumn{5}{|l|}{ Brine/Gas } \\
\hline Brine $/ \mathrm{N}_{2}$ & $80^{\circ} \mathrm{C}$ & $22-24 \%$ & $\mathrm{~N}_{2}$ & \multirow{2}{*}{$\begin{array}{l}\text { Steel } 1020 \\
\text { Stainless } 321 \\
\text { Steel } 1020 \\
\text { Stainless } 321\end{array}$} \\
\hline Brine $/ 0_{2}$ & $80^{\circ} \mathrm{C}$ & $22-24 \%$ & $\mathrm{O}_{2}$ & \\
\hline
\end{tabular}

The most noticeable result of these tests is the difference between mild steel and stainless steel. Mild steel corroded in all cases (Figure 9) while the stainless coupon experienced a gain in mass when oxygen was present 


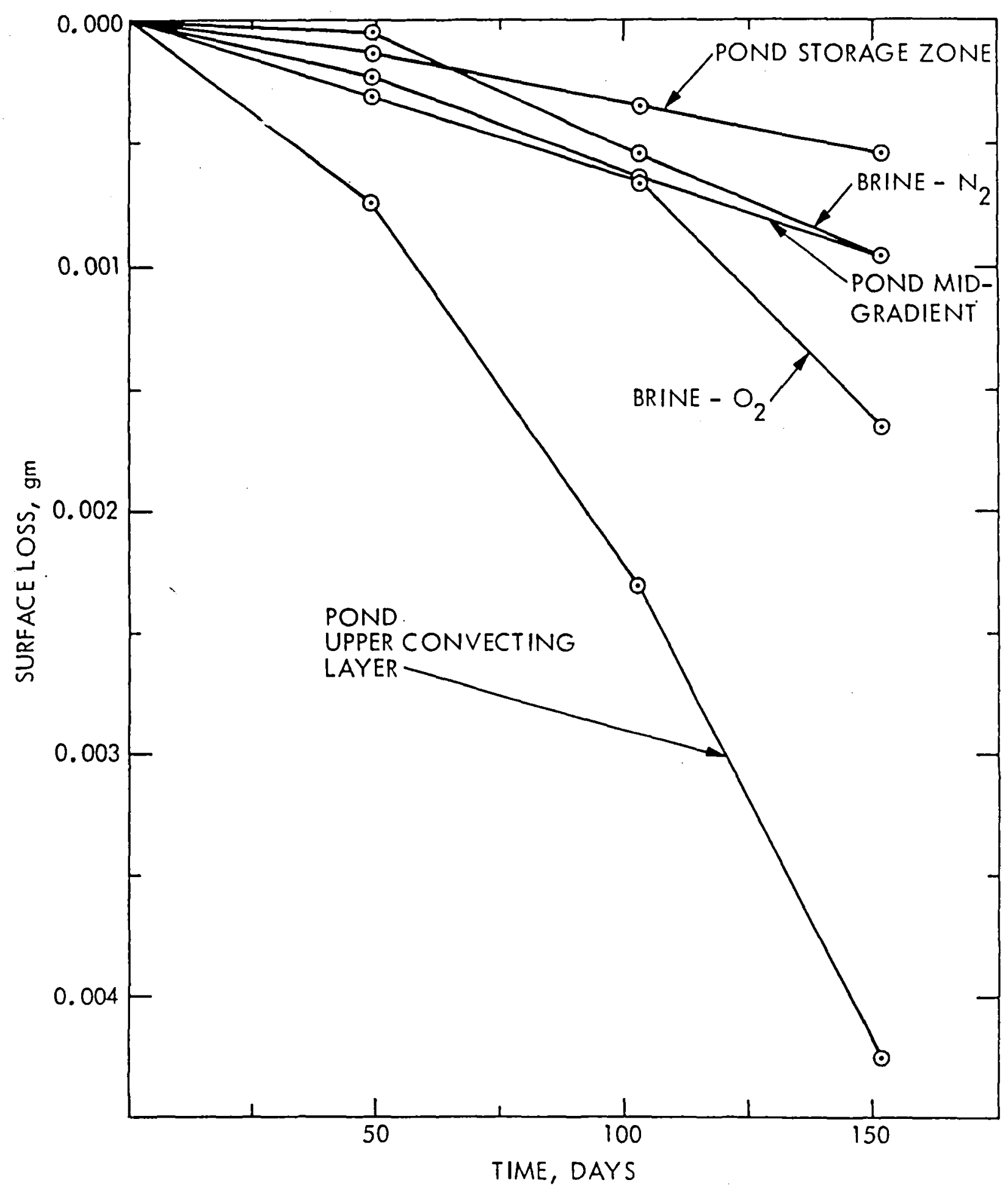

Figure 9. Corrosion of 1020 Steel in Salton Sea Brines (See Table 4 for Conditions) 


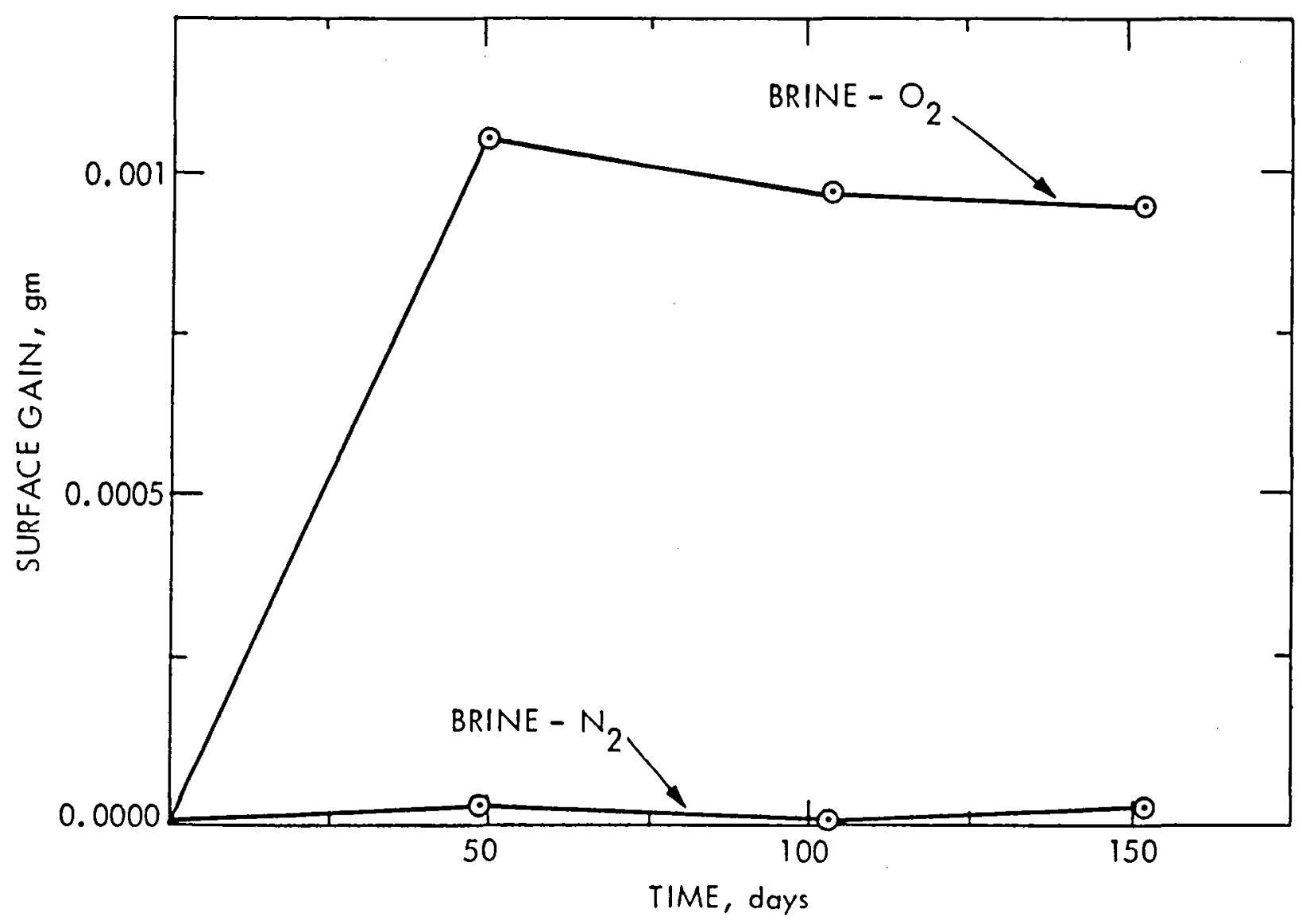

Figure 10. Effect of Salton Sea Brines on Stainless Steel Alloy 321 (See Table 4 for Conditions) 
(Figure 10). In a nitrogen/brine environment, the stainless steel coupon experienced no mass change. Apparently, a tenacious film of corrosion product is formed on the surface of 321 stainless in the oxygen brine environment.

Mild steel (alloy 1020) corroded most rapidly in the upper convecting layer of the laboratory "test tube" pond. This result is consistent with statements made by Ormat personnel and by Professor Carl Nielsen of Ohio State University. The reasoning given is that the corrosion in aqueous salt solutions is controlled by the availability of oxygen. Because the solubility of oxygen in salt solutions decreases with both rising salt concentration and rising temperature, corrosion in the lower convecting zone should be less severe than in the upper convective zone.

The slopes of the curves in Figure 9 can be converted to estimates of an annual corrosion rate. Using the steepest slope for each curve, the annual rate of corrosion for low carbon 1020 steel varies from 0.0013 to $0.015 \mathrm{~cm} / \mathrm{yr}$ $(0.00053$ to $0.0057 \mathrm{in./yr})$ as shown in Table 5 . These data demonstrate that corrosion of mild steel will be more severe in the power plant condensing heat exchangers when pond surface water is used for cooling. Further interpretation of the data is confusing because (1) the corrosion rate appears to accelerate with time and (2) the small variations seen in the storage and gradient zones may be induced by test methods and procedures.

Table 5. Corrosivity of Steel 1020 in Salton Sea Solutions as Determined from Coupon Exposure Tests

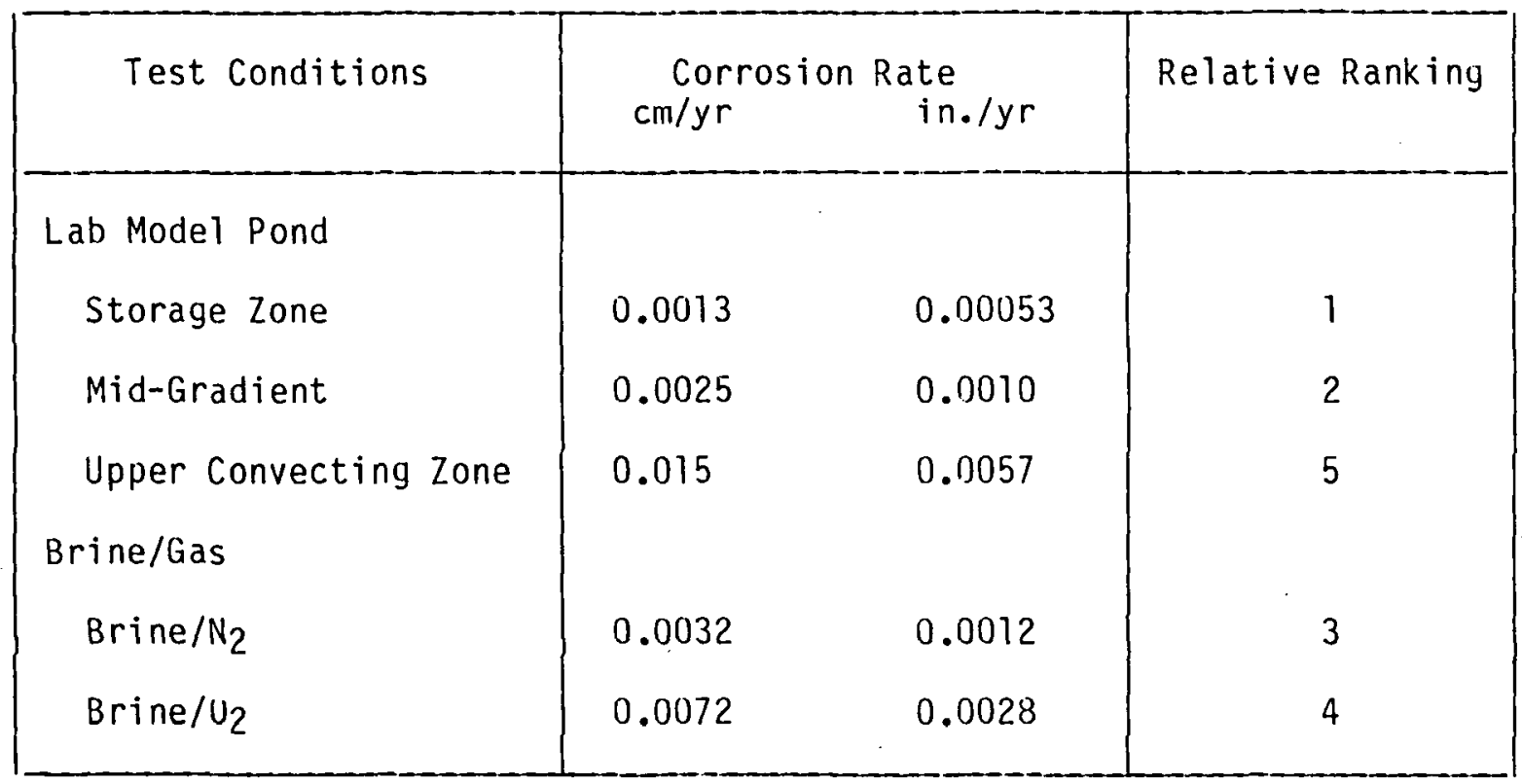

The results of the potentiodynamic polarization (PDP) analyses are presented in Appendix $B$ and summarized below. Table 6 presents corrosion 
rates for six alloys as estimated from this method. In contrast to the sample emersion tests, PDP analyses indicate that corrosion of the selected alloys will be more pronounced in brine than in water with a low salt concentration. There is a reasonable agreement for the corrosion of 1020 steel by Salton Sea water: PDP yielded 0.00406 in./year versus sample emersion, which yielded 0.0057 in./year. Because different stainless alloys were tested, a direct comparison may not be meaningful.

Table 6. Corrosion Rates of Various Alloys as Determined from Potentiodynamic Analyses

\begin{tabular}{|l|l|l|l|l|}
\hline \multicolumn{1}{|c|}{ Material } & $\begin{array}{l}\text { Salton Sea Water } \\
\text { Corrosion } \\
\text { Current, } \\
\text { ma/in.2 }\end{array}$ & $\begin{array}{l}\text { Corrosion } \\
\text { Rate, } \\
\text { in./yr }\end{array}$ & $\begin{array}{l}\text { Corrosion } \\
\text { Rate, } \\
\text { ma/in.2 }\end{array}$ & $\begin{array}{l}\text { Corrosion } \\
\text { Rate, } \\
\text { in./yr }\end{array}$ \\
\hline 6061 -Al alloy & 0.022 & 0.87 & 0.050 & 1.97 \\
1020 Steel & 0.021 & 0.83 & 0.054 & 2.13 \\
Copper & 0.0026 & 0.10 & 0.011 & 0.43 \\
$90 \mathrm{Cu} \mathrm{10} \mathrm{Ni}$ & 0.002 & 0.08 & 0.010 & 0.39 \\
$304 \mathrm{SS}$ & 0.00044 & 0.02 & 0.0005 & 0.02 \\
\hline
\end{tabular}

3.5.4 Conclusions and Recommendations. The one positive conclusion that can be made on the basis of these two preliminary corrosion studies is that stainless steel will be a safer selection than mild steel for all heat exchanger testing in a Salton Sea solar pond power conversion unit. The studies failed to determine whether mild steel can be selected for the hot, concentrated brine regions (vaporizer and preheater).

Critical questions remain regarding corrosion rates and material selection. A much more serious, in-depth study must be undertaken to better quantify corrosion rates and to factor in economic considerations.

\subsection{General Methodology for Site-Specific Investigations}

3.6.1 Background. A concise but comprehensive review of the state of development of solar pond technology is given by E. Lin in Reference 6 . This review lists a number of problems (e.g., reduced radiant energy transmission from fallen leaves, dust, debris, and from algal growth within the pond; 
disruption of the gradient by gas from microbial activity in the subsoil) that have been anticipated or actually encountered during the operation of solar pond experimental installations. In some cases, remedies are given. However, what is lacking in the literature of this young technology is a generalized approach that anticipates problems and uncertainties and deals with them in a timely manner. As the work progressed in Phases 1 and $1 \mathrm{~A}$ of the Salton Sea Experiment, the need for such a generalized approach became ever more apparent. In response to this need, JPL began to organize the Salton Sea investigations in such a way as to reduce the chances of overlooking critical questions and to provide more accurate engineering data for plant design. The product of this effort is a partly developed general methodology.

The development of a general methodology is incomplete. It has evolved as follows: First, the functional characteristics required in a solar pond electric power system are 1isted. Second, those site-specific factors affecting the functional characteristics and economics are identified. Third, methods are searched for and/or developed for measuring the effects and for finding feasible engineering measures for solving problems that are exposed in the investigations of those effects.

3.6.2 Physics, Chemistry, and Biology. The part of the methodology dealing with the physics, chemistry, and biology of site-specific water, salt, and soil is briefly described here. Table 7 is a listing of the functional characteristics and coordinated site-specific factors that can affect them. The development of some methods for measuring and moderating effects are described in this report and in the Phase 1 report (Ref. 1).

A brief view of the status of the investigation of the Salton Sea and of methodology development, in general, is evident in Table 7 . It is clear that some factors have not been investigated. There may also be factors that are not yet identified. It is not as clear in Table 1 that some of the factors studied need more work. However, a number of examples are described in earlier sections of this report. An additional feature is apparent in Table 7: Straightforward, standardized methods must be devaloped in order for the methodology to become efficient and economic. Many of the methods used thus far are still in the research stage.

Throughout this report, heavy emphasis has been placed upon the answering of questions pertaining to salt-gradient solar pond power plants in the Salton Sea. Nevertheless, the general applicability of the methods used or the methods under development is apparent. A program of research focused on the development of a general approach will lead to a more effective and more efficient methodology that can be used in all solar pond site-specific studies. One example is given here to illustrate the direction such generalized research would take. 
Table 7. Methodology Outline: Water, Salt, and Soil

\begin{tabular}{|c|c|c|c|}
\hline Functional Characteristics & More Specific Factors & $\begin{array}{l}\text { Methods Used } \\
R=\text { Research } \\
S=S \text { tandard }\end{array}$ & $\begin{array}{l}\text { Reported } \\
l=\text { Phase } 1 \\
2=\text { Phase 1A }\end{array}$ \\
\hline $\begin{array}{l}\text { 1. Water and brine having appropriate composi- } \\
\text { tions must be provided to the pond at required } \\
\text { rates. (Assumes local supplies and system } \\
\text { requirements have been evaluated.) }\end{array}$ & $\begin{array}{l}\text { 1. Salt and water compositions } \\
\text { 2. Saturated salts, any natural } \\
\text { sources are usually mixtures } \\
\text { of salts with some species } \\
\text { having potential for } \\
\text { precipitation }\end{array}$ & $\begin{array}{l}S \\
S\end{array}$ & 1 \\
\hline $\begin{array}{l}\text { 2. A significant fraction of the incident solar } \\
\text { radiation must be transmitted through the } \\
\text { upper convecting layer and the gradiant layer } \\
\text { to the storage zone. (Assumes site isolation } \\
\text { has been determined and found acceptable.) }\end{array}$ & $\begin{array}{l}\text { 1. Inherent turbidity and color } \\
\text { 2. Water treatment } \\
\text { 3. Air-born dirt } \\
\text { 4. In-pond precipitation } \\
\text { 5. Contamination from the bottom } \\
\text { 6. In-pond organic growth }\end{array}$ & $\begin{array}{l}\mathrm{R}, \mathrm{S} \\
\mathrm{R} \\
\mathrm{R} \\
\mathrm{R} \\
\text { Not InV Inv }\end{array}$ & $\begin{array}{r}1,1 \mathrm{~A} \\
1,1 \mathrm{~A} \\
\text { estigated } \\
1,1 \mathrm{~A}\end{array}$ \\
\hline $\begin{array}{l}\text { 3. Heat loss to the earth below the pond and } \\
\text { through the sides must be low. }\end{array}$ & $\begin{array}{l}\text { 1. Thermal conductivities of } \\
\text { soil strata } \\
\text { 2. Moisture content } \\
\text { 3. Groundwater depth and flow }\end{array}$ & Not Inv & stigated \\
\hline $\begin{array}{l}\text { 4. The gradient zone must retain a stable } \\
\text { gradient and be protected from mixing and } \\
\text { excessive destabilizing forces. (Wind and wave } \\
\text { stresses and gradient control are outside the } \\
\text { the scope.) }\end{array}$ & $\begin{array}{l}\text { 1. Ionic diffusion } \\
\text { 2. Container failure (leaks) } \\
\text { 3. Gas evolution from bottom }\end{array}$ & $\begin{array}{l}\mathrm{R} \\
\text { (see } 7.2\end{array}$ & below) \\
\hline $\begin{array}{l}\text { 5. Design heat-transfer coefficients must be } \\
\text { maintained in heat exchangers. }\end{array}$ & $\begin{array}{l}\text { 1. Mineral scale } \\
\text { 2. Bio-fouling }\end{array}$ & Not Inv & estigated \\
\hline $\begin{array}{l}\text { 6. All materials in contact with waters and } \\
\text { brines must be durable under the environ- } \\
\text { mental conditions imposed by their use in } \\
\text { a solar pond system. }\end{array}$ & $\begin{array}{l}\text { 1. Corrosion in metals } \\
\text { 2. Membrane } 1 \text { iner degradation }\end{array}$ & $\begin{array}{l}\text { R } \\
\text { (Not applica } \\
\text { Salton Sea }\end{array}$ & $\begin{array}{l}1 A \\
\text { ble in the } \\
\text { Experiment) }\end{array}$ \\
\hline $\begin{array}{l}\text { 7. Essential ingredients must be conserved to } \\
\text { minimize maintenance costs }\end{array}$ & $\begin{array}{l}\text { 1. Evaporation } \\
\text { 2. Seepage rate; leaks } \\
\text { 3. Additive recovery }\end{array}$ & $\mathrm{R}_{\text {Not Inv }}^{\text {Not Inv }}$ & $\begin{array}{l}\text { estigated } \\
1 \mathrm{~A} \\
\text { estigated }\end{array}$ \\
\hline $\begin{array}{l}\text { 8. The environmental impact of construction and } \\
\text { operation of the system must be acceptable } \\
\text { in the pond locale. }\end{array}$ & $\begin{array}{l}\text { 1. Earthwork } \\
\text { 2. Brine loss } \\
\text { 3. Salt/brine disposal }\end{array}$ & $\begin{array}{l}\text { S } \\
\text { (see } 7.2 \\
\text { Not Inv }\end{array}$ & $\begin{array}{c}1 \\
\text { estigated }\end{array}$ \\
\hline
\end{tabular}


Light transmission is a key characteristic of solar ponds. The more accurately this quality can be predicted, the more confidently the plant can be sized and costed. Accuracy of measurement is one thing. Proposed research on this element is described in Subsection 3.1. Another main element, water treatment, is one that presents a wider challenge than that which is evident in Subsection 3.2. For example, Salton Sea dissolved color is organic. Salton Sea studies have shown that activated carbon or ozone treatments remove most of the light attenuation caused by these substances. Investigations of other sites have shown that these two treatments are not always effective. At least one other source of color is dissolved minerals. For these, chemical treatments are needed. A hope is that all waters can be treated successfully with one or two standard approaches. Whether or not this is true is one of the questions a generalized search would aim to answer.

Once a reliable light transmission measurement is developed, and a general set of water treatment processes (from which approriate selections can be made) has been acquired, a general approach can be developed for studying new water and brine sources efficiently. The general form of such an approach is illustrated in Figure 11 . Samples would be subjected to a logical sequence of measurements and treatments. The sequence is designed to be self-stopping when acceptable transmission has been reached, thus saving unnecessary laboratory work. The extra branch points in the diagram indicate that further investigative efficiency can be attained if other information is available to help pinpoint the type of light-absorbing contamination. 


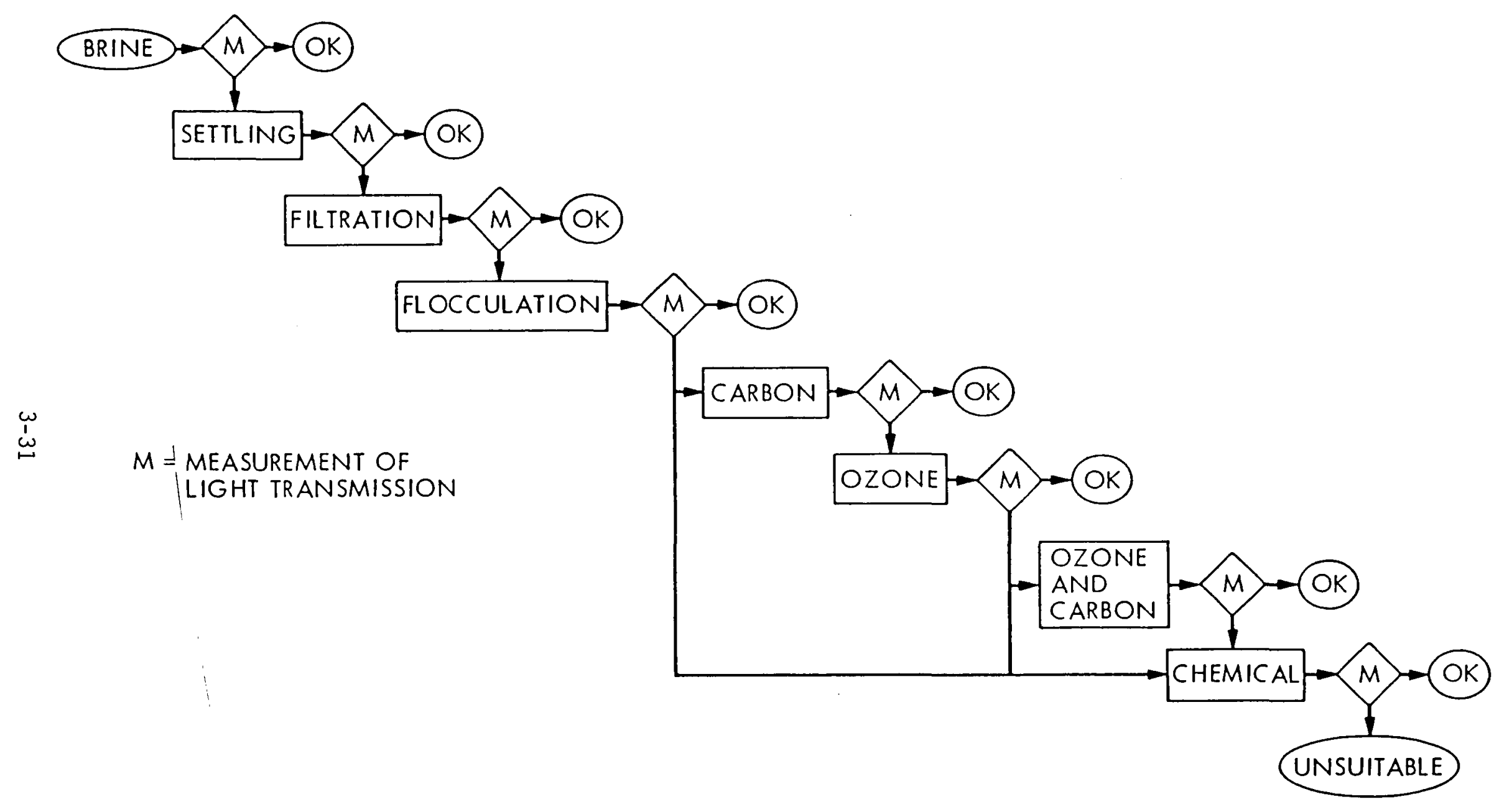

Figure 11. Methodology for Achieving Acceptable Optical Quality in Natural Waters and Brines 
Analytical models are required to investigate the many physical processes and system-level design and performance concerns that are present in a solar pond power plant. Models with detailed physical process descriptions will be required to study and understand wind/surface interactions and upper-gradientzone boundary migration, lower-zone hydrodynamics and heat extraction, and gradient-zone stability and control. Models for system design will have more of a macroscopic point of view, and the solar pond will be viewed as one of many subsystems. In this latter case, a simplified solar pond description will be entirely adequate. Ultimately, industry will desire validated design models or design tools that are scoped in capability to accurately assess the effects of design variables.

JPL began development of a system-level design and analysis model. This model was conceived to have several key elements: a solar pond thermodynamic performance model, a power generation subsystem model, and an economic analysis element. The basic approach was to create these elements or modules and refine them on an individual basis yet retain the capability to easily couple them into a full system design model. This "building block" approach allows for maximum flexibility and substitution of refined descriptions as the technology develops.

A general overview of interconnecting these subsystem models is presented in Figure 12. The primary program control element will perform the administrative functions of data input, data output, information storage and transfer, and sequential calling of the subsystem models.

From the point of view of the requirements of a system design model, JPL began the development of a power conversion subsystem model. The goal of the effort was a preliminary subsystem model, simplified in content but organized in a "building block" concept to facilitate flexibility and ease of change or modifications. As a first step towards a system design model, the power conversion subsystem model was to be made compatible with the solar pond subsystem model so that a first order system simulation analysis could be performed.

This task was terminated prior to completion. The discussion that follows reflects progress to date, planning, program organization concepts, and functional descriptions.

\subsection{Solar Pond Thermodynamic Performance Element}

A solar pond thermodynamic performance model was developed during the previous reporting period and has been reported in Reference 1. This model is very similar to other developed models and describes solar pond performance by a transient, one-dimensional heat conduction equation with a time- and depth-dependent insolation source term. Because the clarity of Salton Sea water is an important issue, the model has been formulated to accept data taken from spectrophotometric measurements. 


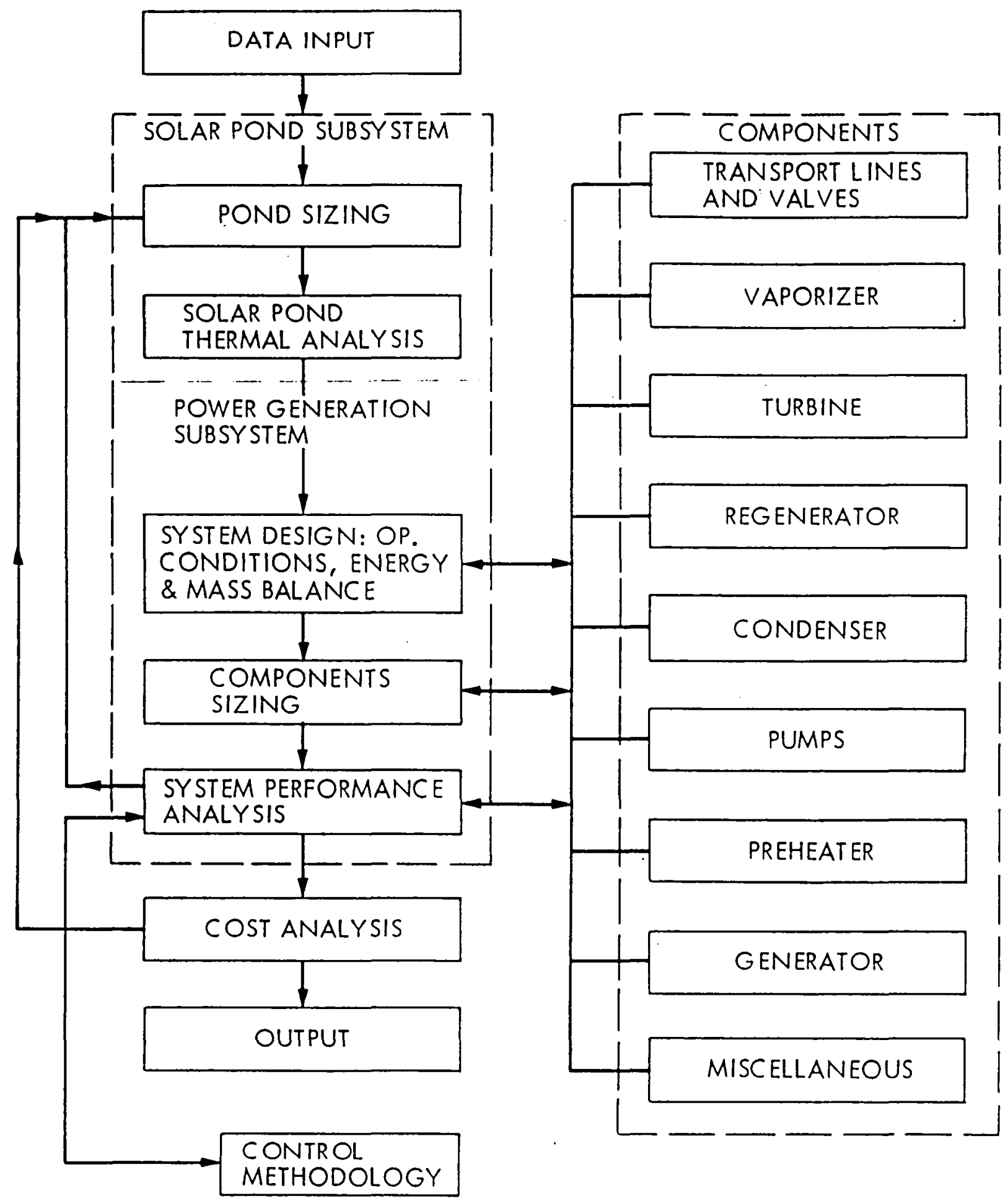

Figure 12. A General Computer Mode1 Information Flow Diagram 


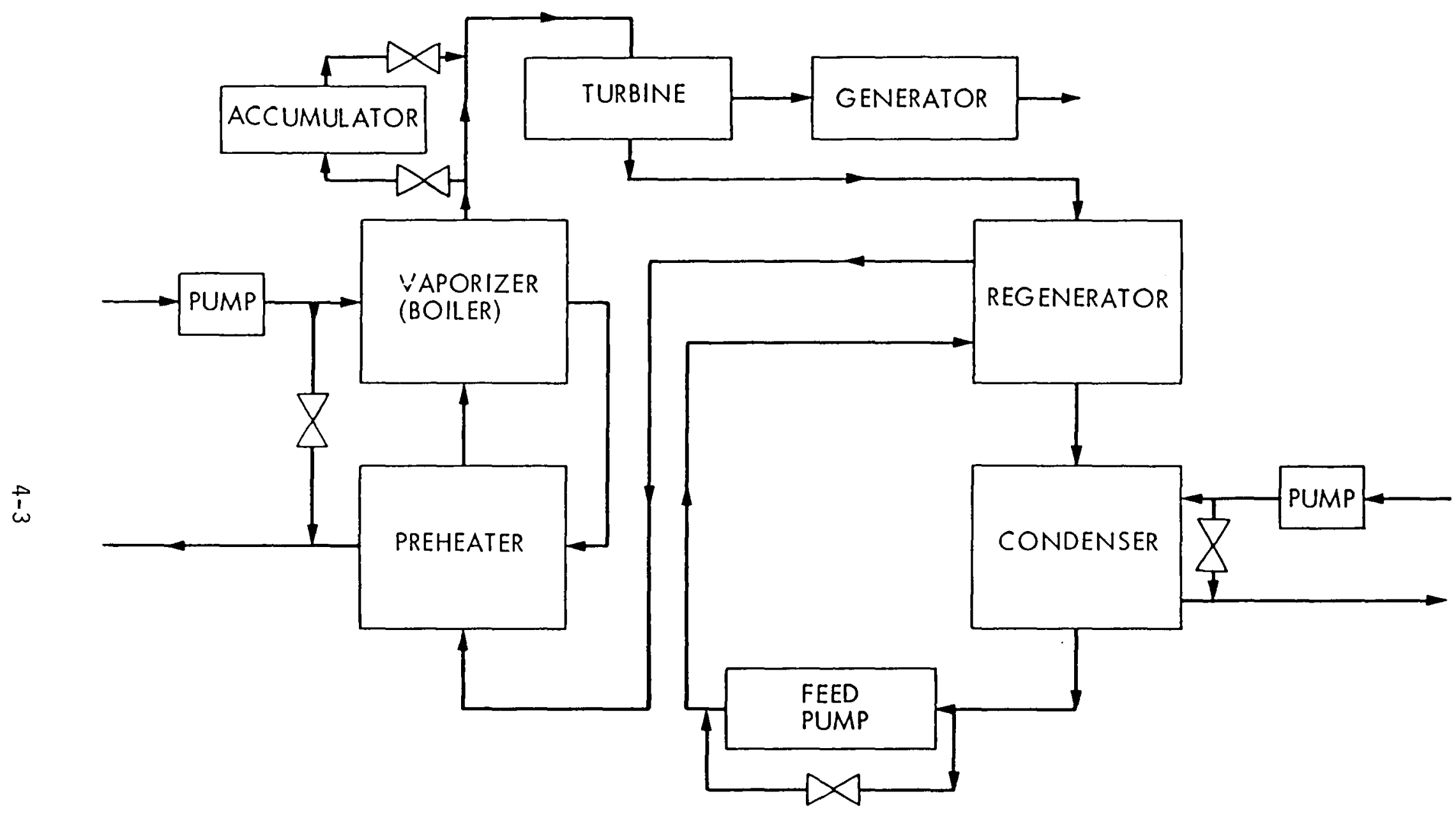

Figure 13. Electric Power Generation Subsystem 


\subsection{Power Generation Subsystem}

The power generation subsystem or power conversion module is a major subsystem of a solar pond power plant. To date, modeling efforts have focused on the solar pond element with little attention directed toward this or the other subsystems.

\subsubsection{Description and Status}

The main elements of the power generation subsystem to be considered in the subsystem model are shown in Figure 13. Each functional element or component will be modeled as a block. To complete the subsystem model, an algorithm will be developed to tie the component models to one another.

Currentiy, the basic concept and the system model structure have been established. Mathematical descriptions for a portion of the component elements in the power generation subsystem have been completed. Remaining work includes completing the component descriptions, writing a subsystemlevel algorithm, and preparing final computer coding. Further details can be found in Appendix $C$.

\subsection{Economic Model}

4.3.1 Objective. The objective of this task was to develop a costestimating procedure for the economic evaluation of a solar pond power plant. The procedure should be capable of estimating the capital costs, the annual operation and maintenance costs, and translating these costs into the break even cost for the produced power.

4.3.2 Description. A solar pond power plant economic model, based on the methodology presented in Reference 7, has been developed. The methodology systematizes the following steps:

(1) Identification of the elements of a solar pond power plant.

(2) Development of the essential cost elements.

(3) Calculation of costs for each cost element.

(4) Computation of system capital cost.

(5) Selection of critical financial parameters.

(6) Computation of costs of delivered energy.

The cost estimating procedure can be manualiy computed or easily transformed into a computer code. 
SECTION 5

REFERENCES

1. Peelgren, M.L., Salton Sea Project, Phase I, Final Report, Jet Propulsion Laboratory, 5107-2, (JPL Publication 81-108), January 15, 1982.

2. The Ralph Parsons Company, Salton Sea Solar Pond Power Plant, Preliminary Design/Cost Estimate Study, prepared for the Jet Propulsion Laboratory under Contract No. 956462, Parsons File No. 6371-1, October 1983 .

3. Ormat Turbines, A Study of the Feasibility of a Solar Salt Pond Generating Facility in the State of California, U.S.A., Volumes I and II, prepared for the Southern California Edison Company under P.0. No. M0079003, Israel, 1981 .

4. Morris, P.E., and Scarberry, R.C., "Predicting Corrosion Rate with the Potentiostat," Corrosion, Vol. 28, No. 12, p. 44, 1972.

5. Lin, E.I.H., et al, A Review of the Salt-Gradient Solar Pond Technology, Jet Propulsion Laboratory, 5107-3, (JPL Publication 81-116), January $15,1982$.

6. Lin, E.I.H., et al, Regional Applicability and Potential of SaltGradient Solar Ponds in the United States, Volumes I and II, Jet Propulsion Laboratory, 5107-1, (JPL Publication 82-10), March 15, 1982.

7. Slonski, M.L., Energy Systems Economic Analysis (ESEA) Methodology and User's Guide, Low-Cost Solar Array Project, Jet Propulsion Laboratory, JPL 5101-102, February 15, 1979. 
APPENDIX A

THE SPECTROPHOTOMETRIC METHOD OF DETERMINING

THE TRANSMISSION OF SOLAR ENERGY IN

SALT GRADIENT SOLAR PONDS

A-1 

THE SPECTROPHOTOMETRIC METHOD OF DETERMINING THE TRANSMISSION OF SOLAR ENERGY IN SALT GRADIENT SOLAR PONDS

by

James Giulianelli, DOE-ASEE Summer
Faculty Research Fellow

Submitted to the Jet Propulsion Laboratory following work supported by a grant from the Department of Energy and the American Society for Engineering Education. 


\section{ABSTRACT}

In order to predict the thermal efficiency of a solar pond it is necessary to know total average solar energy reaching the storage layer.

One method for determining this energy for water containing dissolved colored species is based upon spectral transmission measurements using a laboratory spectrophotometer. This report examines this method and lays some of the theoretical ground work needed when discussing the measurement of transmission of light in water.

Results of in situ irradiance measurements from oceanoGraphy research are presented and the difficulties inherent in extrapolating laboratory data obtained with ten centimeter cells to real three dimensional pond situations is discussed. Particular emphasis is put on the need to account for molecular and particulate scattering in measurements done on low absorbing solutions. Despite these considerations it is expected that attenuation calculations based upon careful measurements using a dual beam spectrophotometer technique combined with known attenuation coefticients will be usefui in solar pond modeling and monitoring for color buildup. Preliminary results using the CSM method are presented. 


\section{INTRODUCTION}

The only source of energy input into a salt gradient solar pond is the solar energy transmitted through the surface and gradient zones above the storage zone. Experience has shown that about twenty percent of the incident solar energy can be converted to storable heat. (of the remainder the energy balance goes something like this for a clear, non-turbid pond: a) from 6-10\%, depending on the site, is reflected, b) about $40 \%$ is lost as absorption of the infrared component ( $>800 \mathrm{~nm}$ ) by the water itself, and $c)$ the remaining third is dissipated as conductive and convective losses within the pond and at the pond's bounraries. (See Fig.l).

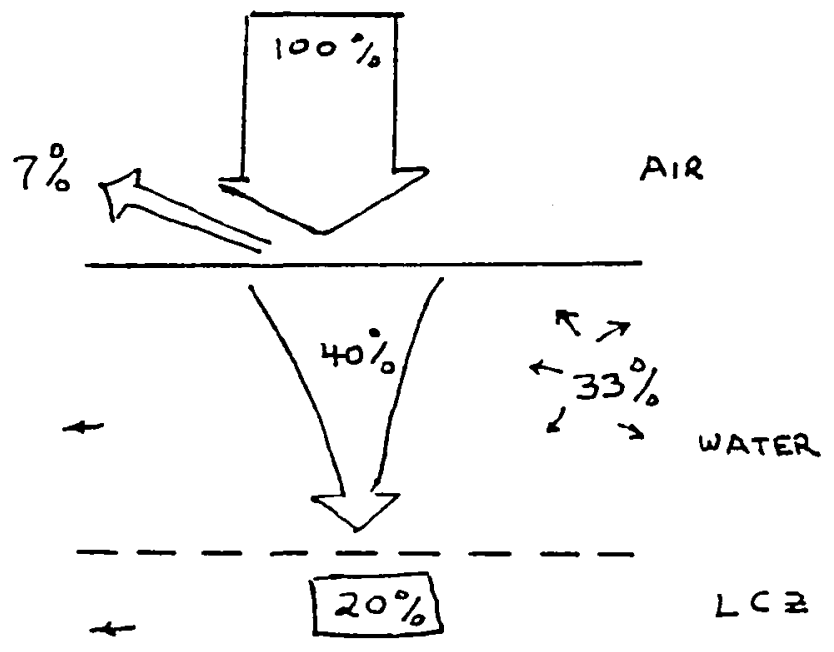

Fig. l Light transmission is a typical solar pond

If the water contains dissolved colored species such as inorganics, yellow organics, or suspended particulate matter or algae, then further preventable energy losses will occur and the. thermal efficiency of the pond will decrease dramatically. Duantitative measure of the transmission of solar energy to the storage layer is thus important and serves two main purposes. First, it is needer as input data in solar pond thermal efficiency models to enable pond sizing to relate directly to a particular water or clarification procedure. Second, it is useful in order to predict the effect on the efficiency of an operating pond of a buildup of the deleterious substances mentioned.

Undoubtediy the most direct way to determine the irradiance incident on the storage layer is by using a properly designed and calibrated pyranometer immersed within the operating pond. This requires the modification of existing equipment, not to mention the existance of an operating pond. Prior to actual pond con- 
struction, useful predictions can be made based upon data using a pyranometer within a large sized tank with or without gradients.

In an effort to eliminate the need for large quantities of solutions and on-site measurements, one approach being developed at JPL and CSM is based upon the extrapolation of spectrophotometer results taken on small quantities of these waters. This approach is compared with the in situ method of determining irraAiance in Table 1 and Appendix 1.

\section{TABLE 1}

\section{Alternate Aporoaches For Determining Solar Energy}

Reaching The Storage Layer In a Solar Pond

In Pond Measurements

- Thermocouple-type pyranometer (Eppley 8-48) modified and calibrated for use in brines.

- Calibrated silicon photovoltaic cell

- Spectroradiometer (gives spectral response under development by manufacturers; expensive)

Laboratory-based

- Spectrophotometer

- Immersed pyranometer in tank, out of doors

- Light source + column + photodiode or pyranometer

The rest of this report begins by briefly reviewing the theory and nomenclature of radiative transfer in solution. Then the general spectrophotometric method will be discussed followed by $a$ comparision of the calculational methos used at CSM and at JPI. Some of the factors which need to be considered in extrapolating laboratory-based measurements to obtain a number expressing energy penetration in real ponds are discussed. Initial results obtained using the CSM program and the most reliable attenuation data for pure water and sea water are also presented.

\section{THEORY AND NOMENCLATURE}

\section{A. Irradiance}

Table 2, taken from Smith and Tyler (1), defines those terms used in oceanography and photobiology research which are used in studies of light transmission in natural waters. The quantity of interest in this research is the irradiance $E(z)$ at the depth $z$ of the lower convective zone. It is the radiant flux incident on an element of surface divided by the area of that element. More 
Table 2. Summary of Radiometric and Dosimetric Quantities Characterizing Flow of Radiant Energy

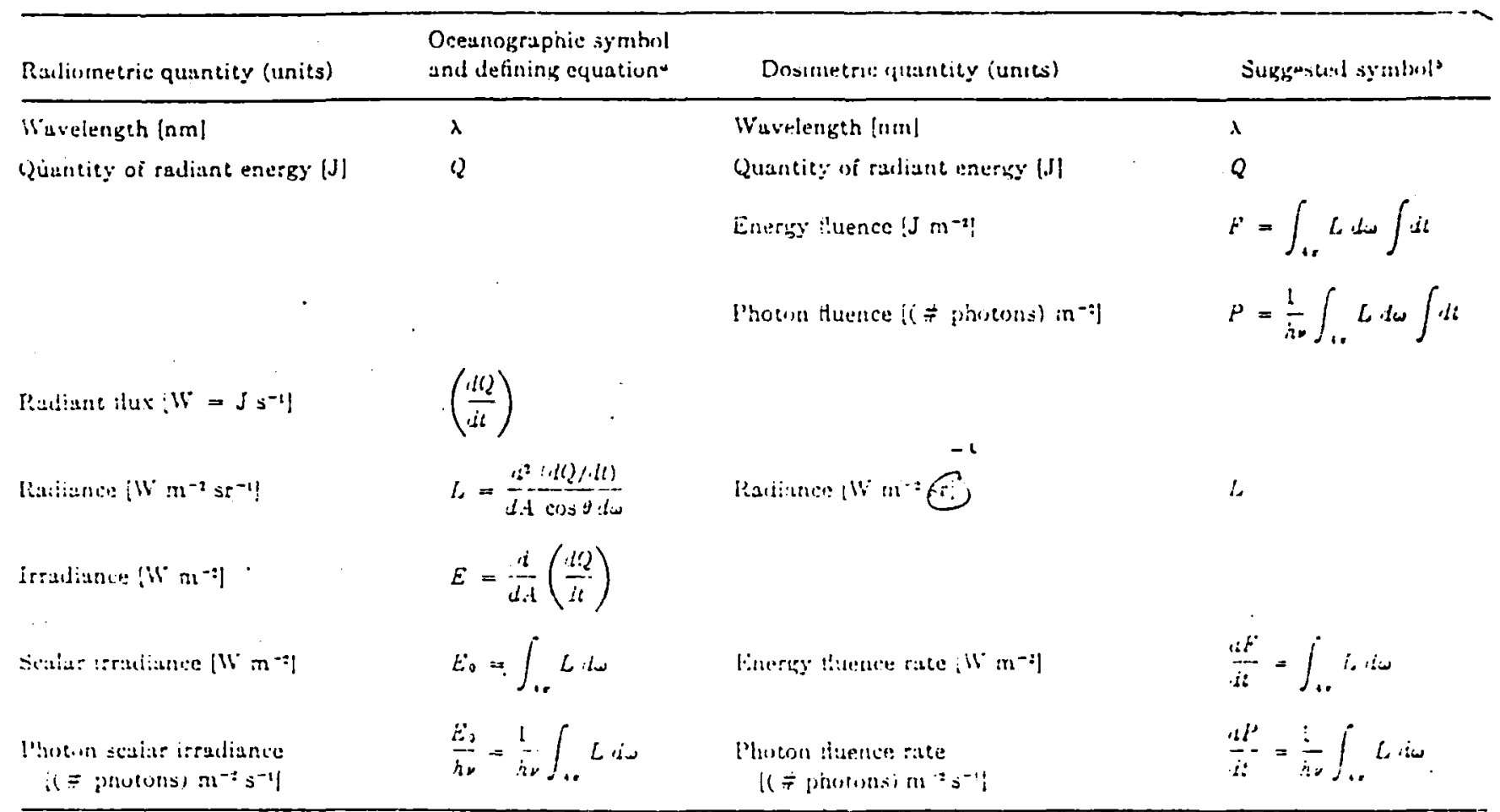

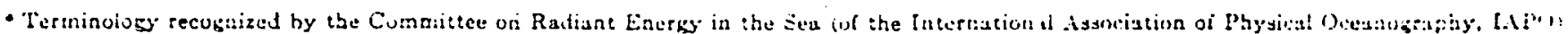
ay guven by Jerlov (19cis).

- Rupert (19it). 
specifically, our concern is with the downwelling irradiance $E_{d}(z)$, which is the flux incident per unit area measured on a horizontally oriented cosine collector facing upward. In terms of the radiance distribution it is

$$
E_{d}(z)=\int_{0}^{2 \pi} \int_{0}^{\pi / 2} L(z, \theta, \phi) \cos \theta d \omega
$$

where $d \omega=\sin \theta d \theta d \phi$

It is this quantity one would like to determine in the laboratory to input into a pond model.

\section{Beer-Lambert Law}

There does not exist a standard terminology among the dif-. ferent fields. The underlined terminology and definitions are. those recommended by the American Chemical Society and ASTM. only the symbols used for length $(z)$ and concentration ( $C$ ) been changed since the ACS approved symbols for these conflict with the standard terminology used by the optical oceanographers (see $C$ below).

The attenuation of a beam of radiation by an absorbing solution can be discussed with reference to the following figure and tefinitions:

2

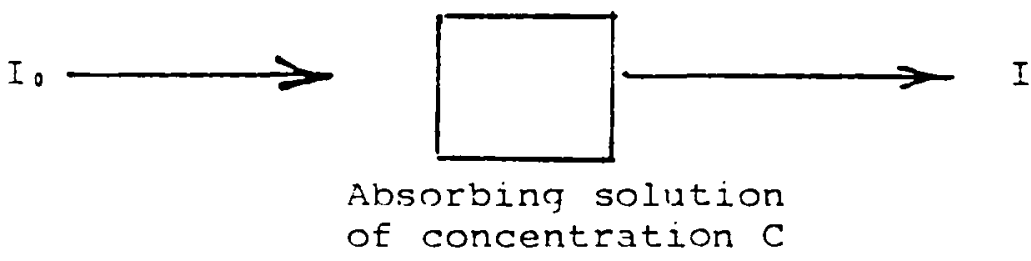

The symbol $\mathrm{T}$ is used for the transmittance, defined as the ratio of the exiting to the incident Elux: $T=I / I_{0}$. It is often expressed as a percentage. The transmittance can be applied to any light field--diffuse, specular or a mixture of both--provided the measurements of incident and transmitted flux are for the same geometrical distribution of radiant energy. A Iimiting case is the beam transmittance, also called $T$, which refers to the transmittance measured with a collimated source, such as in the underwater transimeter used by oceanographers.

The exponential dependence of the radiant flux upon the concentration of the absorbing species and the path length, that is

$$
I=I_{0} \exp (-k z C)
$$

where 6 is the proportionality constant, is normally expressed to the base 10 in chemical research for traditional reasons 


$$
A=\log _{10} \frac{I_{0}}{I}=\mathrm{azc}
$$

The $A$ is called the absorbance and this is the well-known BeerLambert Law, sometimes known simply as Beer's Law. (In the chemical literature this equation is written $A=a b c)$. Note that

$$
\mathrm{A}=-\log _{10} \mathrm{~T}
$$

The constant of proportionality a is the absorptivity. It is sometimes called the extinction coefficient. If the concentration $C$ is given in moles/liter, then the $a$ becomes $\varepsilon$ and is called the molar absorptivity. Most recording spectrophotometers are equiped with readouts in both absorbance $A$ and per cent transmittance, lO0T. Presented as a function of wavelength oither $A, T$, or a constitute the absorption spectrum.

A term not very commoniy used is the absorptance, which is the ratio of the radiant flux lost from a beam by means of absorption to the incident flux, $I_{a} / I_{0}$. In the absence of scattering it will be equal to $1-T$. It would be best to avoid its usage, however, specially since it is often given the symbol $A$, in common with the accepted Beer's Law absorbance.

Beer's law usually applies only in the case of attenuation by absorption only. The inclusion of scattering in the definition will be discussed below. First it is advisable to examine the limitations of Beer's Law. For absorbing media only, the linear relationship between absorbance and path length, Lambert's contribution, is quite general and no exceptions are known. For a fixed path length the linear dependence of absorbance on concentration is not always true. The law is a limiting law usually applied to dilute solutions only $(C<0.01$ moles/l). Molecular interactions or chemical reactions among species cause real or apparent deviations. Changes in the refractive index of the solution also cause departures from Beer's law but can be accounted for by substituting the quantity an/( $\left.n^{2}+2\right)^{2}$ for a. For an absorbing dilute species in two solutions of $\mathrm{NaCl}$, one dilute having $\mathrm{n}=1.330$ and one concentrated (density 1.189 ) for which $\mathrm{n}$ $=1.379$, this difference due to $n$ will cause a $3.2 \%$ variation in the absorptivty observed for the dilute absorbing component.

The presence of stray or scattered light in the instrument will also cause deviations from Beer's law. Such spurious radiation results from reflections from internal surfaces and especially scattering centers in the solution. It can become significant for very low absorbing solutions.

Since conformity to Beer's law is not guarenteed it is always a good practice to prepare a calibration curve with a series of standard solutions. 
C. The total attenuation coefficient

Since natural waters are low absorbing media, scattering can become an appreciable part of the total attenuation. The following nomenclature, approved by the International Association of Physical Oceanography, is also summarizer from publications by Smith and Tyler.

Since in the field of optical oceanography the concentration is usually not an independent variable, this parameter is not explicitly considered in the equations (and Beer's law is rarely referenced). The beam transmittance is written in terms of a fixed path length $z$

$$
\mathrm{T}=\exp (-\mathrm{cz})
$$

where $c$ is the total attenuation coefficient which includes absorption and scattering.

$$
c=a+b
$$

The total scattering coefficient $b=\int_{4 \pi} \int B(\theta) d \omega$

$\beta(\theta)$ is the volume scattering function. The coefficient $b$ can be separated into two parts, representing the forward $\left(0^{\circ}\right.$ to $\left.90^{\circ}\right)$ and back scattering $\left(90^{\circ}\right.$ to $\left.180^{\circ}\right), b=b_{f}+b_{b}$. For pure molecular (Rayleigh) scattering, $b_{f}=b_{b}$.

For solutions the total attenuation coefficient c can also be separated into its component parts.

$$
c=c_{w}+a_{d}+a_{p}+b_{d}+b_{p}
$$

where the subscripts mean: $w$, pure water; $d$, dissolved and colloidal material; $p$, particulate matter. A separate coefficient is sometimes presented for dissolved organic material, ay where the $y$ stands for yellow substance. For optically pure water, that is vater completely devoid of dissolved and suspended particulate material.

$$
c_{w}=a_{w}+b_{m}
$$

where $b_{m}$ is the molecular scattering coefficient for pure water. This coefficient is better known than the absorption coefficient, $a_{w}$.

Data for pure water and pure saltwater (35-39\%) have recently been critically reviewed and presented by Smith (2). A good liscussion of the errors involved in the determinations of $c$ for low absorbing systems such as these is presented in Smith and Tyler (1) where the need for long path length cells (at least one meter) when measuring such low absorbing solutions is discussed. Throuqhout most of the visible spectra the absorption coefficient 


\begin{tabular}{|c|c|c|c|c|}
\hline \multicolumn{5}{|c|}{$\begin{array}{c}\text { Table 3. Diffuse Altenuallon Coeffleient lor Irradlance for Clearest Ocea } \\
\text { Waters }[K:-(\lambda)] \text { and Absorption }\left|\lambda_{m}(\lambda)\right| \text { and Scatterlng } \mid b_{m}(\lambda), b_{m}^{\prime}(\lambda \\
\text { Coefflelents lor Pure Water }\end{array}$} \\
\hline$\lambda(n m)$ & $K_{w}^{s w}\left(m^{-1}\right)$ & $a_{n}\left(m^{-1}\right)$ & $b_{n}^{n+1}\left(m^{-1}\right)$ & $r_{m}^{i n}\left(m^{-1}\right)$ \\
\hline 200 & 3.14 & $3.1) 7$ & 0.151 & 0.116 \\
\hline 210 & 2.05 & 1.99 & 0.119 & 0.09 .35 \\
\hline 220 & 1.36 & 1.31 & 0.0995 & $(1.0 \div-7)$ \\
\hline 2.30 & 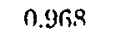 & דיט.? & $0.0 \times 20$ & $0.011: 15$ \\
\hline 240 & 0.754 & $0 .:: 00$ & 0.0655 & איפביה \\
\hline 250 & 0.588 & 0.5 .50 & 0.0575 & $11.14 .4: 1$ \\
\hline 2 in & $1) .481$ & 0.457 & 0.0185 & 1).1:3:5 \\
\hline 270 & $0.39 \cdot 1$ & $0.37: 3$ & (1.0.11ii) & $0,0,1: 1]$ \\
\hline 280 & 0.306 & 0.285 & $0.0 ; 35 ; 3$ & $0.0 \div-2$ \\
\hline 290 & 0.230 & 0.215 & 0.013015 & 0.0231 .5 \\
\hline 300 & 0.154 & 0.141 & 0.0 .362 & 0.0201 \\
\hline 310 & 0.116 & 0.105 & 0.0229 & $0.01 \div 6$ \\
\hline 320 & 0.0944 & 0.0814 & 0.0200 & 0.0153 \\
\hline 330 & 0.076 .5 & 0.0678 & 0.0175 & $0.01: 31$ \\
\hline 340 & 0.06 .37 & 0.0561 & 0.0153 & 0.0118 \\
\hline 350 & 0.0530 & $0.0 .16: 3$ & 0.013 .1 & 0.0103 \\
\hline 360$)$ & 0.04 .39 & $0.11:-9$ & 0.0120 & $11 .(k), 4)$ \\
\hline 370 & $0.0: 15: 3$ & $0.0: 300$ & 0.0109 & $0.00 \mathrm{S1}$ \\
\hline 380 & 0.0267 & 0.11220 & $0 .(x) 9.1$ & $0.1)(17: 3$ \\
\hline 390 & $0.02: 3.3$ & $0.0\lfloor 91$ & 0.008 .4 & $0.0116 \mathrm{i}$ \\
\hline 400 & $0.020 !$ & 11.0171 & 0.0076 & (j.1010.8 \\
\hline 410 & $0.019 \%$ & 0.0162 & 0.00768 & 0.001 .2 \\
\hline 420 & 0.018 .4 & 110153 & 0.10661 & 0.001. \\
\hline $1: 30$ & 0.0172 & $(1.0) 1 \cdot 1 \cdot 1$ & 0.0015 & 0.11142 \\
\hline 1.10 & 0.0170 & 0.111 .45 & 0.131 .89 & $0.13(1: 38$ \\
\hline 4511 & nolltis & $0 .(11.45$ & $0.1)(1.15$ & $0 .(x): 15$ \\
\hline 4130 & 0.01176 & 0.01 .56 & 0.0041 & $1) .00331$ \\
\hline 470 & 0.017 .5 & 0.0156 & 0.00 .37 & $11.17(1+99$ \\
\hline 480 & 11.019 .1 & 0.0176 & n.ar:?.1.1 & $1), 111: 63$ \\
\hline 190 & $0.0 \pm 12$ & 0.0196 & $0.001: 11$ & $1) .11121$ \\
\hline 500 & (1).0.27 & 0.025 & $00 \times 29$ & $11(1110)$ \\
\hline ijo & $0.0: 1: 0$ & $0.0135-7$ & $(1+x) 26$ & 0.131211 \\
\hline $5: 20$ & 010448 & $0.0 .1: 7$ & $0 .(k)=4$ & $11 .(n) 19$ \\
\hline 5,30 & 0.0519 & 0.0507 & $0 .(x) \cdot 23$ & 0.01917 \\
\hline 5.10 & 0.0Eotiti & 0.0 .558 & $0.0(0) 21$ & 0.01016 \\
\hline 550 & $0.06-4 k$ & $0.06: 3 \mathrm{~s}$ & $0.10 n 19$ & (1).i)(1) \\
\hline$\therefore(80)$ & 0.0717 & 0.070 .4 & 0.0018 & 0.01111 \\
\hline 570 & 0.0807 & 0.0709 & $0.001 \div$ & $0.1001: 3$ \\
\hline$\therefore 811$ & 0.109 & 11.1118 & $0.0(116$ & 0.0012 \\
\hline 590 & 0.158 & 0.157 & 1).0015 & $(1.00) 11$ \\
\hline nov) & 0.245 & 0.24 .4 & $0.10 \cap 14$ & 0.06011 \\
\hline 610 & $0.2 y(1$ & $(1.289$ & 0.0013 & $11.0 n\} 0$ \\
\hline 520 & 0.310 & $0.20,9$ & 0.0012 & $0 .(11) \times 19$ \\
\hline 6.30 & $0.2: 211$ & 0.3110 & $0.0 n 11$ & $0.011)(19$ \\
\hline tidn & $0.8: 30$ & $0 . \therefore 29$ & 0.0010 & $0.0000,4$ \\
\hline b.50 & 0.3 .50 & 0.3149 & $11.00 ! 0)$ & $0.0(3) 7$ \\
\hline 6800 & 0.400 & 0.400 & $0.000 \times 9$ & $0.0 n 07$ \\
\hline Bito & $0.4: 10$ & 0.130 & n.(x)is & 0.0007 \\
\hline 6.50 & 0.450 & 0.450 & ז & n.1)(x)ei \\
\hline 690 & $0 . \overline{00}$ & $1 . \therefore(n) 1$ & 0.0007 & $(1.04) \cap i$ \\
\hline ion & 0.6 .50 & 0.6500 & 0.0007 & $1) .01005$ \\
\hline 710 & $0.5: 34$ & $0.8: 39$ & 0.0007 & 11.01105 \\
\hline 720 & 1.170 & 1.169 & $0.00(16)$ & $0.010(1)$ \\
\hline 730 & $1.3(1)$ & 1.799 & $0.11106)$ & ה.101010 \\
\hline .40 & 2.280 & 9.8 .5 & $0.13)(16)$ & $11.13 \times 14$ \\
\hline 750 & 2.47 & 2.9 & 0.0001 .5 & 0.131114 \\
\hline 760 & 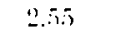 & 3.5 & 0.11005 & 0.01001 .4 \\
\hline 770 & 2.51 & $\because \therefore 1$ & 11.13(1) & $0.10(00) .1$ \\
\hline 780 & $2 . .96$ & $\because 36$ & 0.000018 & $0 .(11)(1: 3$ \\
\hline 790 & 2.16 & 2.16 & $0.0) 1104.4$ & onoulis \\
\hline 2काल & 2.11 & 2.17 & (1). 1$)(1 \times 1.4$ & "1) (x) \\
\hline
\end{tabular}


Eor pure distilled water is about an order of magnitude greater than the scattering coefficient. Experimentally, however, accurate values of $C_{w}$ or $a_{w}$ have been hard to determine since even very small quantities of suspended particles which are larger than the wavelength of the irradiating energy will cause the narrow-angle forward scattering to increase by orders of magnitude. This systematic error due to increased collection of forward scattered flux is responsible for the different results obtained by James and Birge (3) using silvered and blackened meter long tubes.

Smith's analysis of the accuracy of the pure water data has led him to conclude the following error limits for the data presenter in Table 3 , which is probably the most accurate data available.

$\begin{array}{ll}\text { Wave length Range } & \text { Fror Between } \\ 300-480 \mathrm{~nm} & +25 \text { and }-5 \% \\ 480-800 \mathrm{~nm} & +10 \text { and }-15 \%\end{array}$

iore on the coefficient $K_{w}$ and irradiance calculations based upon this tata is presented in section $V$.

This question of the accuracy of the data sbtainable in the laboratory is of formost concern in this modeling work. It is expected that by combining recent literature results with the spectrophotometric technique, meaningful results will be obtained with pond solutions which are less optically pure than the references. This topic is addressed aqain in the section on the spectrophotometric methor and will be the subject of continuing work here CSM.

\section{Saltwater}

The scattering coefficient for saltivater is slightly larger than that of pure water. As to the process of absorption, Smith (2) states that "there is no significant (<10\%) difference between $a_{w}(\lambda)$ for freshwater and saltwater for wavelengths longer than $r 375 \mathrm{~nm}$. The evidence for a possible difference at shorter wavelengths is inconclusive." Just how much of the rising absorption in the near ultraviolet (<400 $\mathrm{nm}$ ), observed in spectrophotometer scans of filtered Salton Sea water is due to scatter rather than absorption is difficult to say at this time (see also below). Data at higher concentration than those present in sea water appear to be scarce, although the conclusions of Usmanov (4), referred to in the paper by Marsh et. al (5), on the decreased transmission rue to absorption in solutions of increasing concentrations uo to $25 \%$ of $\mathrm{MgCl}_{2}$ is to be suspected. It is not clear from his paper how the results of ijsmanov were obtained, but a comparison of the absorption coefficients he uses for pure water with those of Smith shows that his values are greater than tolays best values by over an order of magnitude at waveleng.ths below $460 \mathrm{~nm}$, are closer in the green and again Aiverge in the near infrared. 


\section{E. The diffuse attenuation coefficient}

The beam attenuation coefficients discussed above, while in practice determinable in the laboratory, are still not the coefficients of prime interest in solar pond performance modelling. For this purpose, a wavelength dependent coefficient describing attenuation within the three dimensional waters is needed. Such a coefficient, is the diffuse attenuation coefficient $K(\lambda)$, used in oceanographic studies to describe the penetration of solar radiation into natural waters. It is operationally defined as

$$
E(\lambda, z)=E\left(\lambda, 0^{-}\right) \exp [-K(\lambda) \cdot z]
$$

where $E(\lambda, z)$ is the spectral irradiance at depth $z$ and $E\left(\lambda, 0^{-}\right)$is the irrariance just below the surface. The diffuse attenuation coefficient varies slightly with depth due to a small component of backscattered radiation and, even more importantly, the absorption of diffuse instead of collimated radiation. There is, for example, twice as much absorption per path length for comoletely diffuse radiation as for collimated radiation ( 1 ).

Since $K(\lambda)$ depends upon the light field and is operationally lefined it is called an apparent optical property (AOP). The attenuation coefficient $c(\lambda)$ is an inherent optical property (IOP) since it depends only on the solution and not on the depth. The two are compared for water and sea water in Table 3. $K(\lambda)$ is the most significant coefficient from our point of view since it is a measure of the total irradiance reaching a particular depth.

Near the surface the radiance distribution under water is a complex combination of collimated direct sunlight plus diffuse skylight. For this reason the variation of the $k$ value is large near the surface and can only be considered a property of the water at great depths where the diffuse component is uniform and where the precision of the measurements with rifferent ocean waters can be quite good $( \pm 5 \%)$. Absolute uncertainties in estimating $K_{W}(\lambda)$ are stated by Smith to be "less than $\pm 25 \% "$.

The data presented above in Table 3 for the values of absorbance of pure water and sea water were obtained by Smith indirectly by comparison of recent laboratory lata on $a_{w}(\lambda)$ and $b_{m}(\lambda)$, with accumulated underwater measurements of $K_{W}(\lambda)$ made by the Visibility Laboratory at Scripps Oceanographic Institute. This treatment is based on the conclusion that these scattering coefficients, $b_{m}$, are well-known. Essentially all absorption coefficient values in the range $300-450 \mathrm{~nm}$, determined in the laboratory earlier than the late 1970's, are thought to be too low by as much as an order of magnitude (for the near UV). Systematic errors (stray and scattered radiation) are responsible Eor this. 
Smith's calculation of $a_{w}$ based upon $k_{w}$ and $b_{m}$ values is founcied upon the assumption that half the Rayleigh scattered radiation in fresh water or sea water is back scattered. Therefore,

and

$$
k_{w}>a_{w}+1 / 2 b_{m}
$$

$$
a_{w}<K_{N}-1 / 2 b_{m}
$$

The $k_{w}$ values used were determined from the clearest natural waters (e.3. Crater Lake for fresh water and Sargasso sea for ocean water).

For molecular scattering, having a wavelength dependence of $\lambda^{-4}$, Morel's data (6) was used. For particle scattering, when a wavelength dependence of $\lambda^{-1}$ was assumed, a negligible increase of $+0.001 \mathrm{~m}^{-1}$ in the $\mathrm{K}_{\mathrm{w}}$ values was found by $\mathrm{smith}$.

F. Effect of Scattering

Unlike most studies concerned with radiative transfer in solution, those by Incropera (7) of the School of Mechanical Engineering of Purdue University have been concerned with the effects of particulate scattering as well as absorption. For natural waters containing algae or suspended mineral matter, scattering of light will he the predominant factor in its attenuation.

Incorpera's studies were basically performed using two pieces of equipment. One, an inhouse built system consisting of a laser beam incident on a rotatable fiber optics probe within the cell, was used to determine the scattering phase function. The other instrument in this work was a commercial Shimadzu recorfing spectrophotometer. This apparatus is of an unusual lesign especially useful in the study of suspensions. The photomultiplier may be placed directly next to the sample in order to retect all of the forward scattered radiation. In this mode of operation the absorption coefficient a only is measured. In the normal arrangement, the acceptance angle becomes $5^{\circ}$, as in most other spectrophotometers, such that most forward scattered radiation is not incident on the detector. In this configuration both scatterer and absorber 1 ight is lost to the detector and the extinction coefficient $c$ will be measured. These two situations and repicter in Fig. 2. The ratio of the scattering to the extinction coefficient is called the scattering albedo, $\omega^{*}$. In the

*Incropera calls the scattering, absorption and extinction coefficients $\sigma, k$, and $\beta$ respectively. Since I believe his "extinction" is Smiths "attenuation" and that there is no Eundamental difference in the other coefficients discussed by oceanographers, I am being consistant with the symbols introduced earlier. 
next Section, some of this summer's work having the objective of making this distinction is discussed.

MEASURES
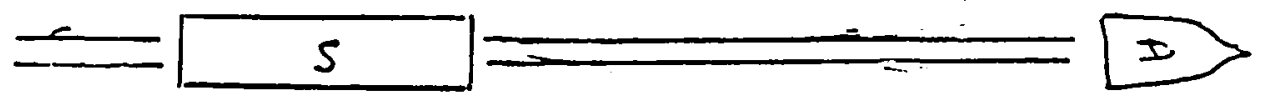

$c$ only

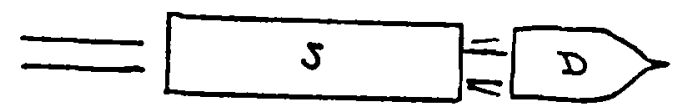

a only

Fig. 2 Sample-detector arrangements required for measurement of extinction (c) and absorption (a) only.

Some of Incropera's results are worth noting and are presented in Table 4 .

Table 4

Selected results from Incropera's research

System

India ink suspension

Algae

$0.79-1.0$

Size of Most Particles (microns)

$0.02-0.06$

0.15

w Dbservations

As might be expected scattering predominates over absorption for the larger algal cells, the opposite being the case for the India ink. The ink would presumably pass through a 0.45 micron filter whereas the algae would not. For both systems the scattering phase function is strongly peaked in the forward direction and follows the generally observed trend that back scattering is reduced with increasing particle size. In the algae study the back scatter was three orders of magnitude less than the forward scatter. 
In the study of the india ink suspensions the extinction coefficient at all wavelengths increased fairly linearly with the concentration (volume $z$ ) of ink.

\section{G. Analytical Approach}

one approach for accounting for attenuation due to suspended matter is suggested by the recent work of Smith (B). In this work, in which the distinction between scattering and absorption is not explicitly discussed, the total diffuse attenuation coefficient $K(\lambda)$ from oceanography measurements is correlated with averaqe phytoplankton concentrations in oceans. In this semiempirical methor, chlorophyll a and pheopigments in water can be Aeterminer in the usual way and their concentrations used to calculate the attenuation. Smith also suggests that this type analysis could be extender to include the influence of dissolver organic material. Extensive in situ irradiance measurements and Aissolved organic carbon analysis would need to be done to establish these new correlations.

\section{SPECTROPHOTOMETER MEASUREMENTS}

\section{A. The Spectrophotometer}

The basic spectrophotometer upon which the measurements at CSM are based is shown in Fig 3 . A collimated monochromatic light beam traverses a small path length ( 1 to $10 \mathrm{~cm}$ maximum in the commercial instrument) quartz cell containing the sample and its transmission relative to a reference solution (distilled water, saline solution, blank cell, or air) is recorted as a function of wavelength. The instrument normally functions in the riual beam mode. The sample and reference signals are alternately chopped in ofder to cancel out variations in signal due to intensity Eluctuations and changing spectral output of the tungsten lamp as well as response changes of the photomultiplier ietector. The measurement is therefore a relative one, with reference to a reference material. The two ways to obtain the ansorbance (or transmission) of a solution are depicted in Table 5. Eor quantitative work it is always desirable to run a background spectrum. 
Table 5

Alternative methods for determining spectral absorbance of sample with a recording spectrophotometer

Reference Compartment Sample Compartment

Method 1

$\begin{array}{lll}\text { Scan } 1 & \begin{array}{l}\text { Ref. Cell + Solvent* } \\ \text { Ref. Cell + Solvent }\end{array} & \begin{array}{l}\text { Sample Cell + Solvent } \\ \text { Sample Cell + Solution }\end{array} \\ \text { Scan } 2 & \text { Spectra of Solute }=\text { Scan } 2-\text { Scan } 1\end{array}$

Method 2
Scan 1
Air
Sample Cell + Solvent
Scan 2
Air
Sample Cell + Solution
Spectra of Solute $=\operatorname{Scan} 2-\operatorname{Scan} 1$

* Solvent could be pure clean water, artificial Salton Sea water, or completely cleaned up natural Salton sea water.

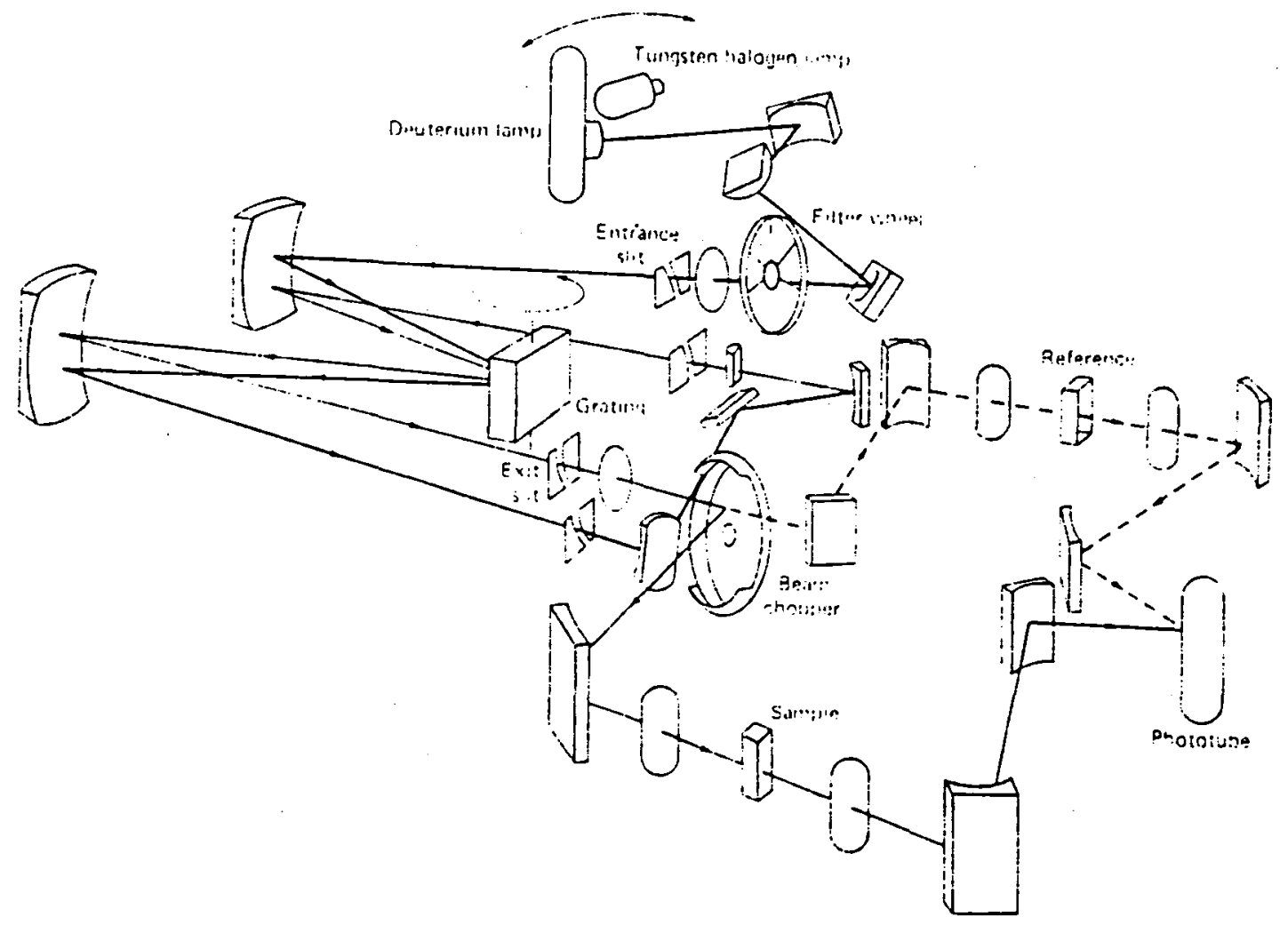

Fig. 3 Schematic diagram of Varian Cary Model 219. 
The Cary Model 14 which was used in the earlier JPL work (5) is a very rugged research instrument with good optics but 'with the risadvantage in this work that the range can only be expanded by substitution of a 0.0-0.20 slidewire accessary, which the Laboratory does not have. This is needed to increase the sensitivity in the important range from 400 into $700 \mathrm{~nm}$ where the absorbance of the solutions is very low. Thus the Cary Model 219, which presents a digital readout and has a scale change option at the switch of a dial, should be user? in future work.

The other available spectrophotometer with very convenient computor and display capabilities is the HP8450A, received on demonstration loan in Building 83 in late July. With its recently leveloped halographic light disperser and 400 individual photorell detectors there are no moving optical parts and a complete spectra can be recorded in one second. Like the Cary 219 a background spectra is recorded in memory and automatically corrected for when the sample spectra is scanned. Although the wavelength resolution of the Cary 219 can be somewhat better than that of the HP8450A, this is of no consequence in this work and the resulting spectra are the same.

One significant feature of all spectrophotometer systems when used for the study of very low absorbing samples is the low acceptance angle by the detector of the transmitter, collimated light beam. This design feature has the dual purpose of eliminating unwanted response to stray light and fluorecence radiation and also permits one photomultiplier to receive light from both compartments. This angle is about $6^{\circ}$ in the Cary instruments and even less in the Hewlett-Packard morel. Therefore, if a significant portion of the beam is scattered in a direction outside of this angle, either by suspended particles, dust, or even ions, this will falsely be interpreter by the instrument as absorption. Beer's Law could still be obeyed by the scattering sample even though all measurements of absorbance are high. The coefficient being observer in a scattering case may well be the extinction, or total attenuation, coefficient.

\section{B. Accessory Equipment Used}

Two accessory pieces of equipment on the available spectrophotometers can be user to assess the importance of scattered radiation. A Scattering Transmission Accessory was borrower for the Cary Model 14 from another Group on Lab but had apparently been specially adapted for their custom-made instrument and would not fit the Cary in Building 83 and so was not used. This accessory, which replaces the entire sample and detector compartment, allows the photomultiplier to be placed within a few inches of the cells and would have given results similar to those of Incropera using the Shimadzu spectrophotometer.

The other accessory, which was used, was the integrating sphere for the Cary 219. This accessory, shown in schematic in Fig. 4 usually serves as a diffuse reflectance attachment. 
It was necessary to build a sample holder to reproducably position a sample cell in front of the entrance to the sphere. The incoming sample beam, which is angled at $3^{\circ}$ away from the perpendicular to the entrance port, is continuously compared to the reference signal, which is diffused by a white screen inside the sphere before exiting. Since a scan can only be done with one cell in place, a background spectra of solvent only is first recorded in memory and subsequent scans automatically correct relative to this one.

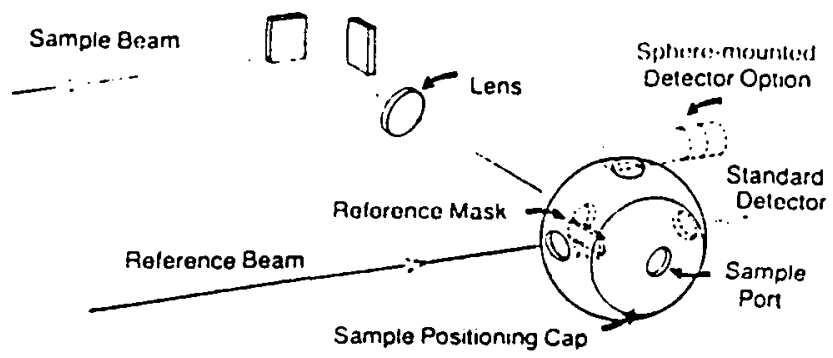

Fid. 4 Beam geometry of integrating sphere accessory

The idea behind using one of these alternative methods of measuring absorbance was to effectively increase the acceptance angle as a measure of how much scattered radiation was being missed at the various wavelengths in the normal mode of operation. For turbid samples this ability of the integrating sphere to capture scattered light is dramatically illustrated by the spectra of diluted milk taken in the normal way and with the integrating sphere (Fig. 5). The white solution of a small drop of milk in a few cc's of water was transparent to the eye. The spectrophotometer interprets the transmission in the visible to be about 60 per cent (at $550 \mathrm{~nm}$ ) of the incident light whereas with the integrating sphere in place scattered light is picked up and zero absorbance is recorded throughout the range. Even undiluted milk in a one centimeter cell registered an absorbance of about 0.08 ( 83 per cent transmission) using the integrating sphere whereas on the Cary 14 the absorbance is greater than 3.0 (less than $0.1 \%$ transmission). This is a truer picture of reality 


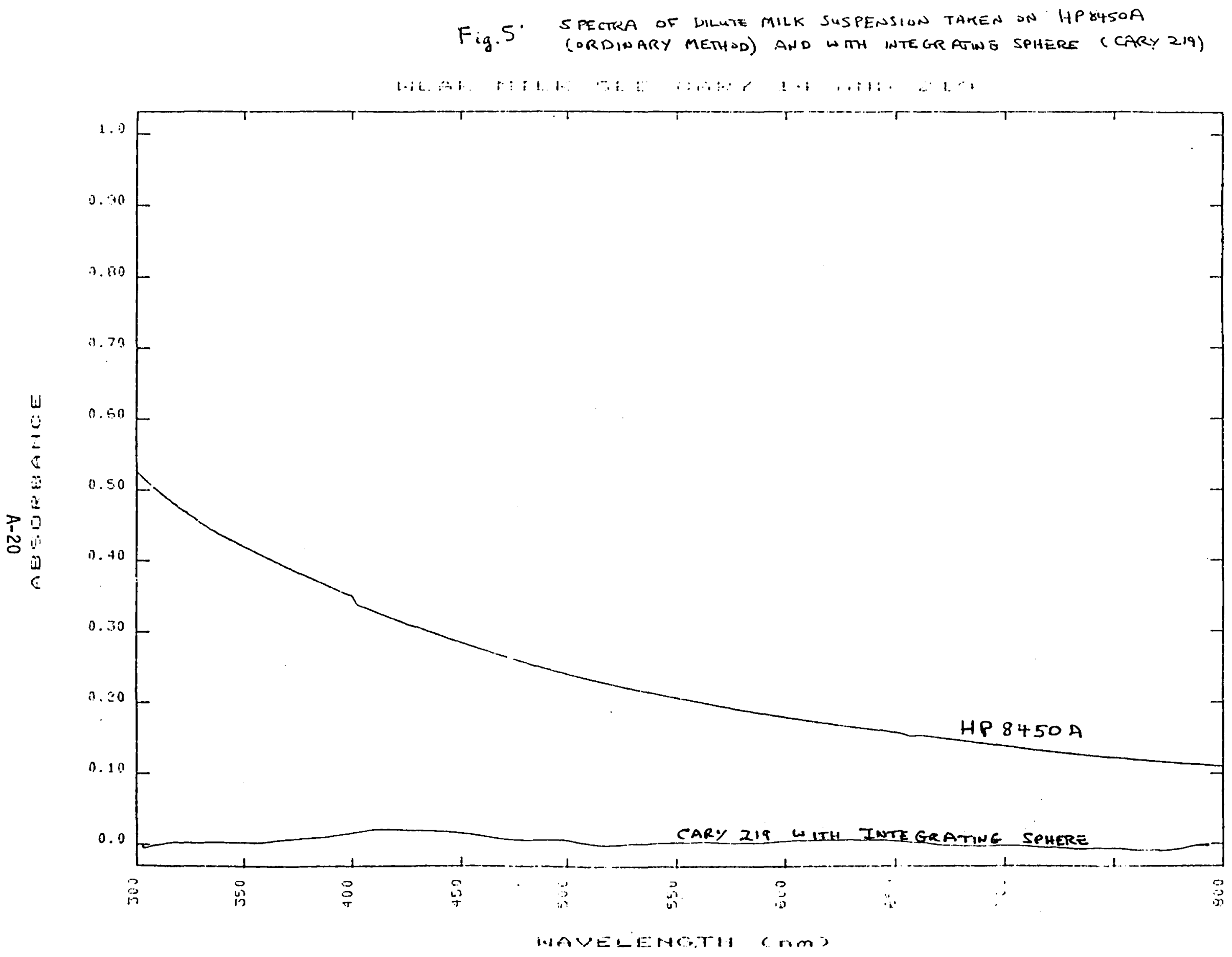


for the non-absorbing, scattering white suspension. The importance of this distinction for the solar pond measurements is that radiation scattered in a forward direction will find its way to the storage layer and should not be misinterpreted as "absorbed" in the upper zones.

\section{Exploratory Experiments using the Integrating Sphere}

Salton sea saturated brine and brines made by diluting full brine were run on the Cary 14 and on the HP8450A in the normal absorption mode and on the Cary 219 using the integrating sphere attachment in the transmission mode described above. Ten centimeter cells were used for the normal runs (a five cm attachment was not available for the HP8450A) and a five centimeter cell was used in front of the sphere. The reference solution in each case was an artificial Salton sea solution made up previously according to the specifications of Dr. Harold Marsh. The full brine, ohtainer by evaporation of Salton Sea water, had been filtered through a $1.2 \mu$ filter, and was colorless to the eye through a 3$4 \mathrm{~cm}$ distance in the bottle.

In general absorbance readings obtained with the sphere were lower than those obtained in the normal manner. In Figure 6 readings at four wavelengths for Cary 219 and the HP8450A are plotter vs the density difference between sample solutions and the reference solution. The Cary 219 readings were taken from the DATA readout on the instrument as the spectra was scanned and stopped at each of these wavelengths to obtain the reading. The plotted values are differences between the sample scan and a previous blank (artificial Salton Sea) and have been multiplied by two to put them on the same $10 \mathrm{~cm}$ path length basis as in the HP case. The density of each solution was determined by accurately weighing $10 \mathrm{ml}$ of the solution.

The reason for the apparent discontinuity in the linearity for the integrating sphere case is not known. The generally lower readings obtained with the integrating sphere could be due to the pickup of all forward scatter and in this case these results would be more in line with extinction by absorption only. The higher values at $340 \mathrm{~nm}$ can not be explained in this way however. The nonlinearity of the data at high concentrations for the normal (HP) scans is another feature of interest. The upturn could be due to increased scatter in the brines at the highest concentration or could result because the absorbing (scattering) species are not in proportion to the density difference plotted. It may will be that the attenuating molecules or ions are not present in direct proportion to. the density. It should also be noticed that the absorbances do not qo through zero absorbance as they should. These discrepencies point out the difficulties encountered in working with practically nonabsorbing solutions.

While this data may be interesting, it does nothing to prove which manner of measurement is best for our purposes, only that there is a difference. In order to check to see if Beer's Law 


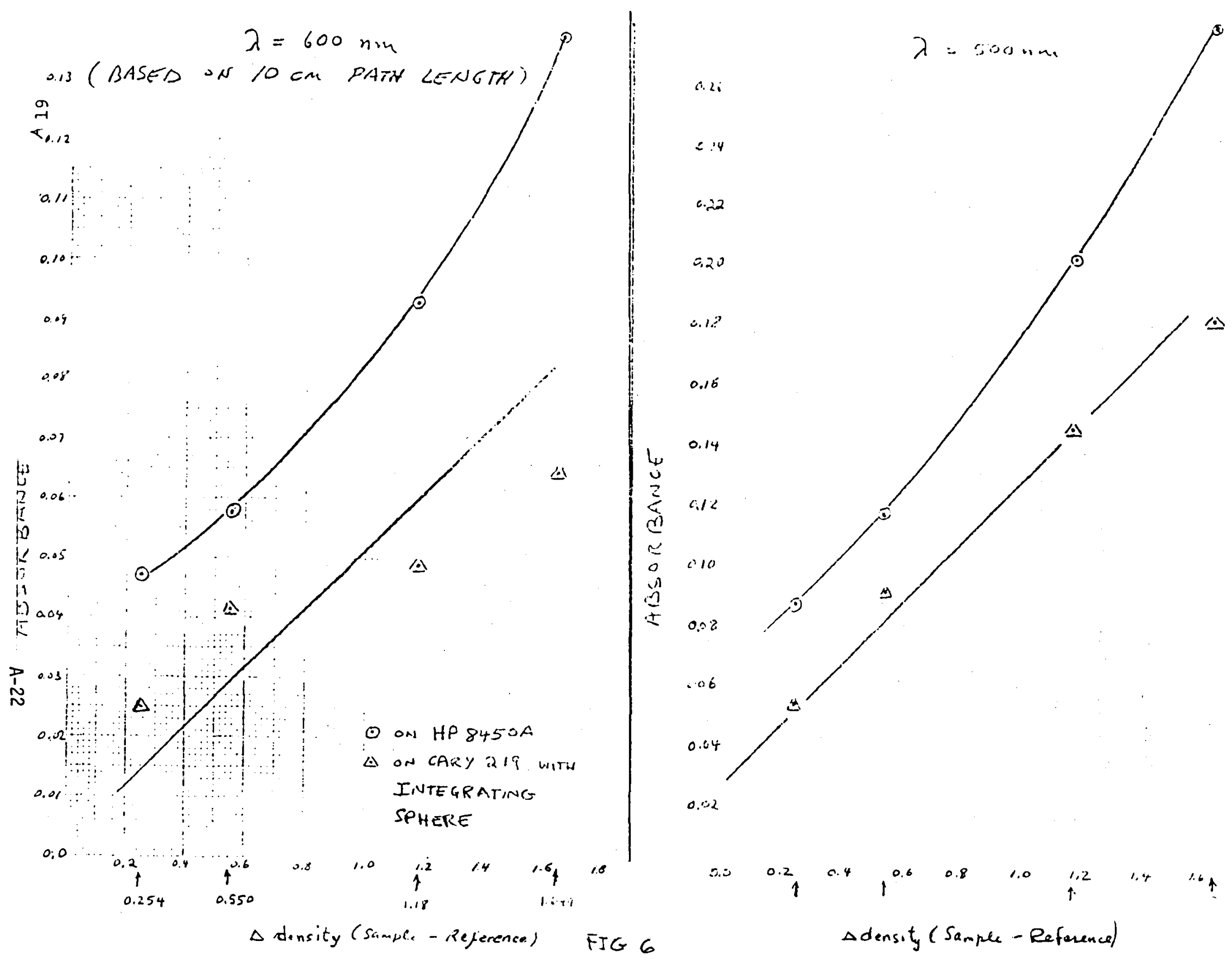


$\lambda=400 \mathrm{~nm}$

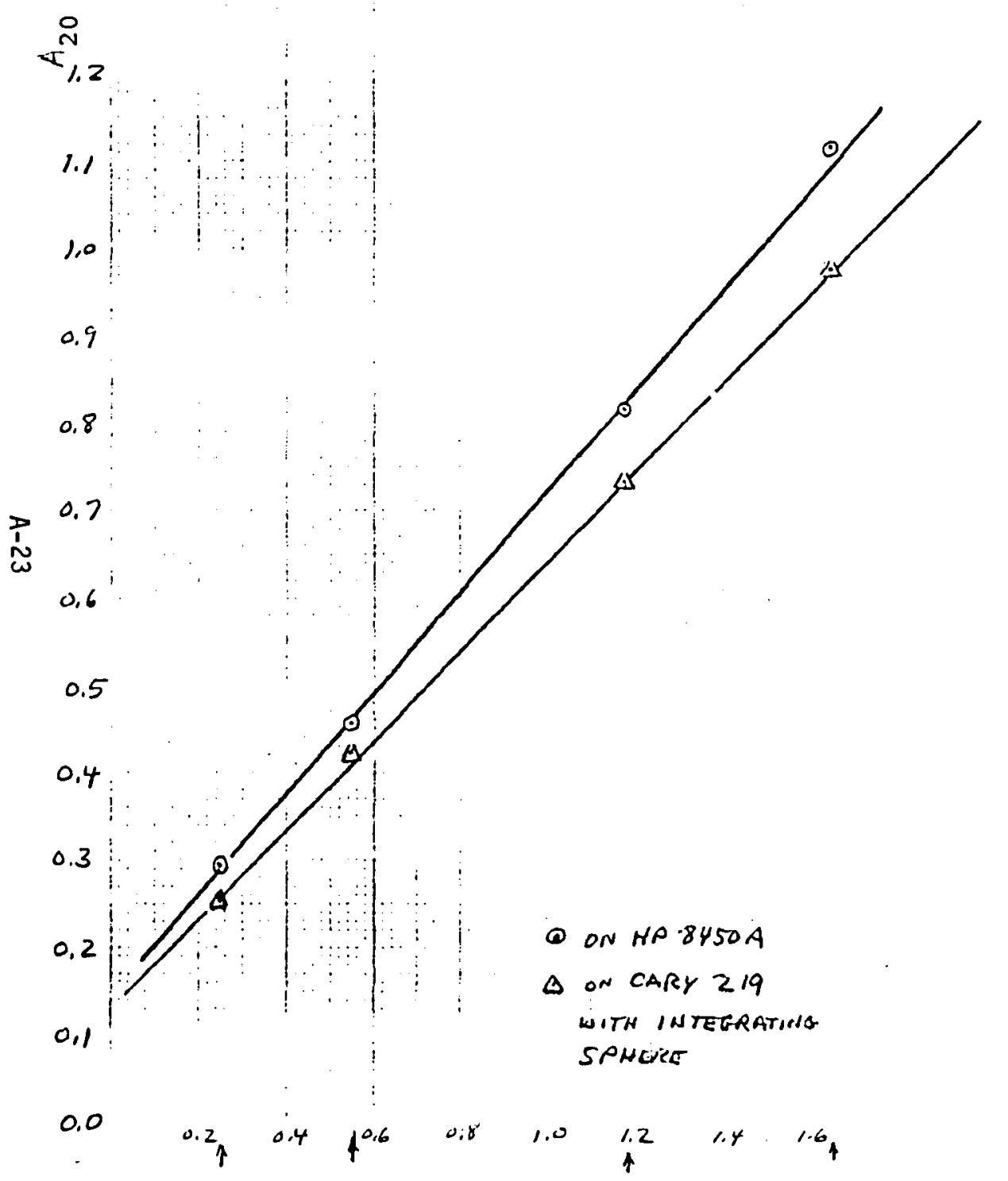

3.3

3.1

2,9

27

2.5

2.3

2,1

1.9

1.7

1.5

1.3

1.1$$
\lambda=340 \mathrm{~nm} \quad /
$$

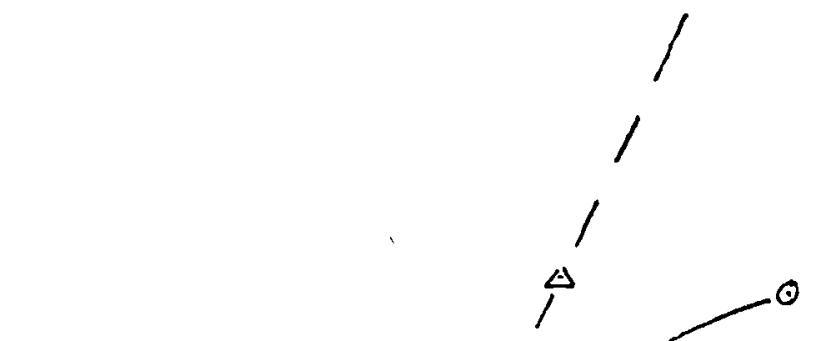

HP $8450 A$

A_- IntEgrating.

SPHERE

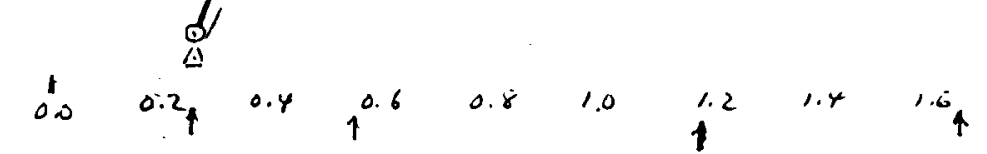

Fia $b(\operatorname{con} t)$ 


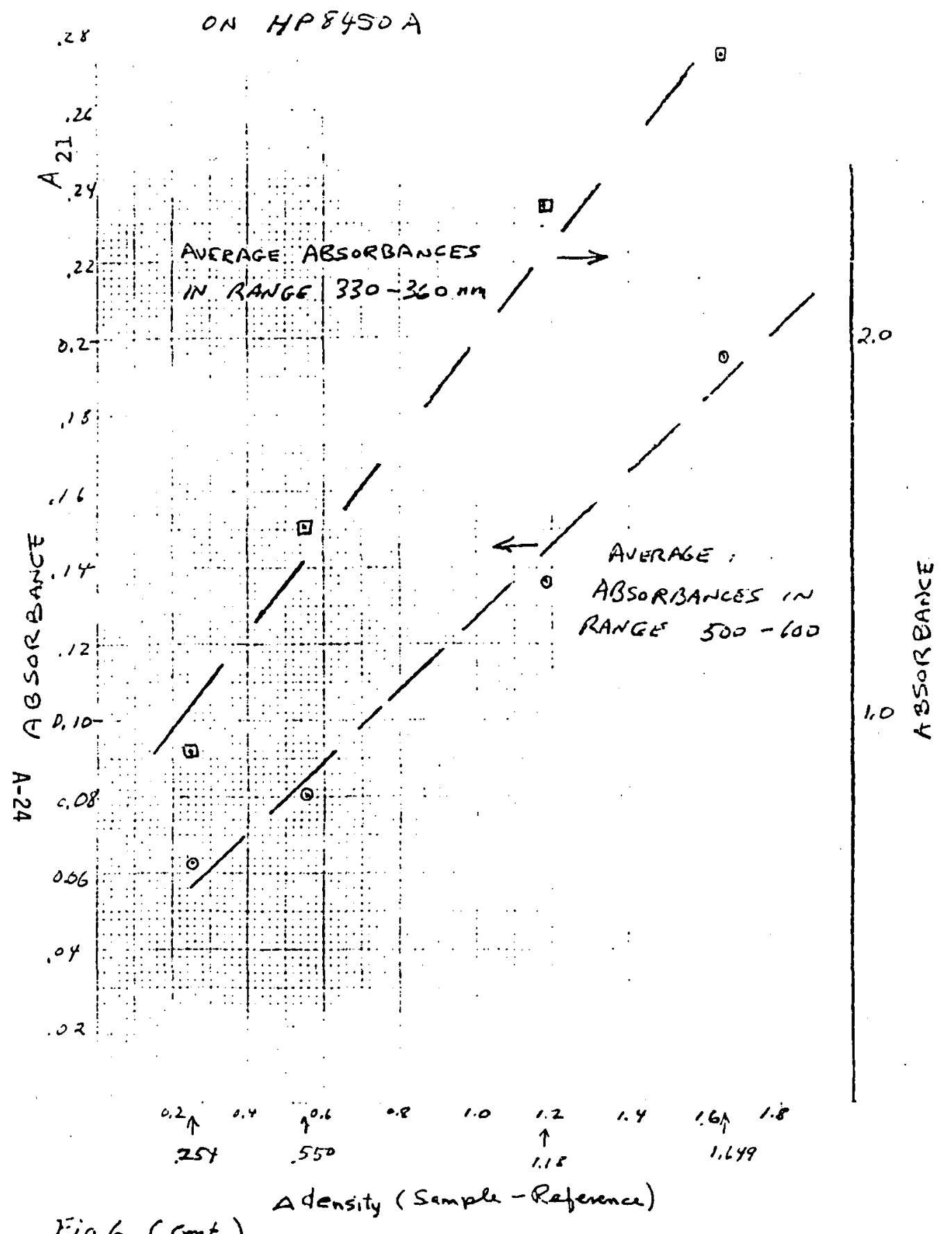


TEST OF BEER: LAN WITH SODIUM DICHROMATE SoLUTIONS IN A ONE CENTImETER CELL IN FRONT OF

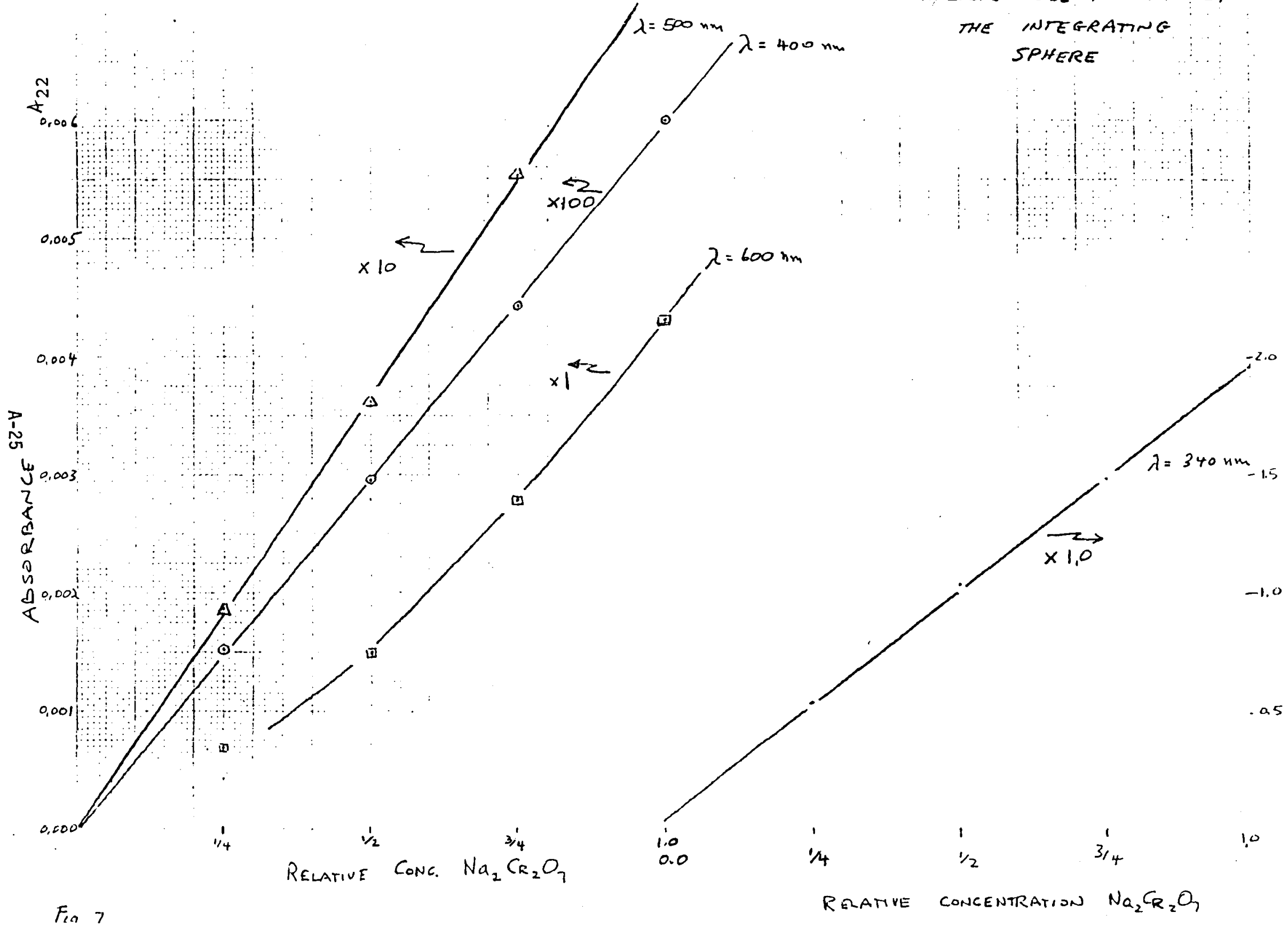


would hold for measurements on absorbing species in dilute aqueous solutions using the integrating sphere, dilute sodium dichromate solutions were also run. These results are plotted for these same four wavelengths in Fig. 7. The absorbance is a linear function of the concentration and even passes through zero in this case. These experiments were done using a one centimeter cell, unlike the previous set, in which a five centimeter cell was used. The concentrated dichromate solution was also measured in the five centimeter cell and at all wavelengths absorbances were less than five times those using the one centimeter cell. This suggests that use of a five centimeter cell in front of the integrating sphere may not yield true absorbance values, even when care is taken to assure that the full beam width, viewed in the green region, passes through both cell faces.

Due to limited time and availability of the instrumentation, further experiments to clarify the importance of forward scattering in the absorption spectra were not performed. In the expectation that the spectrophotometer results, properly interpreted, can be a useful indicator of water transmission, and even pond efficiency, the remainder of the report will discuss the treatment of the data obtained by this method and present selected results obtained at CSM.

IV. TREATMENT OF SPECTROPHOTOMETRIC DATA

A. General

The basic features of the spectrophotometric method for estimating irradiance as a function of depth are summaerized in the following steps:

1) The absorption (or transmission) spectra, relative to a reference, is recorded.

2) The spectra is multiplied by a published solar irradiance spectrum, such as Air Mass 1.5.

3) Transmission is assumed to be an exponential (Beer's Law) or empirically determined function of the salt solution's concentration (density).

4) Transmission is assumed to be an exponential function of the path length (Lambert's Law).

5) By successive calculations the integrated energy passing through a solution with a given density gradient is calculated.

\section{B. CSM Method}

The spectra (absorbance vs. wavelength) is recorded on a Cary 219 spectrophotometer and stored as binary information on a floppy disc of an Apple plus computor. The interfacing (9) of this data ecquisition computor, programed in PASCAL language, and the calculational program POND written in Fortran IV on the CSM DEC10 system is just being completed and is shown in Figure 8 . The basic pond program in Fortran was supplied by John Webb (10). 


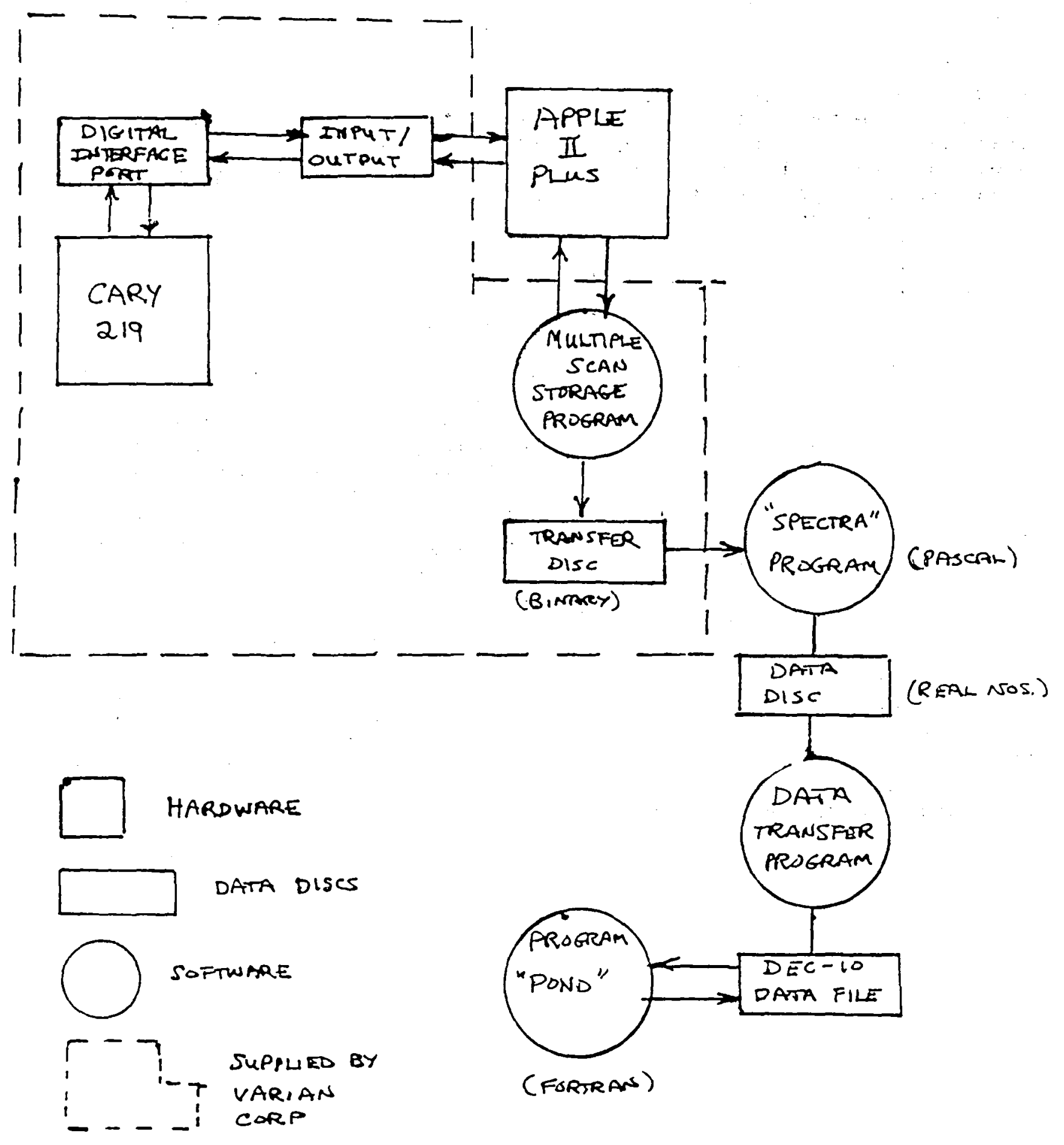

Fig. 8 Cary 219 interfaced with Program POND on CSM computor 
The system will enable the systematic study of the precision of the method and dependence on numerous variables not yet assessed.

The sequence of operations showing how program POND is used to multiply the absorption and solar spectra through depth and density intervals is shown in Figure 9. Integration intervals over depth, concentration and wavelength are selected by the operator, and a linear interpolation of the available data over this range is performed in the operation of the program. At the terminal, or accepted directly from the spectrophotometer in the revised system, the absorption spectra $A(\lambda)$ or the absorption coefficients $a(\lambda)$ are entered. The program first integrates over the stored solar spectrum to determine the total incident energy normal to the surface in the wavelength range for which data is available. The attenuation of the solar irradiance at each wavelength interval by passage through a selected path length ( $\Delta d$ ) of this solution is then calculated and summed over all

wavelengths. Attenuation by distilled water or other reference solution is added in the calculation using the set of absorption coefficient stored as a data file. In the case of pure distilled water or sea water, they can be taken from recent literature (2). After summation over all wavelengths the program repeats the calculation for the next selected depth interval containing the next average concentration (density) of that interval.

Among other information the program lists the fraction of surface insolution transmitted to various depths beneath the surface. Data files containing the absorption diffuse attenuation coefficient and the extinction coefficients for pure natural and salt water, shown in Table 3 , were created and program Pond run using them as input. The infrared data from $800 \mathrm{~nm}$ to $2537 \mathrm{~nm}$ was taken from Webb (10). Table 6 is a typical output, shown for the coeficient $\mathrm{K}_{\mathrm{w}}$. This and the other computor runs are summarized in Table 7 . 


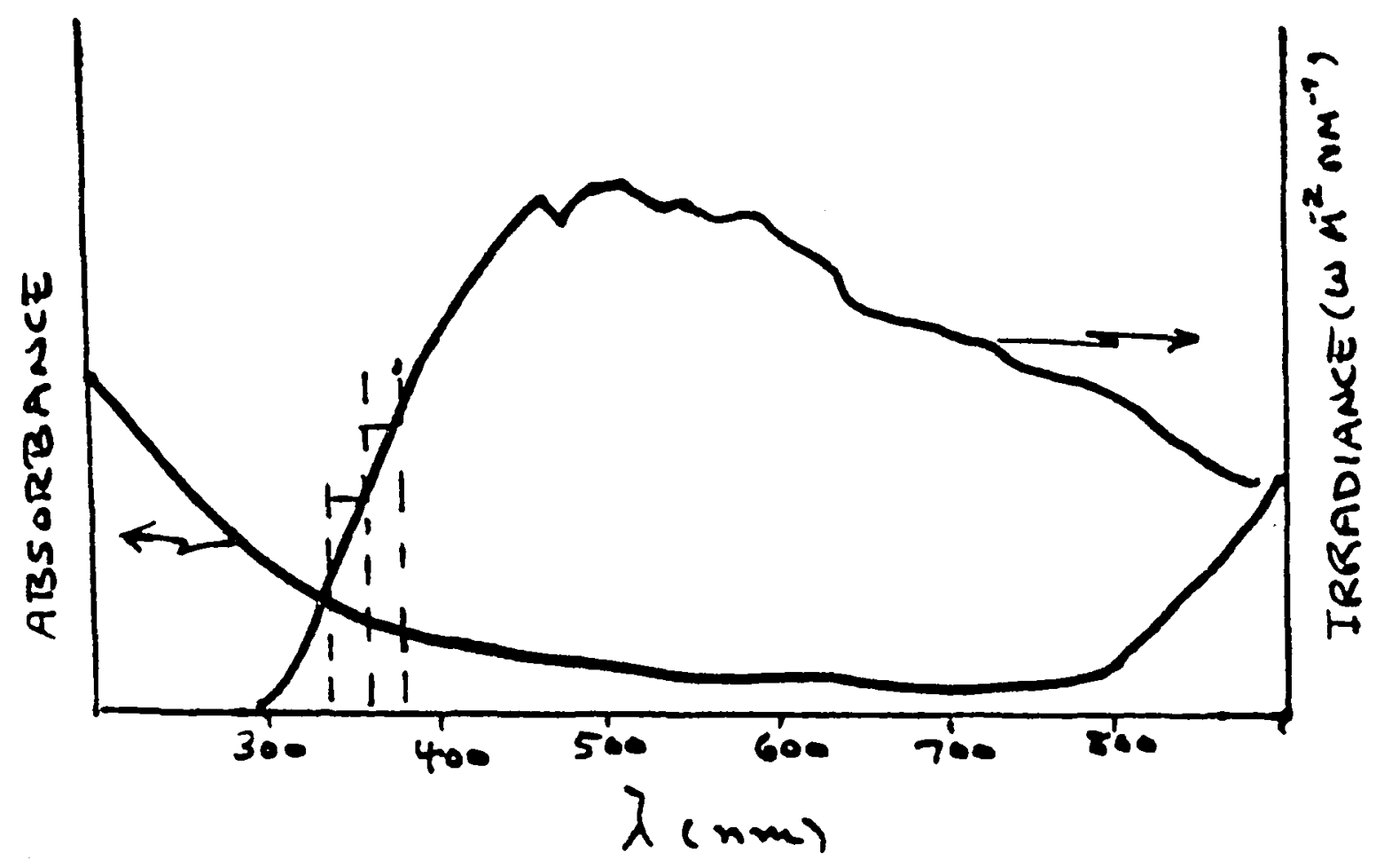

Permanent Data Base

- Insolation Data $S(\lambda) ; e . g$. Air Mass 1.5

- $c_{w}(\lambda)$ distilled water, from literature

- $\mathrm{C}_{\mathrm{s} w}(\lambda)$ saline water, from literature

- Asw $(\lambda)$ saline water, determined in this

Input Variables

- $A_{b}(\lambda, z)-A b s o r b a n c e s$, determined on Cary 219 Relative to the reference 2 , 3, or 4 above

$\cdot \rho(z)$ for solar pond Options

$\cdot z$

$\cdot \Delta \lambda_{i}$
Sequence of Calculation

1. Integrate over $S(\lambda)$, obtain $E_{0}$

2. Calculate $E_{\text {j }}$ absorbed in $j=1$ depth in crement of depth $\ell$
$I_{j}(\lambda)=I_{j-1}(\lambda) \exp \left[-2.303\left(A_{1}+A_{2}\right)\right]$
$A_{1}$-absorbance of solution
of density $d_{j}$ at depth $\ell$
$A_{2}=a b s o r b a n c e$ of reference solution at depth $\ell$

3. Increment $j$, calculate $\left.E_{\mathrm{a}}=\Sigma\right\} \mathrm{E}_{\mathrm{aj}}$

4. Calculate percentage of incident energy absorbed at each depth

$$
P t=100 \mathrm{Ea} / \mathrm{E}^{\circ}
$$


TABLE 6

TOTAL INCIDENT ENERGY AVAILABLE BETHEEN $300.000 A N D \quad 2537.000$
WANONETERS IS

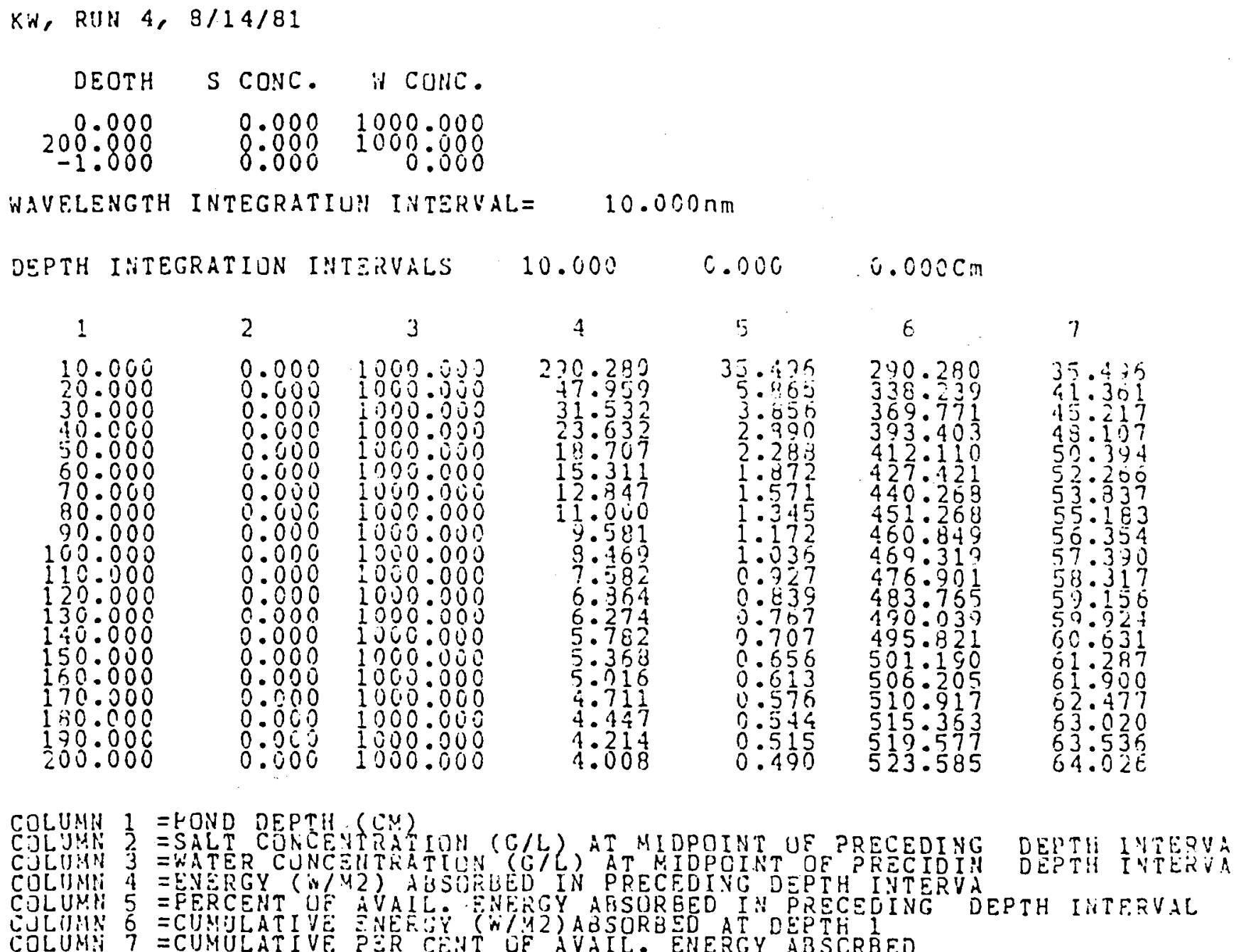

COLUMA $\frac{1}{2}=$ HOND DEPTH (CM) COLUMI 4 E ENSRGY ( COLUMA 5 = FERCENT UE AVAIL. ANERGY AESOREED IN PRECEOING DEPTH IUTFEVAL

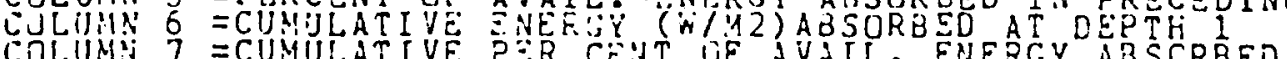


Table 7

Solar energy at one meter depth calculated using program "POND" with Air Mass 1.5 and coefficients from Table 3 .

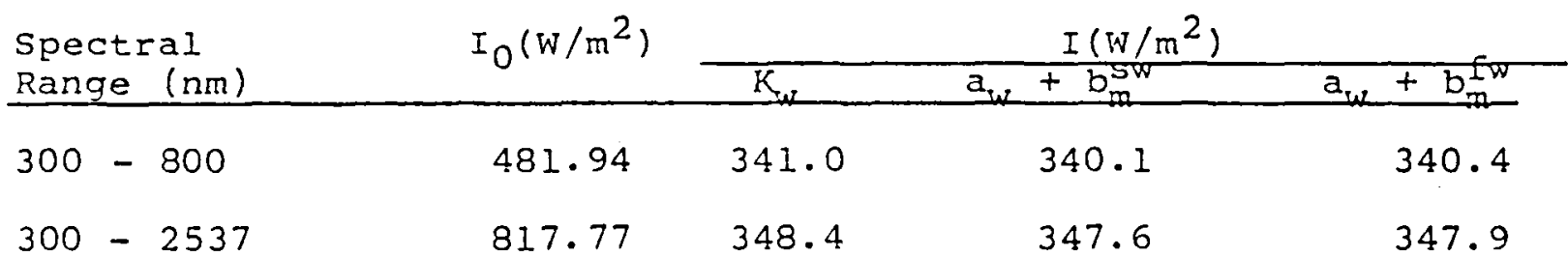

Examination of this data shows that the great majority of the transmitted solar spectram of Air Mass 1.5, that is 98 per cent of it, falls within the wavelength range from $300 \mathrm{~nm}$ to 800

$\mathrm{nm}$. The similarity in the results for $K_{w}$ and $c$ for salt water is expected since the latter were derived from $\mathrm{K}_{w}$ by Smith. The integrated data also show that there is little if any difference between the attenuation in clear fresh water and in salt water.

These results are also in close agreement with the value calculated using Nielson's formula (11), which fits the penetration data to a sum of four exponentials. Substitution in that formula yields 41.4 per cent attenuation at one meter as compared to 42.5 per cent here.

The relative attenuations as a function of depth, as output by the program "POiD", using the total attenuation coefficient $c=a_{w}+b_{m}^{E w}$ for fresh water, is presented in Figure 10.

The absorption spectra for clear saline water and the attenuation data presented above represent the clearest water and best transmissions which can be reasonably expected for solar ponds. The attenuation coefficients are appropriate reference data upon which to base the absorption spectra of any not so clear water being investigated. At the very least data taken on solutions relative to these should give values which reflect the relative transmission efficiency of the various waters studied. Results permit comparisons of efficiencies of ponds using discolored water to ideal ponds made up of clear water. The more colored, but less turbid, the water is the more reliable the comparison.

\section{c. Errors in Spectrophotometric Method}

Although the accuracy of these spectrophotometric measurements and extrapolations is difficult to assess, the precision of the data can more easily be evaluated. It is to be expected that the precision of the measurements in this study is low due to the very low absorbance range of interest. Simple calculus applied to Beer's Law shows that for a single beam instrument large relative errors in measured concentrations occur outside of the range $A=1.0$ to $0.1(T=0.1$ to 0.8$)$. For dual 
Figurse 10

Prograin Pons using $a_{N}+b_{m}^{\text {fw }}$ from Toble 3

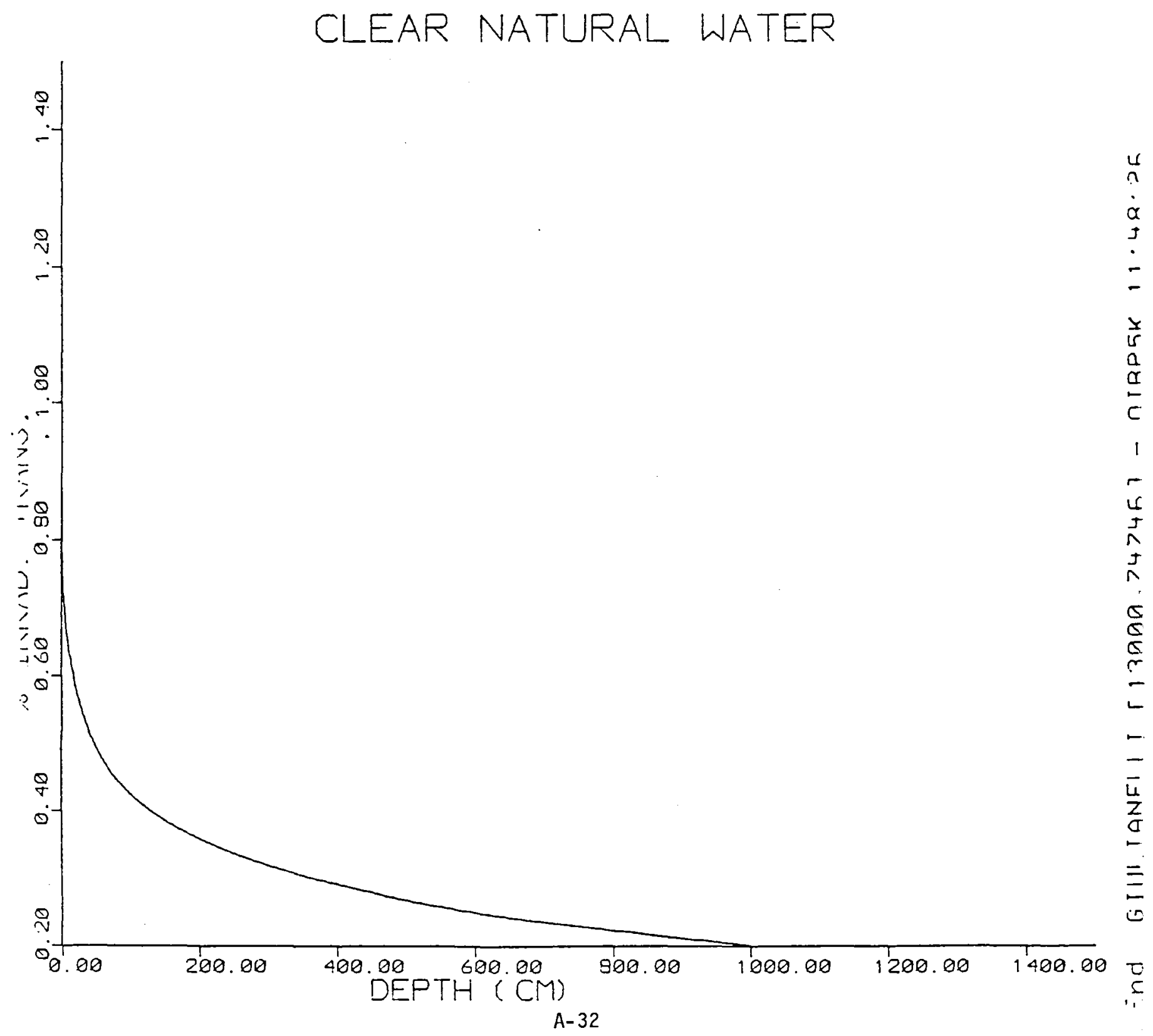


beam instruments the error range is fixed by wavelength dependent detector noise instead of by the reproducibility of scale readings, usually $\pm 0.01 \mathrm{~T}$, and the optimum range becomes from $A=$ 1.4 to 0.4 (12).

The same type of analysis can be applied to the transmittance equation to evaluate the importance of the path length over which the measurements are made, as well as the influence of the $\Delta \mathrm{T}$. Thus, From

the relationship

$$
\mathrm{T}=\exp (-\mathrm{cz})
$$

$$
\Delta c=\frac{-\exp (c z)}{2} \Delta T
$$

readily follows, where $z$ is now the path length in the measurement. (Note: In reference 1 this equation is incorrectly written, although Figure 2 based upon it is correct.) One can see then that for an assumed constant error in the transmittance of 0.01 , the relative error in the determination of an attenuation coefficient of $0.10 \mathrm{~m}^{-1}$ using a $10 \mathrm{~cm}$ cell turns out to be 100 per cent! Can it be this bad? Using a double beam instrument and effectively averaging over the entire wavelength range should improve the precision considerably.

Webb used the statistical analysis of variance approach to estimate the errors in the energy transmitted to one meter. Based on an estimated error of $\Delta T=0.01$ the maximum error propagated was 17 per cent of the transmitted energy at one meter. As Webb's work points out, in the measurement process it is extremely important to minimize errors due to bubbles or dust in solution and other causes of stray or scattered light which increase the uncertainty in the measured transmittance.

There is yet another cause for concern in these spectrophotometric measurements on brines which has apparently not been realized in the work done. A mismatch in the densities of the sample and reference solutions can lead to false readings of absorbances due to differences in the amount of light reflected in the two cases. This effect is illustrated in Figure 11 below.

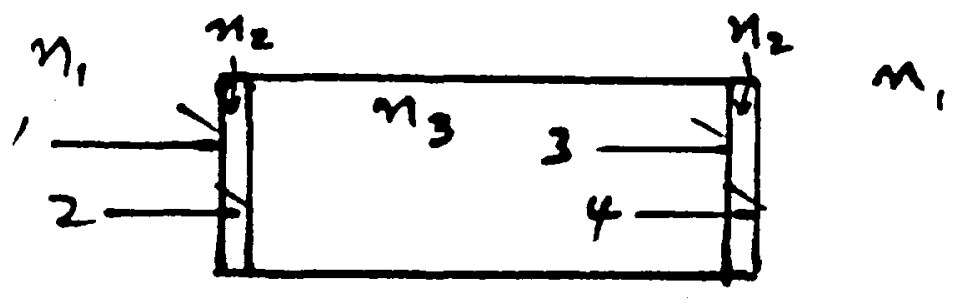

Fig. 11 The amount of reflected energy at an interface depends upon the refractive indices of the two phases. 
The ratio of the reflected to the incident light for normal incidence is given (13) by

$$
\frac{I_{r}}{I_{0}}=\frac{\left(n_{2}-n_{1}\right)_{2}^{2}}{\left(n_{2}+I_{1}\right)^{2}}
$$

where the $n_{1}$ and $n_{2}$ are the refractive indices of the two adjacent phases. In order to evaluate the importance of this effect a sample calculation was done based upon the following refractive index measurements on distilled water and two solutions of sodium chloride done at the usual $\mathrm{Na}-\mathrm{D}$ line

$(\lambda=589 \mathrm{~nm})$ in my laboratory.

$\begin{array}{ll}\text { Distilled water } & \mathrm{n}_{2}=1.3320 \\ 108 \mathrm{NaCl} & \mathrm{n}_{2}=1.3486 \\ \text { Saturated } \mathrm{NaCl} & \mathrm{n}_{2}=1.3765\end{array}$

Table 8 was constructed based upon two cases -- one for reflected losses at $589 \mathrm{~nm}$ using a cell containing only distilled water, the other with a cell containing saturated $\mathrm{NaCl}$. A value of 1.000 was assumed for the refractive index of air, and $n=1.500$ for that of glass.

Table 8

Calculated per cent losses due to reflection

Interface (Fig. 11) Cell with water Cell with saturated NaCl

$\begin{array}{lll}1 & 4.000 & 4.000 \\ 2 & 0.352 & 0.184 \\ 3 & 4.000 & 4.000 \\ 4 & 0.352 & 0.184 \\ 1 & 8.704 & 8.368\end{array}$

Thus there will appear to be 0.336 per cent more transmission through the brine than through the water. If the background scan is recorded with pure water, as it usually is, then in comparison the brine will appear to be this much more transmitting than it actually is, when in fact there is simply less reflection. Carrying the calculation even further, typical transmittance values for full Salton sea brine at two wavelengths can be used to calculate the expected percentage error in the calculated absorbance resulting from this effect. At $550 \mathrm{~nm}$ and absorbance of around 0.2 was observed, measured against artificial Salton sea brine. Were distilled water to have been the reference, a 2.3 per cent error in the absorbance would have resulted. Similarly, for the higher absorbance of 1.0 measured at $400 \mathrm{~nm}$, the error would have been 19 per cent.

Thus the importance of these errors needs to be appreciated in this kind of work. Due attention will be paid to these and other errors in the continuing work in the laboratory. 


\section{Comparisons with JPL Calculations}

Unlike in the JPL program, which varies the angles of incidence of a given solar spectrum and averages the intensity throughout the year, the CSM program ignores the complications introduced by this refinement (see below) and uses a solar irradiance spectrum of fixed intensity and normal incidence to the surface. Differences in the two programs are a result of the different purposes they were meant to serve. The CSM program uses a single collimated sun beam so that comparison among waters can be made. Site specific refinements can be added later if the results justify them. On the other hand the JPL program was written as part of an overall solar to thermal energy model for pond sizing.

Both the CSM and JPL computor simulations asume a constant solar spectral distribution as inputs to the model. The JPL program varies the intensity of this spectrum (Air Mass 2.0) as the angle of inclination changes throughout the year. The question arises whether the assumption that the constant solar spectral distribution throughout the year is a valid one. Solar spectra of varying Air Mass differ mostly in the blue region. To get an idea of what effect the choice of spectra has on the calculated attenuation, the POND program will be run with more than one Air Mass spectra.

\section{SOME FACTORS OF IMPORTANCE IN ENERGY MODELING}

It is appropriate to discuss some of the factors which need to be considered before attempting to use semi-empirical or indoor measurements to predict absolute values of light transmission to a given depth in a real outdoor solar pond. These considerations are in addition to the separate problem of the inaccuracy involved in extrapolating the spectrophotometric data to long path lengths.

\section{A. Surface reflection}

A fraction of the radiation incident on the surface is reflected and does not enter the water. For normal incident radiation about $7 \%$ of the total is reflected at a smooth surface. Reflective losses are somewhat wavelength dependent and increase at high angles of incidence (14). This phenomenon is rescribed by the Fresnel equation and was accounted for in the JPL calculation.

B. Optical path length

The path length $z$ is related to depth by the ratio.

$$
z=\ell / \cos \theta_{2}
$$

where $\theta_{2}$ is the angle that the beam of light inside the pond makes with the vertical. This angle is related to the angle of 
incidence $\theta_{1}$ of the light on the surface by snell's law:

$$
\frac{\mathrm{n}_{1}}{\mathrm{n}_{2}}=\frac{\sin \theta_{2}}{\sin \theta_{1}}
$$

where $n_{1}$ and $n_{2}$ are the refractive indices of the air and pond solution. This angular dependence of path length requires site specific, time integrated solar angle data as is incorporated into the JPL model.

The fact that the refractive index itself is a function of salt concentration has not been taken into account. The following calculation using the refractive index data presented above will show that it is a very minor consideration in the overall calculation.

At a $30^{\circ}$ degree angle of incidence of a ray into a saturated $\mathrm{NaCl}$ solution, the calculated path lenth for a $1.000 \mathrm{~m}$ depth becomes $1.0733 \mathrm{~m}$ instead of $1.0789 \mathrm{~m}$. This assumes $\mathrm{n}_{1}=1.000$. The maximum difference is thus only about $0.5 \mathrm{~cm}$ or $0.5 \%$ between distilled water and highly saline water. For an average salinity of half the concentrated value the error at 30 degrees would be closer to $0.25 \%$.

The other two influences which could affect the refractive index are the change with wavelength (dispersion) and the temperature coefficient (approximately 0.00045 deg -1 , decreasing with increasing temperature). Like the concentration effect, it appears that neither of these will be significant.

These slight dependencies of effective path length upon wavelength and concentration could be accounted for in an energy model, although to do so are probably not worth the effort in view of the magnitude of the other assumptions in the overall model. Furthermore, the incident angle $\theta_{1}$ is dependent upon surface waves and ripples, and this would be difficult to incorporate into a model. According to Weinberger (15) the effect of waves on transmission is slight.

The site specific question and the other uncertainties mentioned have been avoided by the choice of a normal incident beam in the pond calculation. The question arises whether these effects can be incorporated into a single "effective" average incirent angle and path length for each particular site.

\section{Diffuse radiation}

Unlike a laboratory simulated situation, for an outdoor pond a fraction of the sunlight incident at the surface is diffuse. The calculations of Marsh, et.al. correctly apply the Fresnel equation only to that part of the sunlight which is direct and Eurther assume, based on the calculation of Weinberger (15), that $7 \%$ of the diffuse radiation is reflected from the surface. 
The existance of diffusion underwater is reflected by the distinction between the total beam attenuation coefficient $c(\lambda)$, determined in the laboratory (normal incidence), and the diffuse attenuation coefficient for irradiance $K(\lambda)$, the corresponding coefficient resulting from underwater ocean measurments described in Section II E. Determinations of $K(\lambda)$ and $c(\lambda)$ such as those done for sea water and pure water, have of course not been done for brines. Differences between the diffuse and laboratory based coefficients might be even more pronounced for brines, expecially those having a density gradient, due to increased molecular scattering and the occurance of local and variable discontinuities in the refractive index as haloclines appear and disappear. The ability of the spectrophotometric or other laboratory measurement to effectively approximate the in situ attenuation of irradiance lessens as a pond becomes more turbid (scattering) from suspended material or algae. The need for alternative approaches for "dirty" ponds is thus apparent and the eventual need for underwater pyronometer or radiometer data is obvious.

IV. FUTURE WORK

The final stages in the interfacing of the CSM computor and program POND to the Cary 219 through the Apple computor are being completed. Work will then focus on determining the best measurement procedure and the limits of precision using the procedure. The revised technique will then be used to determine transmissions through salton sea water and brines and to determine the improvements resulting from the various clariEication procedures already reported (16). If warrented, the JPL solar pond efficiency program can be revised to accept directly the results of these new measurements. The emphasis of the CSM work this year will continue to be the optical evaluation of relatively dirty industrial grade salts and byproducts as solar pond materials.

The accuracy of the predictions made by this or any other laboratory-based measurement are best established by comparisons with carefully controlled outdoor underwater measurements. It is expected that water samples will eventually be obtained from an operating pond for which radiometric data are available. Comparisons of predictions based upon spectrophotometer scans with irradiances determiner at the surface, just beneath the surface and at various depths should tell how good the predictions are. 



\section{REFERENCES}

1. Smith, R.C., and Tyler, J.E., "Transmission of Solar Radiation into Natural Waters," in Photochemical and Photobiological Reviews, Vol. 1, Smith, K.C, ed., Vol. 3, (1976).

2. Smith, R.C., and Baker, K.S., "Optical Properties of the clearest Natural Waters (200-800 nm)," Applied Optics, Vol 20(2), p. 177, (1981).

3. James, H.R., and Birge, E.A., Trans. Wis. Acad. Sci., 31, 1 (1938).

4. Usmanov, Y., Elisean, V., and Umarov, Y., "On the Optical Characteristics of a Solar Pond," Starodubtsev Physicotechnical Institute, Report No. UDC 662.997:64, pp 78-81 (1971).

5. Marsh, H.E., DeFranco, D.M., Haack, R.F., McMurrin, J.C. Reilly, W.W., Singer, M.J. and Wu, Y.C., "Salt-Gradient Solar Ponds in the Salton Sea: Brine Optical Quality and Performance," presented at the IECEE Conference of ASME, Atlanta, Aug 9-14.

6. Morel, A., and Prieur, L., Limnol. Oceanography 22, 709 (1977).

7. (a) Daniels, K.J., Laurendeau, N.M., and Incropera, F.P., "Comparison of Predictions with Measurements for Radiative Transfer in an Algal Suspension," Int. J. Heat Mass Transfer, 21, p. 1379 (1978); (b) Wagner, T.R., Incropera, F.P., and Houf, W.G., "Visible Radiation Transfer in a Black Ink Suspension," J. Heat Transfer, 102(4), p. 709 (1980).

(c) Incropera, F.P., and Privoznik, K.G. "Radiative Property Measurements for Selected Water Suspensions," Water Resources Research, 15(1), p. $85,(1979)$

8. Smith, K.C. and Baker K.S., "The Bio-optical State of Ocean Waters and Remote Sensing," Limnology and Oceanography, 23(2), p. 247 (1978). Smith, K.C., and Baker, M.S., "Optical Classification of Natural Waters," Limnology and Oceanography 23(2), p. 260 (1978).

9. This interfacing has mostly been the work of Dr. Dean Dickerhoof of the Department of Chemistry of CSM.

10. J.D. Webb, "Optical Transparency of Inexpensive Salt Solutions for Construction of Density-Gradient Solar Ponds," SERI/RR-641-615, JulY, 1981 .

11. Rabe, A. and Nielsen C. E., "Solar Ponds for Space Heating," Solar Energy, 17, p.1, (1975).

12. Christian, G. D., Analytical Chemistry, Xerox College Publishing, Waltham, Massachusetts, p. 345 (1971).

13. Skoog, D. A., and West, D. M., Principles of Analytical Chemistry 2nd ed, Saunders College, Philadelphia, p.103 (1980). 
14. Jerlov, N.G., Optical Oceanography, Elsevier Publishing Company, Amsterdam, 1968 .

15. Weinberger, H., "The Physics of the Solar Pond," Solar Energy, 8(2), p. 45 (1964).

i6. Carpenter, S., Marsh, H., Reilly B., and Haack, R., "Water Treatment for Salt-Gradient Solar Ponds at The Salton Sea," JPL IOM:3417-81-156, 12 Aug., 1981. 


\section{APPENDIX I}

COMPARISON OR RESEARCH GOALS IN LIGHT TRANSMISSION MEASUREMENTS

Goal A - To Develope a Light Sensor For Use Within Operating Ponds.

A. USEFULness

1. To periodically or continuously monitor operating pond

2. To aquire data for energy balance theoretical models used in pond designing.

3. To separately evaluate effects due to algal growth, suspended particles, disolved organic matter, surface films.

4. Jseful measurement for verification of data from other approaches.

B. ADVANTAGES OVER LABORATORY APPROACH

1. Avoids transferring samples to laboratory.

2. Continuous monitoring is possible

3. Data adquistion automatic, by inexperienced personnel.

C. DISADVANTAGES

1. Requires large (at least $10 \mathrm{~m}^{2}$ ) outdoor pond.

2. Maintainance and placement difficulties within ponds.

3. Need for sensitivity calibrations at various temperatures.

4. Finite lifetime of detector.

D. ALTERNATE APPROACHES

1. Absolute energy vs. depth can be measured.

2. Perform relative measurements for monitoring purposes only.

3. Use of transmission meters with built in light source for relative measurements horizontally for monitoring water clarity.

E. STATUS + UNSOLVED PROBLEMS

Commercial pyranometers need modification to withstand temperature and brine. Continuously submersed instruments probably not feasible.

F. RESEARCH RECOMMENDED

1. Develope flat window, submersible, temperature compensated pyranometer detector.

2. Investigate use of fiberoptics to elimate need to place sensor in pond.

3. Study advanced methods of monitoring:

a. Portable laser.

b. Fixed source/detector combinations. 
G. JPL Research and Role

1. Survey available equipment, purchase and modify pyranometer for use in ponds.

2. Calibrate and test instrument in outdoor pond.

Goal B -- To Determine Transmissions in the Laboratory by Spectrophotometric Method

\section{A. USEFULNESS}

1. To evaluate degree of optical clarification of water by a given process.

2. To be used for as input to solar thermal model.

\section{B. ADVANTAGES OVER IN SITU APPROACH}

1. Pond need not be built in order to test water's clarity.

2. Sampling is simpler and results are independent of meterological conditions.

3. Comparisons can be made of water from different ponds and sources.

4. Color content can be varied in order to quantify its effect.

5. Sensor need not be immersed in harsh environment of high temperature brines.

\section{DISADVANTAGES}

1. High sensitivity spectrophotometer is necessary.

2. Computor aquisition and manipulation of data is necessary.

3. Research needs to be done to determine validity of the method.

D. ALTERNATIVE APPROACHES

1. Concern can be with absolute values of energy transmitted based upon meteorological time dependent data for the site.

2. Results can be obtained based upon clarity of water relative to clearest filtered colored water obtainable at the site.

3. Solutions can be analyzed for algal (chlorophyl), organic color, and particulate content, and these values combined with predetermined attenuation coefficients for these substance to calculate the transmission through the original solutions.

\section{E. STATUS AND UNSOLVED PROBLEMS}

Present method of extrapolating spectrophotometric data is subject to uncertainties which may yield low results for transmissions. Efforts to determine the degree of error of these results and put them on a quantitative basis are in progress.

\section{F. RESEARCH RECOMMENDED}

1. Determine actual functional dependences of absorbance on concen- 
trations and path length.

2. Determine how to account for effect of scattering due to molecules, ions, and suspended particles.

3. Investigate use of the integrating sphere to eliminate effects due to scattering.

4. Verify predictions of laboratory measurements with solutions and irradiance data from outdoor ponds.

5. Revise Salton Sea model calculations incorporating new results distinguishing absorption and forward scattering and accounting for the expected error inherent in the data treatment.

6. Research use of derived attenuation coefficients together with chemical analysis of the solution for predicting the transmission. 
APPENDIX B

MATERIAL SELECTION CONSIDERATIONS

FOR SOLAR PONDS

B-1 

MATERIAL SELECTION CONSIDERATIONS FOR SOLAR PONDS

S. Sastri, T.K. Vaidyanathan, H. E. Marsh, and R. French

S. Sastri is Professor, Department of Mechanical Engineering Technology, New York City Technical College, Brooklyn, NY 11201 ;

T.K. Vaidyanathan is Associate Professor, Department of Dental Materials Science, New York University Dental Center, New York, NY 10010 :

H. E. Marsh is Member Technical Staff, Solar Energy Conversion Systems Section, Jet Propulsion Laboratory, Pasadena, California 91109;

R. French is Project Manager, Jet Propulsion Laboratory, Pasadena, California 91109. 

The escalating price of energy has generated a broad search for the potential exploitation of solar energy. Perhaps, solar ponds represent the ultimate goal of this auest for the use of solar energy. A salt gradient solar pond is an efficient, low cost solar energy collection and long range storage system for low temperature heat. Recently, Jet Propulsion Laboratory has conducted a feasibility study ${ }^{1,2}$ for a salt gradient solar power plant in or near the Salton Sea of California. The operating principle of the system is shown in Figure 1. Hot water from the solar pond is pumped to the evaporator which uses the heat to produce high pressure organic fluid vapor. The high pressure organic fluid vapors are used in a turbine to generate power. The vapors then proceed to the condenser in which they are cooled and condensed. The liquid from the condenser is pumped by a circulating pump back to the evaporator. Included in the system is also another heat exchanger, whose duty is to raise the system efficiency. It transfers heat from the hot vapor leaving the turbine, to the liauid, before entering the evaporator, thereby reducing in this way the amount of heat needed from the pond. As can be seen in the figure, the salt gradient involved in the pond varies from $3.8 \%$ in the upper layer salton sea water to $20 \%$ concentrated brine in the storage layer. In adition, oxygen is also present in the solutions. The heat exchanger materials to be used in the system need careful selection because of the extreme concentration of aggressive halide ions and oxygen present in tha $\leq y \leq t e m$. In addition the temperature of the 
lower storage layer may reach as high as $90^{\circ} \mathrm{C}$.

Z.angrand $0^{3}$ and Wittenberg ${ }^{4}$ have reported on the use of brass and copper in heat exchange application situations for solar ponds. Due to the highiy corrosive situation in solar ponds, alternate candidate materials must also be considered for heat exchange applications. Although no other candidate materials are mentioned in the literature for solar ponds, there are several publications $5-7$ on the performance of materials in marine condensers and heat exchangers. Thus, data areavailable for the following groups of metals: carbon steels, stainless steels, copper-nickel alloys, aluminum alloys, cobalt-chrome alloys, and titanium alloys. Based on the requirements of heat transfer performance, mechanical strength, corrosion resistance, fabricability, cost, etc., the following candidate materials were selected for a further study to evaluate the corrosion resistance of these alloys: SAE 1020 steel, SAE 304 stainless steel, Type $M$ copper, 6061 - T6 Al alloy, and C706 $000(90 \mathrm{Cu}$ $10 \mathrm{Ni}$ a $110 \mathrm{y}$ ).

The study included potentiodynamic anodic polarization analysis, corrosion rate calculation via corrosion behavior diagrams, and immersion weight loss measurements.

Anodic polarization analyses of the alloys were carried out in aerated Salton sea water $13.8 \%$ salt concentration) and concentrated Brine (20\% salt concentration). The alloys were anodically polarized from the corrosion potential to an upper potential of +1000 mv(SCE). Disc samples of each alloy were netallographically mounted and polished througr blo grit emery paper prior to the study. 
The polarization setup comprised of a potentiostat, a Universal potential programmer, a logrithmic converter, an electrometer probe, an X-Y recorder anc corrosion cell*. A scanning rate of $0.2 \mathrm{mv} /$ sec was used in the polarization.

Since the alloys studied were expected to show active or active-passive polarization behavior, the corrosion rate of the specimens was also determined by the use of corrosion behavior diagram method described by Morris, et al. A scanning speed of $20 \mathrm{mv} / \mathrm{sec}$ was used forthis portion of the study.

For comparison with the above electrochemical methods, weight loss measurements were also carried out on 1020 steel - $1 / 8 " x 1 / 2 " x 1 / 2 "$ specimens were suspended in solutions of Salton Sea water and concentrated Brine and weight loss determined after 15 weeks.

\section{$\underline{R}$ e $\underline{\text { u }} \underline{1} \underline{\underline{t}} \underline{\mathrm{s}}$}

Figures 2 and 3 are the potentiodynamic anodic polarization profiles of the different alloys tested in Salton Sea water and concentrated Brine solution respectively. Figure 4 shows a typical corrosion behavior diagram of 304 stainless steel. Figure 5 shows the weight loss measurements of the 1020 steel. The corrosion rates of various alloys, calculated from the Corrosion Behavior Diagrams as described by Morris, et al, are given in Table I.

* Princeton Applied Research Laboratory Corrosion System $331-2$. 


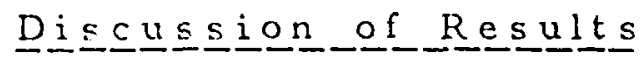

The polarization profiles in Figures 2 and 3 reveal that the corrosion resistance of the alloys decreases in the following order in both salton Sea water and concentrated Brine solutions: stainless steel, Cu/90Cu loNi, 1020 steel, Al. Only stainless steel shows spontaneous passivation at corrosion potertial and the passive behavior is stable through $+200 \mathrm{mv}(\mathrm{SCE})$ in Salton Sea water and through +100 $m v(S C E)$ in concentrated Brine solution. Copper and $90 \mathrm{Cu}-10 \mathrm{Ni}$ alloys show only minor anodic loops which is probably not due to any passivation effect, as pointed out by Uhlig, et al 9 . The behavior of copper and $90 \mathrm{Cu}-10 \mathrm{Ni}$ alloys are intermediate in that the potential current profiles are more noble than 1020 steel and Al, but relatively more active than stainless steel. The active polarizarion behavior of Al and 1020 steel together with the measured low corrosion potentials of these materials indicate poor corrosion performance of these alloys in solar pond heat exchange situations.

The corrosion rate and corrosion current values in Table II also confirm the above features. The corrosion rates vary from $0.10 \mathrm{mpy}$ for stainless steel to $3.96 \mathrm{mpy}$ for 6061 Al in Salton Sea water.

Although the above data would indicate that stainless steel would be the best candidate material for solar pond application, the largehysteresis loop associated with the forward and reversescan in Figure 4 indicate a significant potential for pitting type of corrosion.

Comparison of the salt sca water and Brine solvion corrosion behavior and corrosion rate both indicate that the Brine solution caus more active corrosien. However, tho weight loss measurements 
in Figure 5 indicate that weight los follows a different pattern. Thus, the active corrosion effects in concentrated salt solutions, especially at higher temperatures, may result not from anodic dissolution effects but also insoluble corrosion product formation.

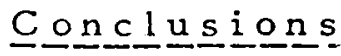

1. Among the various candidate materials tested, stainless steel shows the best potential for applications as heat exchanger components in solar ponds.

2. Even stainless steel may lead to pitting type of corrosion.

3. Weight loss measurements are probably unsatisfactory for corrosion evaluation in solar pond situations. 


\section{REFERENCES}

1. M.L. Peelgreen "Salton Sea Project" JPL publication \#81-108. Jan. 1982 .

2. "A Study of the Feasibility of a Solar Pond Generating Facility in the State of California, USA" Ormat Turbines, May 1981 .

3. Zangrando, et al "Heat Extraction from a Salt Gradient Solar Pond" presented at International Conference on Alternative Energy Sources, Miami Beach, Ela. Dec. 1977 .

4. Wittenberg, L.J. "Salt Gradient Solar Ponds" paper presented at 1980 International symposium of Solar Energy Utilization, U. of Western Ontario, Canada, Aug. 1980 .

5. R. O. Lewis and F.C. LaQue "Evaluation of Copper Nickel Alloys for OTEC Applications" Argonne National Laboratory publication ANL/OTEC - BCM - 0.19, April 1981 .

6. Tuthill, A. H. and C.M. Schillmoller "Guidelines for Selection of Marine Materials" paper presented at The Ocean Science and Ocean Engineering Conference Marine Technology Society, Washington, D.C., June 1965 .

7. Jacobsen "Material Selection Considerations for Bluoride Thermal Energy Storage, technical report AFAPL-TR-77-9, Air Force Aeropropulsion Laboratory, May 1977 . 
8. Morris, P.E. and Scarberry, R.C., "Predicting Corrosion Rate With The Potentiostat", Corrosion, $28(12): 44(1972)$.

9. Mansfield, F. and Uhlig, H. H.: "Effect of Electron Donor and Acceptor Elements in Passivity of CuNi Alloy/s", J. Electrochem Soc. 117 (4):427-432 (1970). 


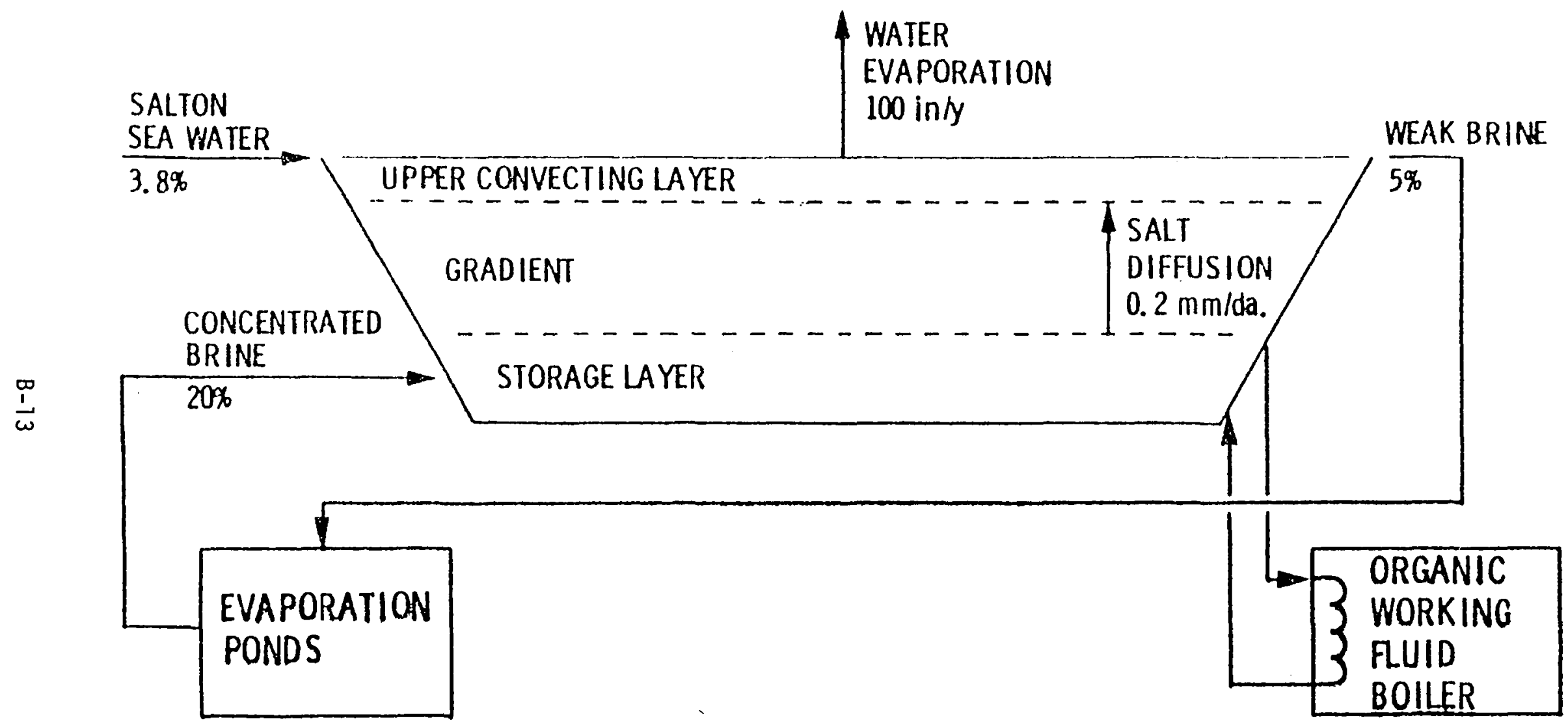

Figure 1: Operating Principle of Solar Pond 


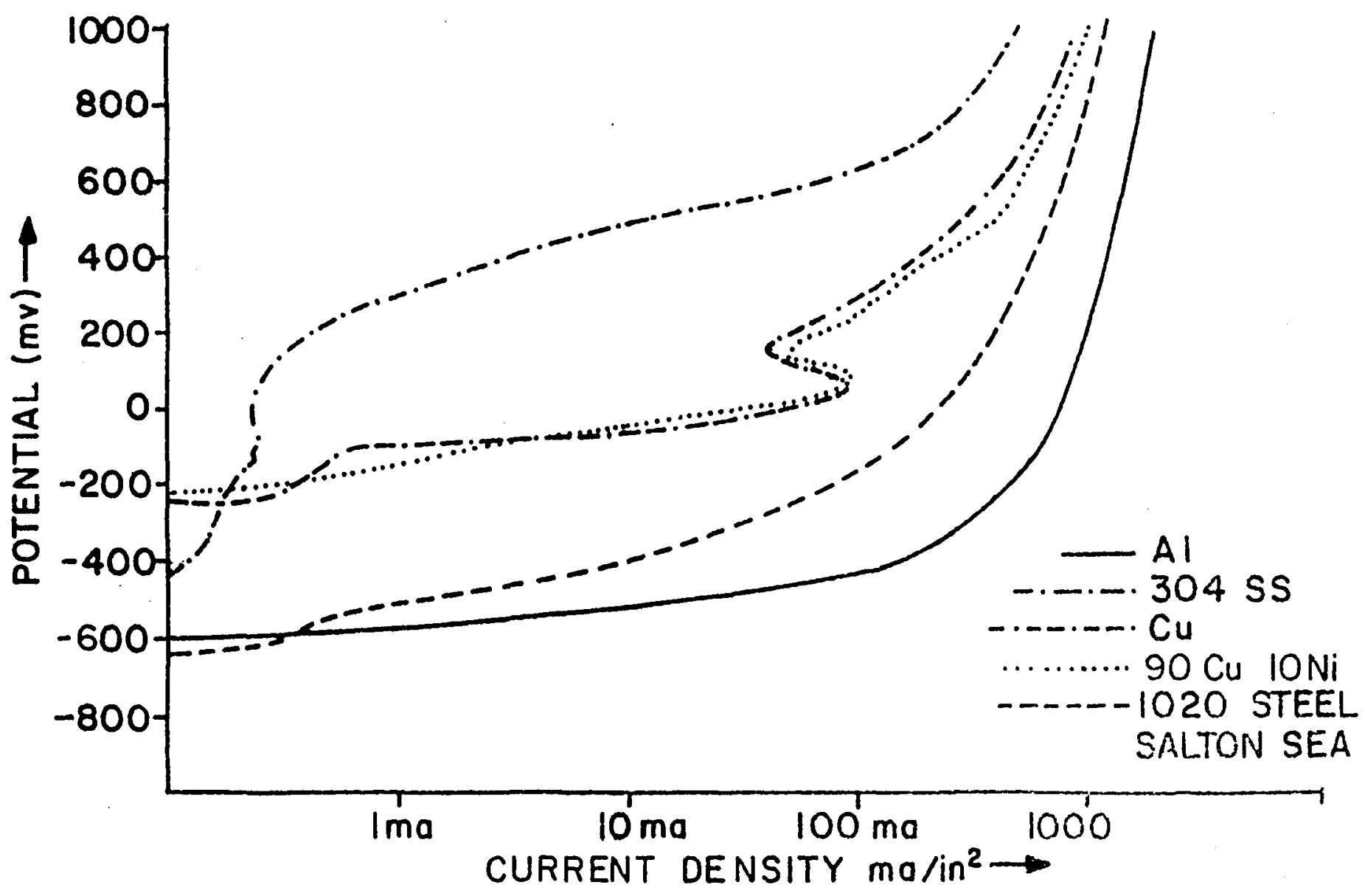

Figure 2: Potentiodynamic Polarization Profiles oi various alloys in Salton Sea Water. 


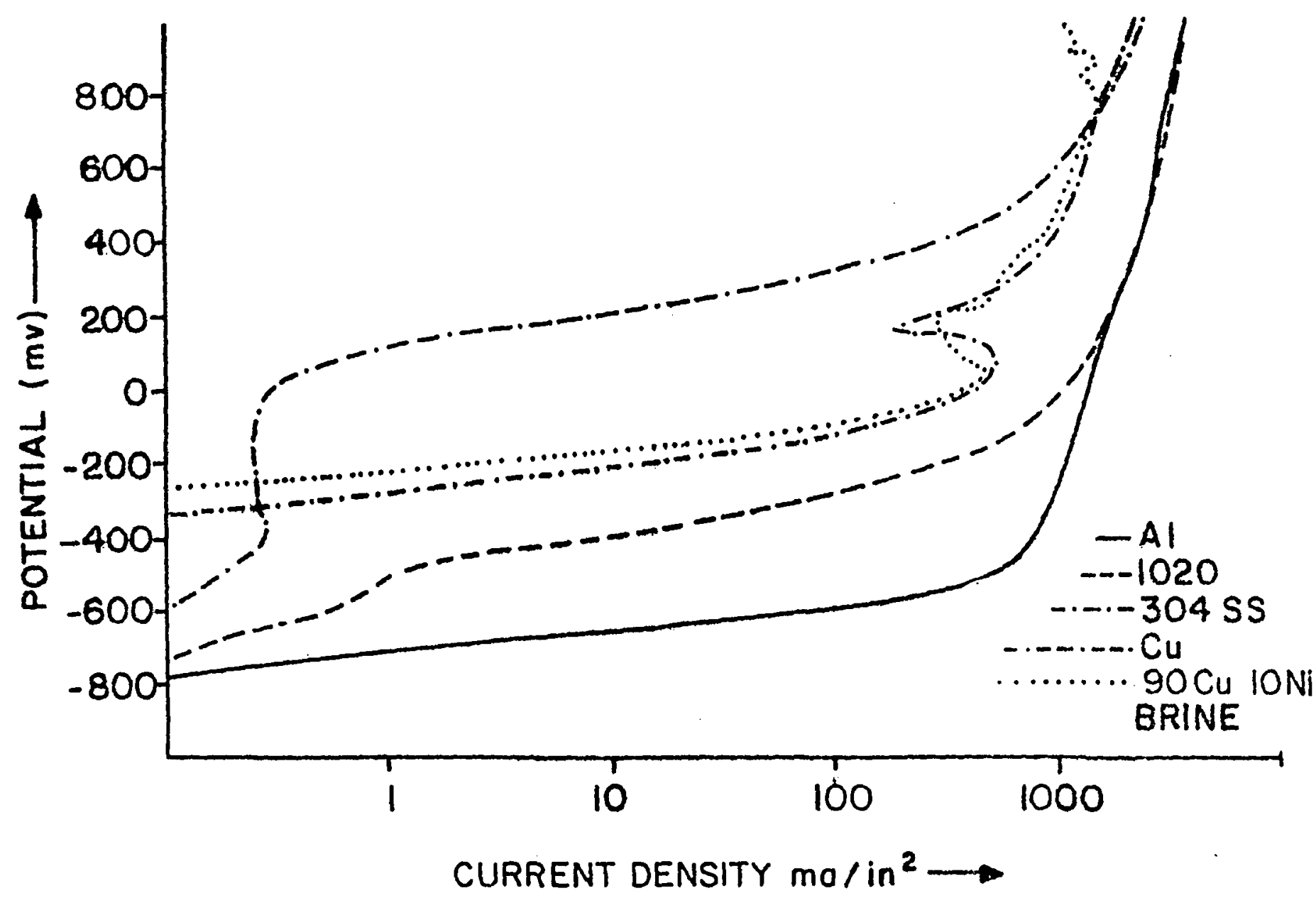

Figure 3. Potentiodynamic Polarization Profiles of various alloys in Brine Solution. 


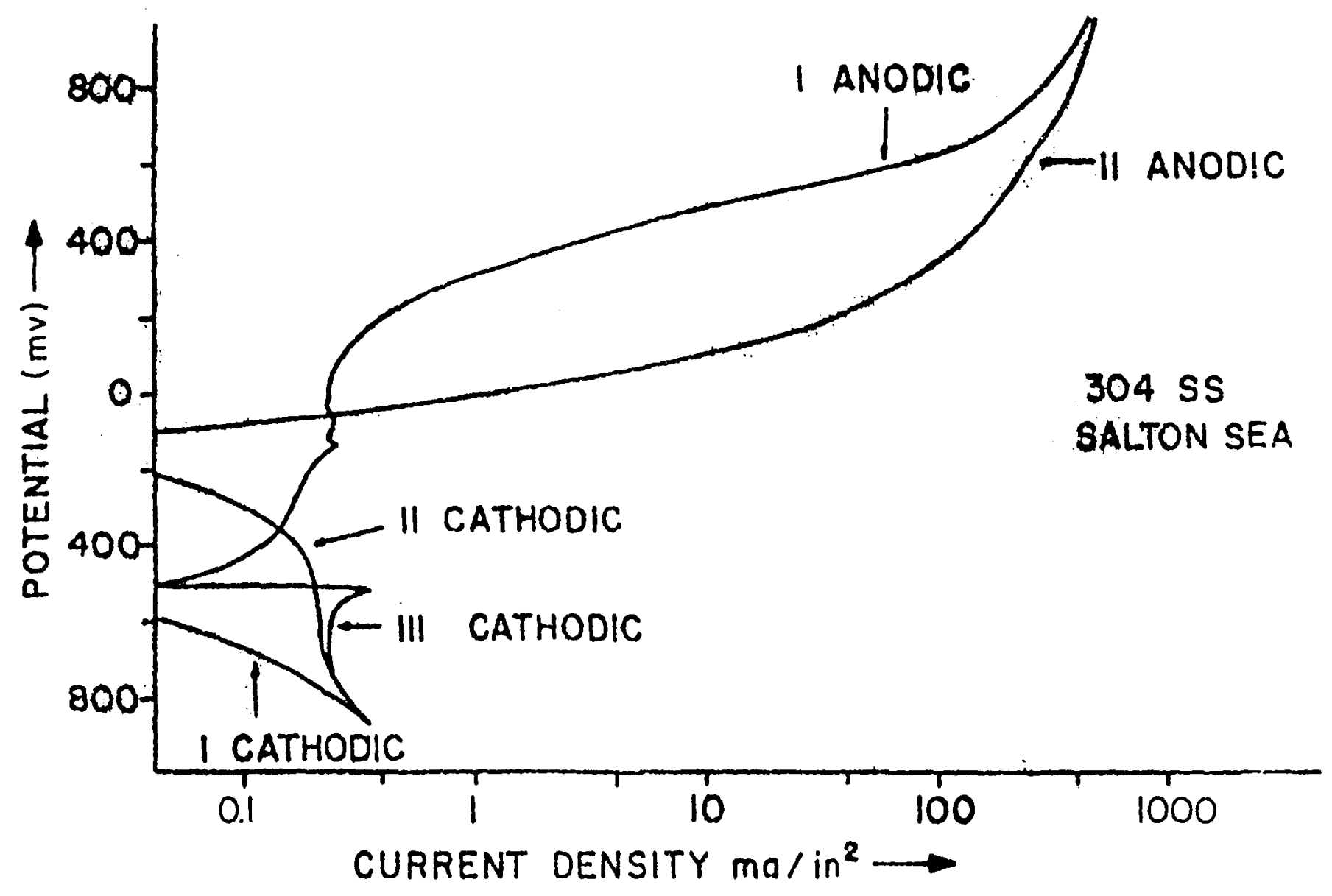

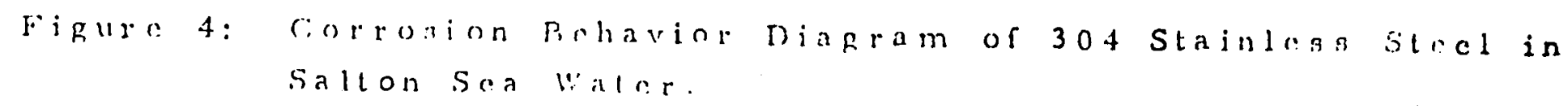




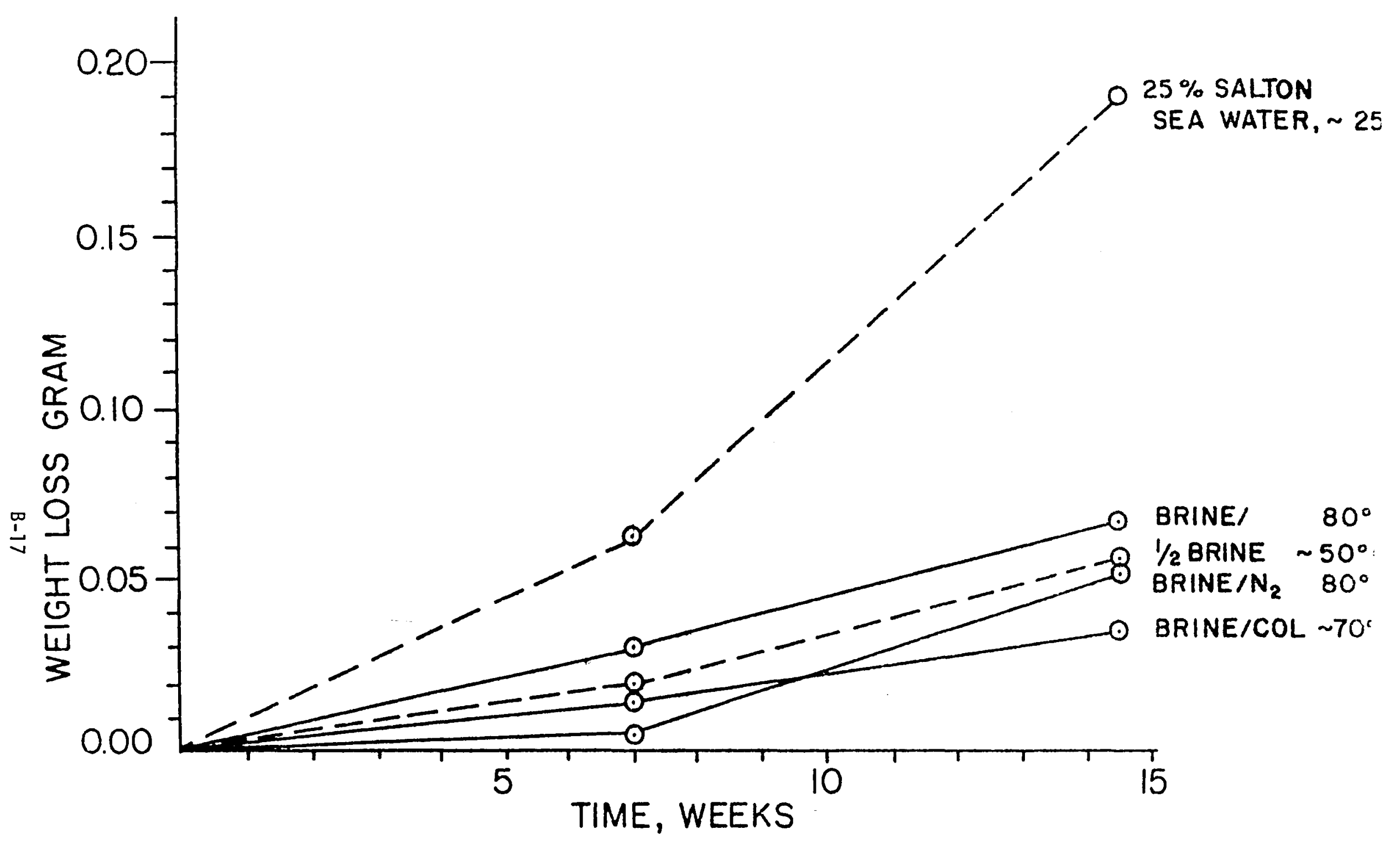

Weight Loss Trends in Various Enviroments

FIGURE 5 
T A B LE. I.

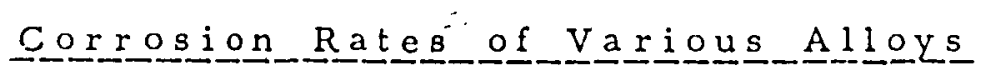

Salton Sea Water

$\begin{array}{cc}\text { Corrosion Gurrent } & \begin{array}{c}\text { Corrosion Rate } \\ \text { maling }\end{array}\end{array}$

$6061-A 1$ a $110 y$

.022

1020 Stee 1

Copper

$90 \mathrm{Cu} \quad 10 \mathrm{Ni}$

$\stackrel{\infty}{\infty} 304 \mathrm{~S} . \mathrm{S}$.
.021

.0026

.002

.00044
3.96

4.06

1. 005

0.73

0.10
Brinc Solutiion

Corrosion Gurrent Corrosion Ratc
ma/in

.050

9. 01

.054

$10 \cdot 4$

.011

4.25

.010

3.66

.0005

0.114 
APPENDIX C

\section{A SUMMARY DESCRIPTION OF A COMPUTER PROGRAM CONCEPT FOR THE DESIGN AND SIMULATION OF SOLAR POND ELECTRIC POWER GENERATION SYSTEMS}

\section{A. INTRODUCTION}

A solar pond electric power generation system is a complex system involving many major subsystems, i.e., an electric power generation subsystem, an electric power transformer and switch yard, a large solar pond, a water treatment plant, and numerous storage and evaporation ponds. Because a solar pond can store thermal energy over a long period of time, plant operation at any point in time is dependent upon past operation and future perceived generation plans. This time or past history factor introduces a new dimension in the design process. The design optimization of a plant must go beyond examination of operational state points and consider the seasonal variations in solar, solar pond energy storage, and desired plant annual duty-cycle profile.

Models or design tools will be required to optimize a plant design. These models should be developed with care in order to include a proper but not excessive level of detail. The model should be targeted to a specific objective and not conceived as a "do everything" analysis tool, i.e., system design and not gradient-zone stability. This Appendix gives a general discussion of the concept of a total system design model.

\section{B. THE GENERAL ANALYTICAL TOOL CONCEPT}

A comprehensive tool for the design and analysis of a solar pond electric power generation system should contain a solar pond thermal model, a power conversion model, a cost analysis model, a comprehensive solar pond data base, and a full accounting of parasitic power losses.

A "building block" concept reflecting the physical elements or subsystems of the plant has been selected. Each component or functional element is viewed as a box with inputs, outputs, and internal mathematical functions or data tables. Each assembly or subsystem, in turn, is composed of groupings of components tied together by equating appropriate input/output signals. As a result, a subsystem or assembly becomes a package that relates directly to a physical item. The motivation and advantage of this concept is to retain within the model (computer program) an easy method of finding specific components and changing or modifying the describing functions. For example, 
a modified description of a heat exchanger can be verified on a stand-alone basis, then easily inserted into the system model. Additionally, subsystems can be used as separate programs for limited analytical purposes.

Design optimization will be achieved by varying basic design parameters and running system simulations.

\section{BASIC STRUCTURE OF THE PROPOSED SYSTEM MODEL}

The basic structure of the proposed full system model can best be described by referring to the flow diagram in Figure $\mathrm{C}-1$. The major subprograms of the system model include a solar pond thernal model, a power generation model, a cost analysis model, a data base, and input/output functional blocks. The top level or system model controls all computations and evaluates intermediate results relative to specified requirements.

The general scheme will be to first define a total system on the basis of a point design, then perform a time-dependent simulation analyses. At the conclusion of the simulation analyses, adjustments to the basic design may be necessary if performance requirements have not been adequately met.

The program will be structured to accept input data and decide whether preliminary pond sizing is necessary. If sizing is necessary, an appropriate algorithm will be called. Design point or annual average performance of the pond will then be determined and used as an input in initial sizing of the power conversion equipment.

With the output from the pond model and additional specifications from the input data stream, the power system program performs energy and mass balances, sizes components, and estimates system performance and capital costs. If the system performance is satisfactory, the computation moves on to the simulation block; if not, a new design condition is selected and the process is repeated.

Once a satisfactory design point is achieved, a more comprehensive system simulation is performed. The system simulation includes the time variability of weather, demand electric output, non-linearities of equipment and control, and the integrated effect of off-design operation.

The program will utilize a hierarchy of control with the optimization algorithm contained at the top level. the capability to perform parametric studies will be included as an option in the optimization algorithm.

\section{STATUS OF MODEL DEVELOPMENT}

The concept of the full model requires development and integration of several subsystem models. Because of time and resource limitations, the intent of the initial work has been to plan the entire program and then 


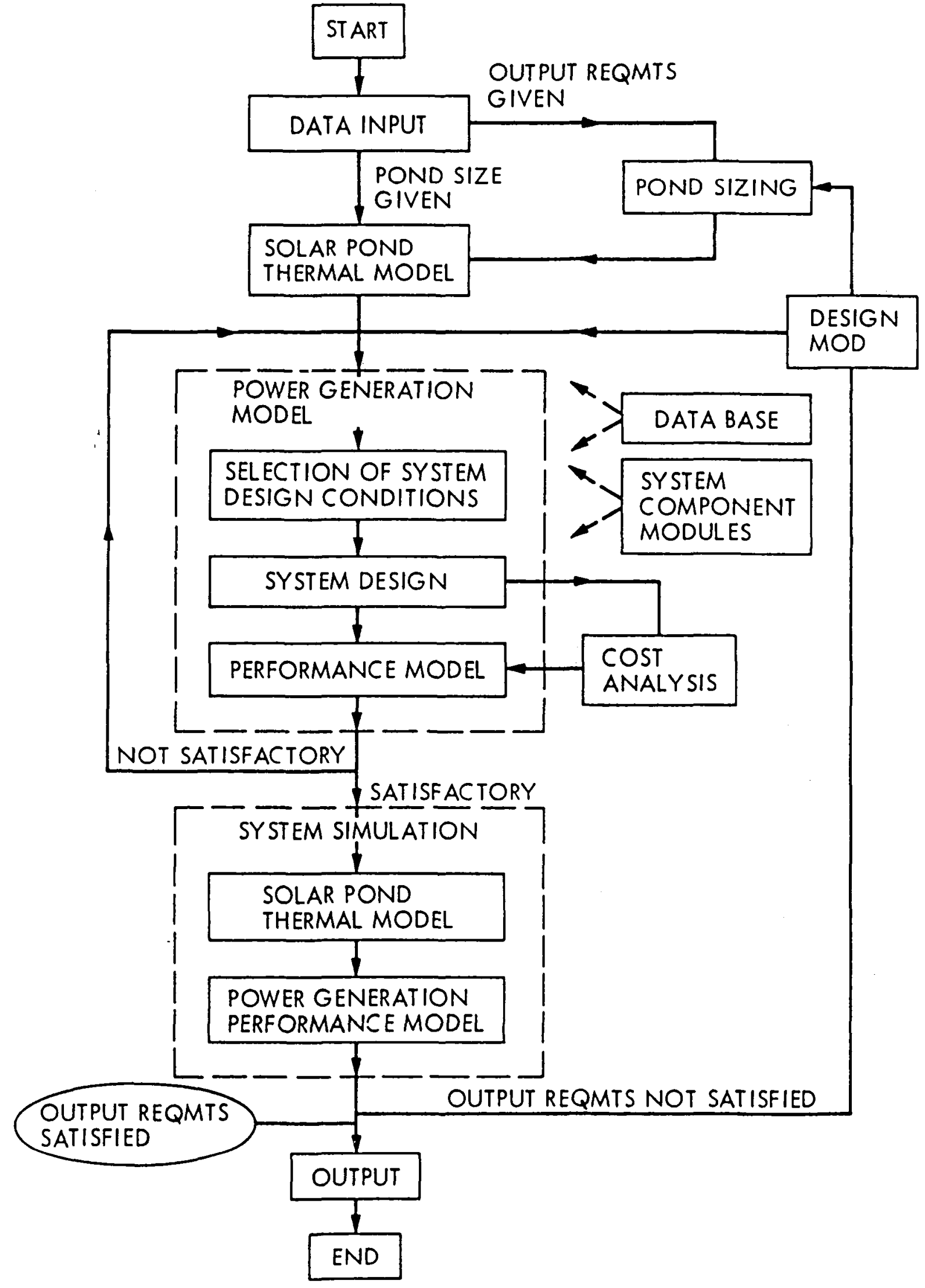

Figure C-1. Basic Structure of the System Model 
to concentrate on the development of the electric power generation model. once this is achieved, then the major blocks of the system will exist in program or procedural form.

The model development effort was curtailed before substantial progress was achieved. The following summarizes the progress made toward developing the power generation subsystem model.

The major components of a power generation subsystem are shown in Figure $\mathrm{C}-2$. The creation of a subsystem computer program requires that the performance characteristics of each component be established. Then input/output parameters are defined and the components (mathematical descriptions) are arranged into a computational flow path.

A heat exchanger is an example of a major component. Figure $\mathrm{C}-3$ shows a sketch of a typical heat exchanger. The mathematical relations describing the characteristics of any heat exchanger depend on the type of heat exchanger but, in general, the following holds:

$$
\begin{aligned}
& T_{h o}=T_{h i}-E \cdot\left(\frac{C_{\min }}{C_{h}}\right) \cdot\left(T_{h i}-T_{C i}\right) \\
& T_{C o}=E \cdot \frac{C_{\min }}{C_{0}} \cdot\left(T_{h i}-T_{C i}\right)+T_{C i} \\
& \dot{Q}=E \cdot C_{\min } \cdot\left(T_{h i}-T_{c i}\right)
\end{aligned}
$$

where $E$ is the heat exchanger effectiveness given below for various types of heat exchangers. 


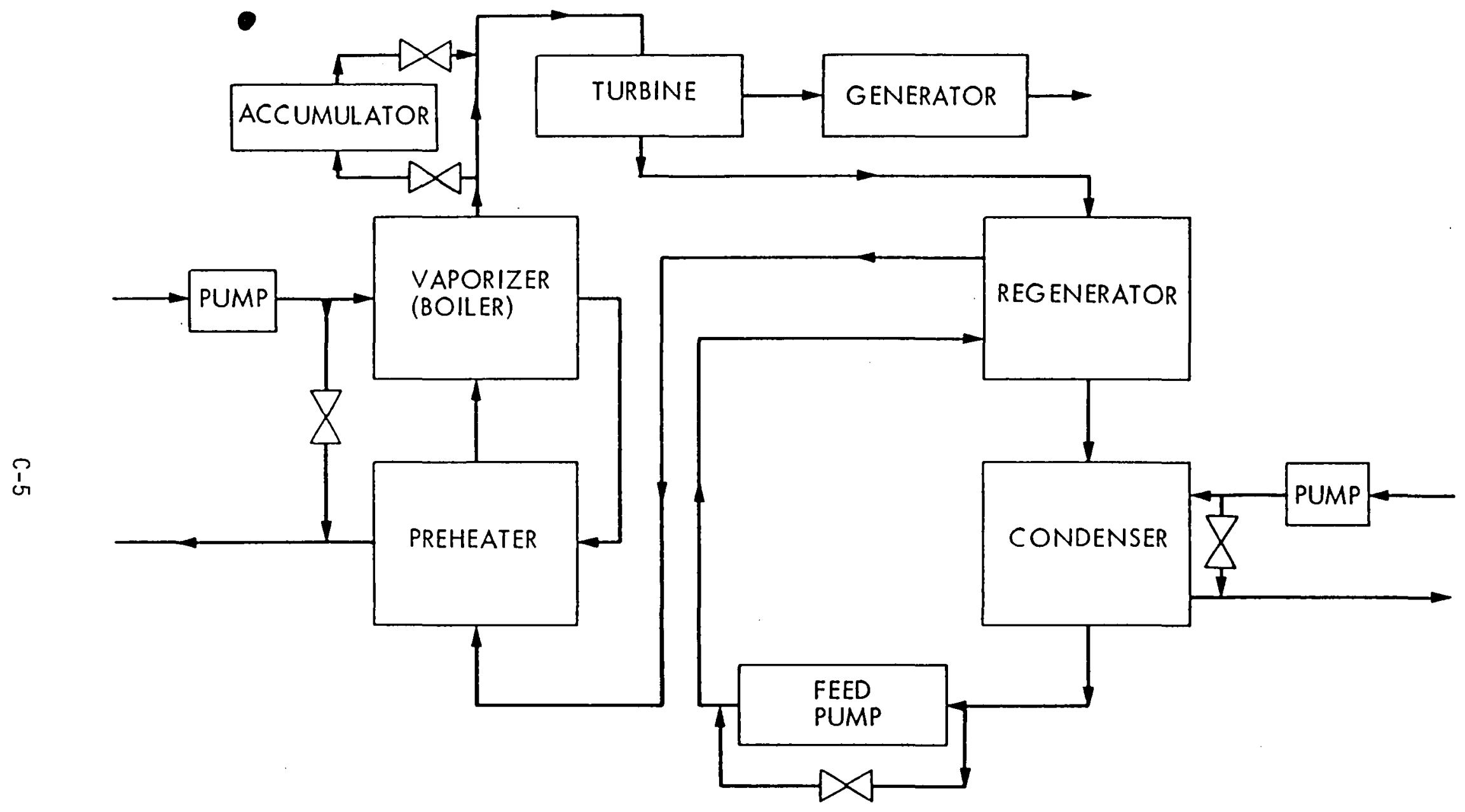

Figure C-2. Electric Power Generation Subsystem 


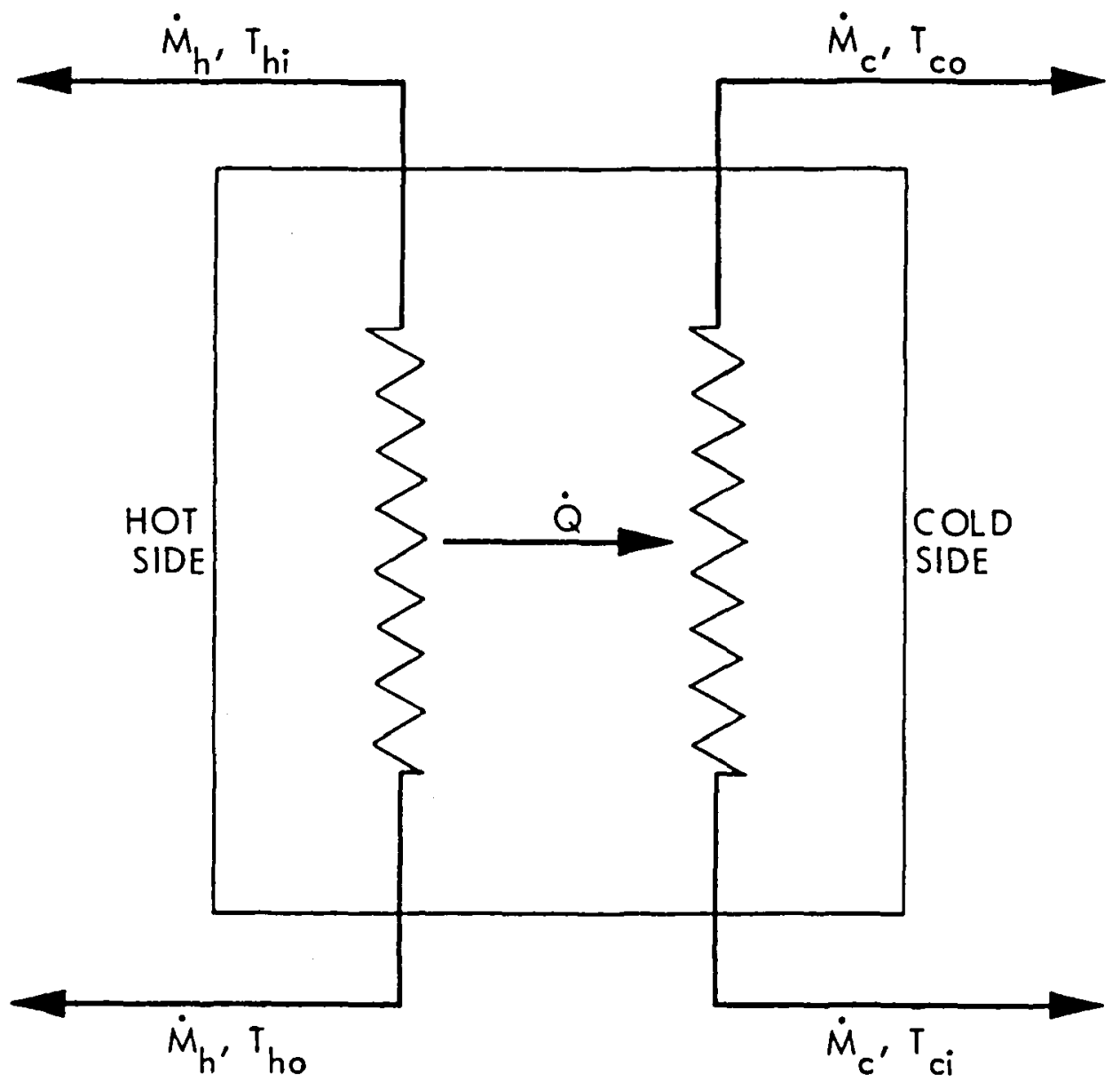

Figure C-3. Heat Exchanger Description 
1. For parallel flow heat exchanges

$$
E=\frac{1-\operatorname{Exp}\left[-\frac{U A}{c_{\min }} \cdot\left(1+c_{\min } / c_{\min }\right)\right]}{1+c_{\min } / c_{\max }}
$$

2. For counter flow heat exchanger

$$
E=\frac{1-\operatorname{EXP}\left[-\frac{U A}{C_{\min }} \cdot\left(1-C_{\min } / C_{\min }\right)\right]}{1-\left(C_{\min } / C_{\min } \cdot \operatorname{ExP}\left[\left(-\frac{U A}{C_{\min }}\left(1-C_{\left.\left.\min / C_{\max }\right)\right]}\right.\right.\right.\right.}
$$

3. For cross flow heat exchanger

$$
\begin{aligned}
& \text { If } C_{\max }=C_{h} \text {, then } \\
& E=1-\operatorname{ExP}\left[-\gamma \frac{C_{\max }}{C_{\min }}\right] \\
& \gamma=1-\operatorname{Exp}\left(-\frac{U A}{C_{\min }} \cdot \frac{C_{\min }}{C_{\max }}\right)
\end{aligned}
$$

$$
\text { If } \begin{aligned}
C_{\min } & =C_{h} \text {, then } \\
E & =\frac{C_{\max }}{C_{\min }}\left[1-\operatorname{Exp}\left(-\gamma_{c} \frac{C_{\min }}{C_{\max }}\right)\right]
\end{aligned}
$$

and

$$
\gamma=1-\operatorname{Exp}\left[-\frac{U A}{C_{\min }}\right]
$$


Parameter definitions:

$c_{c}=\dot{M}_{c} \cdot C_{p c}$, cold side fluid capacity rate

$c_{h}=\dot{M}_{h} \cdot c_{p h}$, hot side fluid capacity

$\mathrm{C}_{\max }=$ maximun capacity rate

$\mathrm{C}_{\min }=$ minimum capacity rate

$C_{p c}=$ cold side fluid specific heat

$C_{p h}=$ hot side fluid specific heat

$\dot{M}_{C}=$ cold side mass flöw rate

$\dot{M}_{h} \quad=$ hot side mass flow rate

$\dot{Q}=$ total heat transfer rate

$\dot{Q}_{\max }=$ maximum heat transfer rate

$T_{c i}=$ cold side inlet temperature

$T_{\text {co }}=$ cold side outlet temperature

$T_{h i}=$ hot side inlet temperature

$T_{\text {ho }}=$ hot side outlet temperature

UA overall heat transfer coefficient.

CONCLUDING REMARKS

The basic concept of a solar pond power plant design model has been established, the basic structure of the model is also conceived, and characteristics for some of the components have been formulated. The concept is good and the final product will be useful to the future development of the technology of solar pond power plants. 